UCRL-53766-Summary

Distribution Category UC-20

\title{
DISCLAIMER
}

This report was prepared as an account of work sponsored by an agency of the United States Nrepared as an aced States Government nor any agency thereof, nor any of their Neither the Uniled Stess or impliad, or assumes any legal liability or responsibility for, me accuracy, completenese, or usefulness of any information, apparatus, product, or process disclosed, or represents that its use would not infringe privately owned rights. Reference herein to any specilic commercial product, process, or service by trade name, trademark manufacturer, or otherwise does not necessarily constitute or imply its endosere The views mendation, or favoring by the United States Government or any age or relect those of the and opinions of authors expresed berein do not

UCRL--53766-Summ.

DE88 003270

\section{Summary of the Report of the Senior Committee on Environmental, Safety, and Economic Aspects of Magnetic Fusion Energy}

\author{
J. P. Holdren, Chair,
}

D. H. Berwald, R. J. Budnitz, J. G. Crocker, J. G. Delene, R. D. Endicott, M. S. Kazimi, R. A. Krakowski, B. G. Logan, and K. R. Schultz

Manuscript date: September 10, 1987

\section{LAWRENCE LIVERMORE NATIONAL LABORATORY University of California - Livermore, California - 94550}


The Senior Committee on Environmental, Safety, and Economic Aspects of Magnetic Fusion Energy (ESECOM) was organized under the administrative auspices of the Magnetic Fusion Energy Division of the Lawrence Livermore National Laboratory with financial support from the Office of Fusion Energy (OFE) of the U.S. Department of Energy (DOE). The Committee, however, is national in composition and independent in its mode of operation. Its members have served as individuals, not as representatives of their institutions, and the members alone are responsible for the findings presented here.

The members of ESECOM are: J. P. Holdren (Chair), University of California, Berkeley, Calif.; D. H. Berwald, Grumman Aerospace Corporation, Bethpage, N.Y.; R. J. Budnitz, Future Resources Associates, Berkeley, Calif.; J. G. Crocker, Idaho Nationai Engineering Laboratory (INEL), Idaho Falls, Idaho; J. G. Delene, Oak Ridge National Laboratory (ORNL), Oak Ridge, Tenn.; R. D. Endicott, Public Service Electric and Gas Company, Newark, N.J.; M. S. Kazimi, Massachusetts Inst1tute of Technology (MIT), Canbridge, Mass.; R. A. Krakowski, Los Alamos National Laboratory (LANL), Los Alamos, N. Mex.: B. G. Logan, Lawrence Livermore National Laboratory (LLNL), Livermore, Calif.; and K. R. Schuitz, GA Technologies Inc., San Diego, Calif. 


\section{CONTENTS}

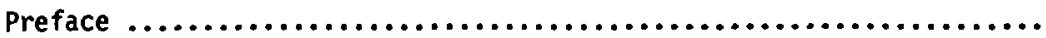

Abstract

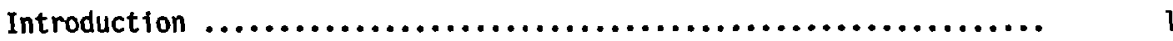

The Rationale for Developing Magnetic Fusion Energy .............. 2

Scope of ESECOM's Analysis ................................. 7

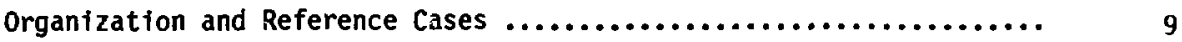

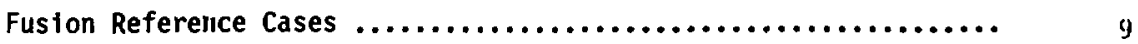

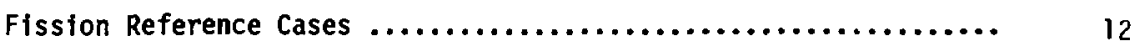

Plasma/Engineering/Economic Analysis ...................... 13

Safety/Environment Analysis ................................ 24

Determination of Radioactive Inventories .................... 24

Accident Analysis ..................................... 27

Levels of Safety Assurance $($ LSA $\ldots \ldots \ldots \ldots \ldots \ldots \ldots \ldots \ldots \ldots \ldots \ldots ., 35$

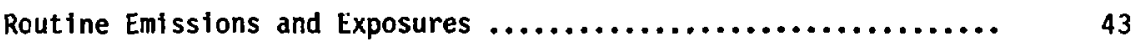

Tritium ....................................... 46

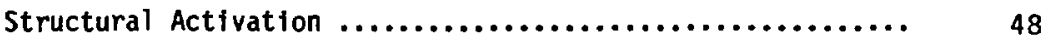

Coolant Activity ................................. 48

Carbon-14 ...................................... 50

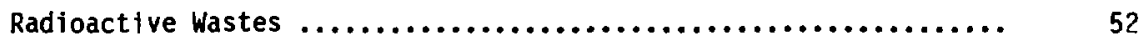

Unwanted Links to Nuclear Weaponry ....................... 57

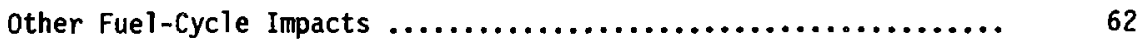

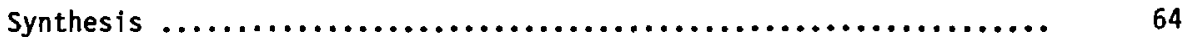

Integration Safety, Environment, and Economics ................ 64

Uncertainties and Omissions ............................ 72

Findings in Brief ..................................... 79

The Potential of Magnetic Fusion Energy ..................... 79

Technology and Economics .............................. 82

Envi ronment, Safety, and Economics ....................... 84

Implications for MFE R\&D $\ldots \ldots \ldots \ldots \ldots \ldots \ldots \ldots \ldots \ldots \ldots \ldots \ldots \ldots \ldots \ldots \ldots, \quad 87$

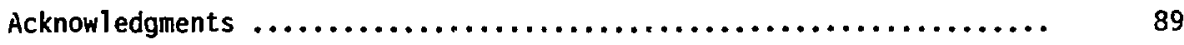

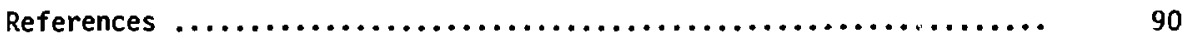


The Senior Committee on Environmental, Safety, and Economic Aspects of Magnetic Fusion Energy (ESECON) has assessed magnetic fusion energy's prospects for providing energy with economic, environmental, and safety characteristics that would be attractive compared with other energy sources (mainly fission) available in the year 2015 and beyond. ESECOM gives particular attention to the interaction of environmental, safety, and economic characteristics of a variety of magnetic fusion reactors, and compares them with a variety of fission cases. Eight fusion cases, two fusioil-fission hybrid cases, and four fission cases are exanined, using consistent economic and safety models. These models permit exploration of the environmental, safety, and economic potential of fusion concepts using a wide range of possible materials choices, power densities, power conversion schemes, and fuel cycles. The ESECOM analysis indicates that magnetic fusion energy systems have the potential to achieve costs-of-electricity comparable to those of present and future fission systems, coupled with significant safety and environemntal advantages.

\section{INTRODUCTION}

In many ways, fusion is the ultimate energy source: it is the fire that lights the sun and the rest of the stars; it is the source of the elements that constitute the universe; it can wring from a gram of deuterium fuel as much energy as the comb stion of 10 tons of coal, enabling the trace of deuterium in each gallon of sea water to provide as much energy as 300 gallons of gasoline. It is also so difficult to harness for meeting civilization's energy needs that more than three decades of intensive scientific and engineering effort have not sufficed to accomplish the task.

Today, several experimental fusion-energy machines that are in the early stages of operation or the advanced stages of construction are within reach of demonstrating the scientific feasibility of the magnetic-confinement approach to harnessing fusion. (That is, they are close to attaining a combination of fuel temperature and confinement quality capable of yielding a fusion-energy release equal to the energy requirement for heating the fuel.) Yet U.S. public and governmental support for pursuit of long-term energy options is imperiled by a combination of overall budgetary stringency, competing claims 
on research funds, and an oil-glut-induced complacency about the future of energy supply. The time is therefore ripe to reexamine the goals, potentials, and priorities of fusion-energy development, both as an aid to planners shaping the future of fusion research and development after the scientificfeasibility milestone is attained, and as a progress report to a larger community that is understandably concerned about the priorities and payoffs in energy $R \& D$.

The goals of the fusion energy program encompass more than understanding the physics and technology of heating and confining fusion fuels; more than applying this understanding to the construction of devices that can convert fusion energy into the forms civilization needs (such as electricity and fluid fuels); and more than unlocking the nearly inexhaustible energy resources that such devices could use. For if fusion is to make an important contribution to civilization's energy needs, it is not enough that fusion energy systems work--they must do so with economic, environmental, and safety characteristics that are attractive compared with those of other energy sources available in the same time frame.

The Senior Committee on Environmental, Safety, and Economic Aspects of Magnetic Fusion Energy (ESECOM) was organized in late 1985 to provide an up-to-date assessment of magnetic fusion energy's prospects for meeting this last requirement. We have given particular attention to the interaction of environmental, safety, and economic characteristics in fusion-reactor design, and to identifying those directions within fusion technology that seem most likely to lead to combinations of these characteristics that would make fusion an attractive long-term energy source compared with (or in symbiosis with) fission and other options. We have not considered inertial-confinement fusion explicitly, although, inevitably, some of our findings could be applied to the inertial-confinement as well as to the magnetic-confinement approach.

This summary presents our findings in compact iorm. The reader interested in more detail and documentation should consult the much longer main report. ${ }^{1}$

\section{THE RATIONALE FOR DEVELOPING MAGNETIC FUSION ENERGY}

As background for our assessment, it is appropriate to discuss briefly the overall rationale for developing magnetic fusion energy (MFE)--that is, the combination of possible characteristics of MFE and possible 
characteristics of the energy future that could lead to an important role for MFE technologies.

The scientists and engineers working to develop MFE have long considered the attractions of achieving their goal to be self-evident: the attainment of an energy supply for civilization that would be at once safe, clean, affordable, and inexhaustible. But safety, cleanness, affordability, and inexhaustibility are all relative attributes, not absolutes. The yardsticks by which these attributes are measured--and society's weighing of their importance relative to one another--depend on the context: the time horizon of interest, the projected energy demands in that time frame, the characteristics of all the energy sources potentially available to meet those demands, and the priorities given to economic vs environmental and safety concerns.

The time horizon for large-scale commercial appifation of MFE is, at the earliest, the year 2015 and beyond, and more probably 2030 and beyond. The energy break-even or scientific feasibility demonstration expected in the next few years will need to be followed by an intensive program of technological development aimed at demonstrating engineering feasibility (the actual generation of significant net energy from $D-T$ fue 1 ) in a device that can operate more or less continuousiy and can convert the fusion energy into electricity and/or other usable forms. The challenges of establishing engineering feasibility for MFE (including especially materlals issues, magnet design, plasma current drive, fuel handling, impurity removal, tritium control, and remote maintenance of neutron-activated components) are different in character than the scientific-feasibility challenges that have taken more than 30 years to overcome, but it is entirely possible that they will require as much or more money and effort.

Assuming that funding for MFE R\&D in the U.S., Europe, Japan, and the Soviet Union combined remains at or above its 1985 level of about $\$ 1.5$ billion (U.S.) in 1985 dollars per year, it is reasonable to suppose that establishing the engineering feasibility of MFE by constructing and operating a demonstration power reactor at near-commercial scale will require another 20 years beyond the proof of scientific feasibility. Just how much this timetable could be accelerated by substantially increasing the funding for fusion R\&D is controversial. There is little doubt, however, that the attainment of a successful demonstration reactor will be delayed if funding is reduced. 
The establishment of engineering feasibility for MFE in the form of a working large-scale demonstration reactor--say, by 2010--still will not ensure this technology's commercial success. Passing the further threshold of commercial feasibility requires that the solutions to the scientific and engineering challenges of MFE be combined in ways yielding economic, environmental, and safety characteristics that are attractive compared to those of other energy options capable of meeting the same societal needs. Whether and when commercial feasibility of MFE actually will be achieved depends, therefore, not only on the characteristics of future fusion technologies that cannot be completely described today; it also depends on the characteristics of several alternative technologies that may be available to fill a simflar niche in the energy futures of the U.S. and the world.

Early in the period of fusion's potential availability, its competitors may include coal-fired power plants, light-water and advanced-convertor (nonbreeder) fission reactors, and early fission breeders. In the longer term, the list of possible competitors expands to include advanced fission breeders and large-scale solar-electric plants. The possibilities in the early part of fusion's potential availability (as well as later) also include a symbiosis between fusion and fission systems, in which fusion reactors would breed fissile fuel for "client" fission convertor reactors.

Although more is known about the custs and other characteristics of the near-term technologies competing with fusion than about those of the longerterm possibilities, significant economic and environmental uncertainties are associated with near-term and long-term alternatives alike ${ }^{2-4}$ :

1. Coal. Recoverable coal resources amount to perhaps 5000 terawattyears (TW-yr) worldwide, or about 500 times civilization's annual use of all industrial energy forms in the mid-1980s. But mining, transporting, processing, and burning this coal pose environmental problems that may prove expensive to abate, and the potentially intolerable climatic impacts of accumulating atmospheric carbon dioxide from fossil-fuel combustion may put a lid on coal use altogether.

2. Nonbreeder Fission Reactors. Use of the world's high-grade uranium resources in nonbreeder fission reactors might yield as little as $1000 \mathrm{TW}-\mathrm{yr}$ or as much as $5000 \mathrm{TW}-\mathrm{yr}$ of thermal energy, convertible to a third as much electricity. In the U.S., this technology has been costlier than projected in monetary terms, and its future costs are subject to uncertainty and dispute. It has also been controversial with respect to safety, environment (including 
waste management), and links to nuclear weapons, and its continued public acceptability in some countries can be questioned.

3. Fission breeder reactors. This technology could stretch uranium resources a thousandfold or more (a factor of 50 - 100 from better utilization of the high-grade resources and the rest from rendering lower-grade resources of uranium economically exploitable). But the economics of breeders are more uncertain and the safety and environmental controversies potentially more acute than for conventional (nonbreeder) fission reactors.

4. Biomass and Hydropower. The renewable energy sources most heavily used today, biomass and hydropower, provide about $2 \mathrm{TW}-\mathrm{yr} / \mathrm{yr}$ worldwide. Whether this figure could be expanded by more than a factor of 2 or 3 is highly uncertain in view of competing uses for the resources and rising environmental as well as monetary costs.

5. Sunlight. More abundant renewables, most notably the $88000 \mathrm{TW}-\mathrm{yr} / \mathrm{yr}$ of sunlight reaching Earth's surface, are more dilute and, so far, more costly than hydropower or biomass to convert to electricity or fluid fuels. The eventual cost of large-scale production of electricity or fluid fuels from sunlight is uncertain by at least a factor of 3 , and some of the approaches for doing so may have significant environmental costs.

In addition to these uncertainties about the supplies, costs, and acceptability of alternatives to fusion, there is great uncertainty about future energy demand: studies of the potential worldwide demand for energy around 2030, for example, have generated estimates ranging from about $10 \mathrm{TW}-\mathrm{yr} / \mathrm{yr}$ (about the same as in 1985) to more than $30 \mathrm{TW}-\mathrm{yr} / \mathrm{yr}$ (Refs. 5,6). What fraction of future energy demand will be provided by centrally generated electricity or other energy forms that could be supplied by fusion technologies is also uncertain. (Electricity generation accounts for 30 to $35 \%$ of primary energy use in most industrial nations today.)

Against the backdrop of so uncertain an energy future, what are the potential attractions of fusion that might justify the continuing investments needed to bring it about? Different attractions pertain to different time frames and scenarios:

1. Most obviously, the energy-supply potential of fusion is huge: a hundred million $\mathrm{TW}-\mathrm{yr}$ based on oceanic lithium as the limiting ingredient in a D-T fuel cycle, a few hundred billion $T W-y r$ based on the D-D fuel cycle. ${ }^{7}$ In the very long term (more than a few thousand years), only fission breeder reactors and large-scale use of solar energy will be able to compete with 
fusion-electric generation (or fusion breeding of fissile fuels) as mainstays of civilization's energy supply.

2. There is a good chance that fusion w11l be cheaper than large-scale solar-energy technologies, and possibly it, will be less disruptive environmentally. There is a good chance that fuston will be safer than fission breeders, and cheaper if safety advantages can be translated into lower costs. Given sufficient margins in these respects, fusion would become the clear cholce as civilization's primary inexhaustibie option for centralstation electricity supply and fluid-fuels production.

3. In the near term, the competitors for fusion are more diverse--but so are their llabilities. Environmental-control requirements could increase fossil-fuel costs to well above today's levels, and the $\mathrm{CO}_{2}$ problem could limit fossil-fuel use altogether; fission could be deened unacceptable by the public hecause of concerns about reactor safety, waste management, and weapons links; technologies for large-scale harnessing of solar energy could remain very expensive. If all (or even most) of these potential problems come about, then having an affordable, safe, and environmentally attractive fusion option available at the earliest possible date would become extremely important.

4. Even if the possibiitity of debilitating shortcomings in nonfusion energy alternatives is excluded, fusion technology might achieve a combination of versatility and economic, environmental, and safety characteristics so attractive that fusion would displace previously satisfactory energy sources and, perhaps, transform patterns of energy use in ways that cannot be foreseen In detail.

5. Finally, if the above-mentioned concerns about the economic, environmental, and safety characteristics of fission reactors do not foreclose the fission option, an important complementary role for fusion could materialize through the use of fusion-hybrid-breeder reactors to supply fission convertor reactors with fuel. This approach might be able to improve system economics (and, conceivably, system safety and proliferation resistance) compared with pure-fission systems, while providing a fusiontechnology "stepping stone" toward pure-fusion electricity generation.

The case for giving high priority to R\&D on MFE obviously depends not only on the possibility that such benefits will materialize but more Importantly on the 11kelthood that they w11l. While that likelihood cannot be evaluated in a fully persuasive manner on the basis of current information, ESECON viewed its task, broadly construed, as one of clarifying the prospects 
for attaining these benefits by assessing the environmental, safety, and economic potential of an array of fusion-reactor possibilities derived from the existing knowledge base.

\section{SCOPE OF ESECOH'S ANALYSIS}

The Committee undertook to address the following sets of specific questions:

1. What will be the likely economic, environmental, and safety characteristics of magnetic-fusion reactors if such reactors are based on the D-T fuel cycle, the confinement schemes and design concepts most extensively studied to date, present leading-candidate materials, and extrapolation of power-plant construction practices from the fission industry? What trade-offs and interactions among economics, environment, and safety are evident under these circumstances?

2. What are the possibilities for improving fusion's performance with respect to economics, or environment, or safety, or (most importantly) the combination of these achlevable in a single design, by using (a) alternative materia?s, (b) alternative blanket designs, (c) alternative energy-conversion schemes and outputs (such as fissile fuels), (d) alternative confinement schemes, (e) alternative fuel cycles, and (f) alternative balance-of-plant designs, construction practices, and siting arrangements made possible by such innovations? Can such reactors be designed to preclude fatalities from acute radiation exposure even under "incredible" circumstances, while remaining economically competitive?

3. What changes in present programs of MFE research and development might increase the likelihood of achieving improvements of these sorts?

4. How do the prospects of fusion with respect to environment, safety, and economics compare with those of its likely competitors? Are there promising symbioses between fusion and other energy sources?

Because of the 11 mited time and resources avallable for this study, our analysis of fusion's pctential competitors and symbionts has been confined mainly to fission technologies. Fission provides the most appropriate comparison because it is the most obvious aild best understood competitor for fusion in the central-station electricity-generation niche in the long term. Fission is also the most obvious focus of an examination of potential symbiosis because of the much-studied possibility of using fusion-fission 
hybrid breeders of fissile material to fuel client fission-converter reactors that might be cheaper and/or safer than self-sustaining pure-fission breeders. Examining fission has the further merit that the experience oi the fission industry with power-plant engineering, construction, safety analysis, and regulation and licensing offers a number of insights about the possibiifties for and difficulties with approaches aimed at reducing the costs of fusion.

In addition to confining our investigatic: of conjetition and symbiosis to fission, we further narrowed the scope of our undertaking by oniting from detafled consideration any potential appilications of fusion energy other than central-station electricity generation and production of fissile fuel. Such applications could include production of synthetic chemical fuels, production of weapons materials for the nuclear stockpile, production of radioisotopes for industrial and medical applicatiors, and use of fission neutrons to transmute fission-reactor radioactive wastas into shorter-ifived substances. Many of these applications have been reviewed recently el seshere. 8,9

Even with these restrictions in the scrne of our work, the breadth and complexity of the assessment being undertaken were datriting. Clearly, such a task could only be attempted in so short a time by making the fullest possible use of other recent and ongoing work--in the national laboratories, in the universitics, and in industry--on the possible shape of fusion technology and on its likely environmentai, economic, and safety characteristics. In this connection, we have benefited particularly from: the work of the Department of Energy's (DOEs) "Low Activation Materials Panel"10; the STARFIRE" ${ }^{11}$ and MARS $^{12}$ design studies; the Blanket Comparison and Selection Study ${ }^{13}$; the work of Sheffield et al. at ORNL on the Generamak mode ${ }^{14}$; the DOE/ORNL. Nuclear Energy Cost Data Base ${ }^{15}$; the dissertations of Piet ${ }^{16}$ and Fetter ${ }^{17}$ on methods of safety and environmental assessnent for fusion; the 1983 ORNL review of environmental implications of magnetic fusion, ${ }^{18}$ and the review of this topic published by the IAEA in $1986^{19}$; the ongoing fusion-safety work at INEL and $\mathrm{MIT}^{20,21}$; the 1986 Brookhaven study of proliferation and safeguards issues in future technologies ${ }^{22}$; the studies of reversed-field-pinch reactors at LANL $^{23}$ and of low-activation ceramics at GA Technologi $\epsilon_{3}^{24}$; the fusiun-fission hybrid studies coordinated by LLML $^{25}$; and the Technical Planning Activity (TPA) for MFE coordinated by the Argonne National Laboratory for the DOE. ${ }^{26}$ We have also profited from coinaring nctes with the authors of studies being conducted more or less in parallel with ours in the European Conmunity ${ }^{27}$ and in Japan. ${ }^{28}$ 
At the same time, it must be emphasized that the impressive body of work fron which we were able to draw, combined with such new analyses as will be described here, were together far from sufficient to provide convincing answers to all of the questions posed. It is too early in the evolution of fusion technology for that to be possible. Necessarily, then, our answers are incomplete ratiner than comprehensive, tentative more often than confident, and qualitatice as often as quantitative. We think, nonetheless, that these findings illuminate some important dimensions of the topic, and we hope that they will provide a useful stepping stone in the ongoing process of understanding the prospects of MFE and steering research efforts toward achieving its highest potential.

\section{ORGANIZATION AND REFERENCE CASES}

ESECON's work was organized in four phases:

1. Identifying and describing a set of reference cases--fuston, fission, and fusion-fission hybrid reactors--selected to span a wide range of technical characteristics based on reasonable extrapolation from present knowledge.

2. Analyzing, in a consistent framework, the economic, environental, and safety charac $:$ stics of these reference cases (including, in some instances, tine efferts of varying plasma performance, scale, and power density within an otherwise fixed design).

3. Integrating and synthesizing the findings from Phase 2 to provide a comparative assessment of various fusion systems relative to one another and relative to the reference fission and fusion-fission hybrid breeder systems, and identifying trade-offs and symbioses among environmental, safety, and economic characteristics (including, for example, possible cost savings achievable through attaining different types and degrees of safety assurance).

4. Developing conclusions about directions in MFE R\&D that could improve the prospects for achieving fusion's full potential with respect to economics, environment, and safety.

\section{FUSION REFERENCE CASES}

The ten fusion and fusion-fission cases were chosen to permit exploration of a wide range of variations associated with different materials choices, power densities, conversion schemes, and fuel cycles, subject to certain 
obvious constraints: the total number of cases had to be kept within reason; the combination of cases had to be constructed as an interrelated array to permit comparisons anong variations with something in common; and the cases chosen had to be describable in sufficient detail to permit the use of the kinds of economic and safety models capable of 11 luminating differences among the cases in a consistent and persuasive way.

The following set of ten cases emerged--over a period of months--from these considerations:

1. A point of departure D-T fusion reactor using a tokamak configuration, with vanadium-alloy structure and liquid lithium as the coolant/ breeder (denoted in figures and tables herein as $V$-LI/TOK);

2. A hellum-cooled variant of the Case 1 tokamak, with reduced-activation ferritic steel (RAF) structure and $\mathrm{LI}_{2} \mathrm{O}$ solid breeder (RAF-He/TOK):

3. A high-power-density, reversed-field pinch (RFP) with RAF structure, a water-cooled copper-alloy first wall and limiter, and self-cooled lithium-lead breeder (RAF-PbLI/RFP);

4. Another high-power-density RFP with a V-Li blanket minimally modified from that of the point-of-departure tokamak (V-L1/RFP):

5. A low-activation tokamak with silicon carbide (SiC) structure, helium coolant, and $\mathrm{Li}_{2} \mathrm{O}$ breeder (SIC-He/TOK);

6. A pool type tokamak with vanadiun structure and molten-salt (FLiBe) coolant/breeder (V-FLIBE/TOK):

7. An advanced-conversion variant of the point-of-departure tokanak with synchrotron-radiation-enhanced magnetohydrodynamic (WHD) conversion ( $V$ MHD/TOK):

8. An advanced-fuel, water-cooled tokamak based on the $\mathrm{D}-\mathrm{He}^{3}$ fuel cycle with direct conversion of microwave synchrotron radiation ( $\left.\mathrm{V}-\mathrm{DHe}^{3} / \mathrm{TOK}\right)$;

9. A baseline fusion-fission hybrid tokanak with RAF structure, 11thium coolant, beryllium neutron multiplication, and thorium metal as the fertile material (RAF-LI/HYB); and

10. An advanced technology hybrid tokamak with stainless-steel structure, helium coolant, and L1/F/Be/Th molten-salt blanket (SS-He/HYB).

The point of departure $V$-Li/TOK system and the RAF-He/TOK variant represent improvements on STARFIRE ${ }^{11}$ technology using the two leadingcandidate blankets from the Blanket Comparison and Selection Study. ${ }^{13}$ These are steady-state, D-T fueled, superconducting tokamaks, for which TroyonGruber beta scaling ${ }^{29}$ and current drive at an efficiency of 0.2 amp/watt have 
been assumed; these latter assumptions hold for the other tokanak cases studied as well. The RFP cases rely heavily on early studies performed at the Los Alamos National Laboratory ${ }^{23}$ and a more recent multi-institutional study being directed by UCLA ${ }^{30}$; these are resistive-coll machines with oscillatingfield current drive and a nominal 1 imit on beta that has been observed experimentally. The SiC-He/TOK blanket is based on work done at GA Technologies, ${ }^{24}$ while the V-FLIBE/TOK puol design is the work of a group led

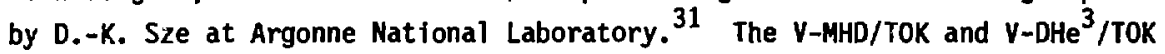
advanced-conversion and advanced-fuel blankets are largely the work of B. G. Logan at LLNL, ${ }^{32}$ stimulated in the latter case by innovative work at the University of Wisconsin on a possible solution to the problem of heifum-3 availability. ${ }^{33}$ The hybrid-breeder blankets are based on studies coordinated by LLNL over the past several years. 24,34 It should not be assuned, however, that any of the ESECOM cases are identical to the itnal designs in studies on which we drew: In many cases, we made modifications to maintain consistency among the ESECOM cases; in some cases, ongoing studies refined their own designs further after ESECOM's specifications were fixed; and in some cases, ESECON did not require or use the level of design detall available because our analytical approaches were tailored to a lesser level.

The committee's aim in selecting these particular cases was to provide a basis for exploring variations in environmental, safety, and econimic characteristics that may follow froin different combinations of materials choices, power densities, energy-conversion schemes, and fuel cycles. The circumstance that only tokamaks and RFPs were examined does not reflect any shared opinion about the prospects of other confinement schemes; rather, it resulted from the sheer convenience of being able to obtain consistently calculated cost estimates from a preexisting engineering-econumics model that is restricted to toroldal geometries. The role of the RFP cases, in particular, was to permit investigation of higher-power densities than could be attained for tokamaks within the framework of the Generomak model.

The different cases do represent, of course, differing degrees of extrapolation from materials choices, physics parameters, and engineering features that might be considered reasonably certain to be attainable based on current knowledge. An examination that confined itself only to conceptual designs of fusion reactors that were solidly based on existing physics and engineering data bases could rot claim to have addressed fusion's full potential, nor couid such a study say much about directions worth 
investigating in pursuit of markedly improved performance. Such cases as 5 through 8--featuring (respectively) ceramic structural materials to achieve extremely low activation, a pool-type design for passive cooling under nearly any accident conditions, enhanced MHO conversion to reduce balance-of-plant complexity and cost, and a $\mathrm{D}-\mathrm{He}^{3}$ fuel cycle to reduce neutron activation and tritium problems--are less credible than more conventional designs. But analyzing these cases, as examples of a much larger set of advanced approaches, has enabled us to avoid unduly constraining our assessment of fusion's long-range possibilities.

\section{FISSION REFERENCE CASES}

Four fission reference cases were selected for comparison (and for investigation of symbiosis with the fusion-fission hybrid breeders) as follows:

1. A "best present experience" pressurized-water reactor (PWR-BPE) (Westinghouse) (Ref. 14);

2. The large-scale prototype breeder (LSPB) (Elect:-ic Power Research Institute/DOE) (Refs. 35,36);

3. The power reastor inherently safe module breeder design (PRISM) (General Electric) (Ref. 37); and

4. A modular high-temperature gas reactor (MHTGR) (GA Technologies/GasCooled Reactor Associates) (Ref. 38).

These cases were picked to serve different functions in the study. The PWR-BPE provides a reference point rooted in experience; it serves as a sort of caitbration for the economic and safety indices of the advanced fission and fusion cases, as well as representing a minimuin-perfomance fission client for the fusion-hybrid breeder. The LSPB and PRISM systems represent a standard and an alternative approach to fission breeding: they are potential direct competitors with fusion for the long-term, central-station, electricitygeneration market. The MHTGR could be considered a competitor for fusion in the near future, before uranium has become costly enough to justify breeding, and as an advanced client for breeders of either the pure-fission or the fusion-hybrid varieties. 


\section{PLASMA/ENGINEERING/ECONOHIC ANALYSIS}

The fusion and hybrid-breeder cases were developed and analyzed with the assistance of the Generomak magnetic-fusion physics/engineering/costing model, ${ }^{14}$ modified appropriately for our purposes.

The physics/engineering part of the Generomak model accepts as input the desired values of net electric power output, plasma beta, aspect ratio and Elongation of the toroidal plasma, Troyon coefficient, and maximum toroidal field at the coil. (The combination must be chosen to give an acceptable value of the edge-plasma safety factor, $q_{+}$) These inputs are used together with chosen blanket/shield characteristics (materials, radial dimensions, densities, inlet and outlet temperatures), conversion-efficiency relations, and current-drive assumptions in an iterative calculation of the plasma major and minor radi1, $R$ and $a_{1}$ the toroidal field in the plasma, $B_{\phi}$, and the plasma current, $I_{\phi}$, corresponding to the desired net electric power. Also calculated in this process are plasma volume, plasma ignition margin, fusion power, neutron wall loading, reactor thermal power, overall thermal efficiency, current-drive and other auxiliary power, "fusion island" volume, and the masses of the blanket, reflector, shield, and coils. Some of the main physics and engineering parameters of the ten fusion and fusion-fission hybrid cases are summarized in Tabie 1.

The economics part of the Generomak model then uses these results to calculate the direct capital costs of the fusion island, based on unit costs supplied to the model for fabricated materials (e.g., $400 \$ / \mathrm{kg}$ for reactor parts fabricated fron vanadium/chromium/titanium alloy, $90 \$ / \mathrm{kg}$ for superconducting col1s) and for certain specific components (e.g., power supply for current drive is costed at $2.25 \$ / W$ ). Most of these costs are based on those developed in the Starfire study, ${ }^{11}$ updated to January 1986 tollars used as the cost basis throughout ESECON's work. Some of the Starfire figures have been further modified based on the committee's judgment that more recent information warranted changes.

Balance-of-plant costs in various categories (land, structures and improvements, heat transfer and transport equipment, turbine-plant equipment, and so on) are obtained by assuming that reference costs, updated from the Starfire study, scale wi. in thermal power, electrical power, or fusion-island 
Table 1. Selected physics and engineering parameters of fusion cases.

\begin{tabular}{|c|c|c|c|c|c|c|c|c|c|}
\hline & $\begin{array}{l}V-L 1 \\
\text { TOK }\end{array}$ & $\begin{array}{l}\text { RAF-He } \\
\text { TOK }\end{array}$ & $\begin{array}{l}\text { RAF-Li } \\
\mathrm{Pb} / \mathrm{RFP}\end{array}$ & $\begin{array}{l}V-L i \\
R F P\end{array}$ & $\begin{array}{l}\text { Sic-He } \\
\text { TOK }\end{array}$ & $\begin{array}{l}\text { V-FLIBE } \\
\text { TOK }\end{array}$ & $\begin{array}{l}\text { V-MHD } \\
\text { TOK }\end{array}$ & $\begin{array}{l}\text { V-DHe } \\
\text { TOK }\end{array}$ & $\begin{array}{l}\text { RAF-Li } \\
\text { HYB }\end{array}$ \\
\hline Aspect ratio, A & 4.0 & 4.0 & 6.0 & 6.0 & 4.0 & 4.0 & 3.6 & 3.6 & 4.0 \\
\hline Plasma elongation, $\mathrm{K}$ & 2.5 & 2.5 & 1.0 & 1.0 & 2.5 & 2.5 & 2.5 & 2.2 & 2.5 \\
\hline Total plasma beta, $\beta$ & 0.1 & 0.1 & $0.1^{\mathrm{a}}$ & $0.1^{\mathrm{a}}$ & 0.1 & 0.1 & 0.12 & 0.12 & 0.1 \\
\hline Safety factor, $q$ & 2.3 & 2.3 & 0.02 & 0.02 & 2.3 & 2.3 & 2.1 & 2.1 & 2.3 \\
\hline Max field at coil, $B_{\phi C}(T)$ & 10.0 & 10.0 & 0.69 & 0.66 & 10.0 & 10.0 & 12.0 & 16.0 & 10.0 \\
\hline Torr field in plasma, $B_{\phi}(T)$ & 4.29 & 4.25 & 0.43 & 0.42 & 3.88 & 4.61 & 5.98 & 10.12 & 4.27 \\
\hline Major radius, $R_{T}(m)$ & 5.89 & 6.07 & 4.69 & 4.69 & 7.02 & 5.12 & 5.05 & 8.56 & 4.99 \\
\hline Plasma current, $I_{\phi}$ (MA) & 15.8 & 16.2 & 22.4 & 21.7 & 17.0 & 14.8 & 25.1 & 60.2 & 13.3 \\
\hline Neutron wall loading $\left(\mathrm{mW} / \mathrm{m}^{2}\right)$ & 3.20 & 3.18 & 16.6 & 14.6 & 2.53 & 3.70 & 3.74 & 0.09 & 2.64 \\
\hline Fusion power (MW) & 2862 & 3027 & 3291 & 2896 & 3226 & 2504 & 2753 & 3258 & 1700 \\
\hline Blanket thickness (m) & 0.71 & 0.70 & 0.60 & 0.32 & 0.79 & 1.20 & 0.40 & 0.45 & 0.76 \\
\hline Blanket/shield gap (m) & 0.10 & 0.10 & 0.10 & 0.0 & 0.40 & -- & 0.05 & 0.05 & 0.10 \\
\hline Shield thickness (m) & 0.83 & 0.92 & 0.10 & 0.45 & 1.08 & 0.05 & 0.60 & 0.60 & 0.53 \\
\hline Neutron energy multiplication & 1.27 & 1.27 & 1.33 & 1.272 & 1.20 & 1.30 & 1.30 & 1.10 & 2.44 \\
\hline
\end{tabular}


Table 1. (continued)

\begin{tabular}{|c|c|c|c|c|c|c|c|c|c|}
\hline & $\begin{array}{l}V-L i \\
\text { TOK }\end{array}$ & $\begin{array}{l}\text { RAF-He } \\
\text { TOK }\end{array}$ & $\begin{array}{l}\text { RAF-Li } \\
\mathrm{Pb} / \mathrm{RFP}\end{array}$ & $\begin{array}{l}V-L i \\
R F P\end{array}$ & $\begin{array}{l}\text { Sic-He } \\
\text { rok }\end{array}$ & $\begin{array}{l}\text { V-FLIBEE } \\
\text { TOK }\end{array}$ & $\begin{array}{l}\text { V-MHD } \\
\text { TOK }\end{array}$ & $\begin{array}{l}\mathrm{V}-\mathrm{DH} \mathrm{e}^{3} \\
\text { TOK }\end{array}$ & $\begin{array}{l}\text { RAF-Li } \\
\text { HYB }\end{array}$ \\
\hline Tritium breeding ratio & 1.28 & 1.11 & 1.03 & 1.28 & 1.06 & 1.20 & 1.05 & 0.0 & 1.02 \\
\hline Total thermal power (MW) & 3563 & 3648 & 4216 & 3580 & 3827 & 3179 & 3414 & 3271 & 3725 \\
\hline Primary coolant intet $\mathrm{T}_{\mathrm{j}}\left({ }^{\circ} \mathrm{C}\right)$ & 300 & 275 & 350 & 300 & 250 & 600 & 770 & 150 & 275 \\
\hline Primary coalant outlet $\mathrm{T}_{0}\left({ }^{\circ} \mathrm{C}\right)$ & 550 & 510 & 500 & 550 & 500 & 650 & 1470 & 150 & 450 \\
\hline Thermal conv. efficiency & 0.404 & 0.400 & 0.343 & 0.404 & 0.380 & 0.446 & 0.370 & 0.350 & 0.374 \\
\hline Recirculating power fraction & 0.12 & 0.13 & 0.12 & 0.12 & 0.13 & 0.11 & 0.05 & 0.03 & 0.11 \\
\hline Net electric power $\left(\mathrm{MW}_{\mathrm{e}}\right)$ & 1200 & 1200 & 1200 & 1200 & 1200 & 1200 & 1200 & 1200 & 1200 \\
\hline Volume of fusion power core $\left(\mathrm{m}^{3}\right)$ & 2669 & 2965 & 428 & 457 & 4573 & 2507 & 2490 & 4907 & 1635 \\
\hline Mass of fusion power core $(\mathrm{Mg})$ & 11482 & 12270 & 2663 & 2396 & 14348 & 4239 & 11268 & 19296 & 6614 \\
\hline Mass power density $\left(\mathrm{kW}_{\mathrm{e}} /\right.$ tonne $)$ & 105 & 98 & 451 & 501 & 84 & 283 & 107 & 62 & 181 \\
\hline
\end{tabular}

${ }^{a}$ A total beta of 0.1 for the RFPs corresponds to a pololdal beta of 0.2 . 
volume raised to an appropriate fractional exponent. Thus, for example, the reactor bullding and hot cells (cost account 21.1) are costed at

$$
C_{\text {bldg }}(M \$)=\$ 174.4 \times\left(V_{F P C} / 2409\right)^{0.67} \text {. }
$$

where $\$ 174.4$ million is the updated Starfire figure for this component given a fusion-1sland volume of $2409 \mathrm{~m}^{3}$. (The fusion island comprises the plasma chamber, first wall, blanket, shield, coils, and coil structure.) Total capitalized investment cost in 1986 dollars is obtained by multiplying the direct costs for the fusion island and balance of plant by factors accounting for indirect costs (proportional to design-and-construction lead time), contingency, and interest during construction.

Costs of the blanket, limiter, coolant, and other major items that turn over on a time scale that is short compared with the plant 11 fetime are treated analogously to fuel costs in the fission fuel cycle, following the methodology embodied in the Nuclear Energy Cost Data Base (NECDB) at ORNL. 15 Calculation of other operation and maintenance costs also follows the NECDB motiel. Following standard engineering-economics techniques, as embodied in the NECDB, then ylelds a levelized constant-dollar cost of electricity (COE). The unit costs, scâling factors, and other engineering/economics assumptions that enter the capital-cost and COE calculations are summarized in Table 2. It should be clear from the description of this procedure that the $\mathrm{COE}$ will depend not just on the choice of blanket type, input unit costs, and economics conventions, but also on the initial choice of the combination of physics parameters--beta, aspect ratio, elongation, max:mum toroidal field at the coil, and so on. It was essential for our purposes that the point-ofdeparture tokamak, which was to be the anchor or reference point from which, the other tokamak cases would be developed, should be based on choices of the physics parameters that are not only reasonable in light of present knowledge of tokamak possibilities but also close to the values that would minimize the COE subject to this constraint of physical reasonableness. Accordingly, we determined the physics parameters for the point-of-departure case by using the Generomak model in an iterative mode, seeking a COE minimum.

Although the actual "marching variable" used in this iterative process was the maximum magnetic field at the primary coll $B_{\phi C}$, it is particularly informative to show the results as a function of the ratio of net electric 
Table 2. Economics parameters and assumptions for fusion cases (ail costs in 1986 dollars).

\section{UNIT COSTS FOR FABRICATED MATERIALS:}

$V 15 \mathrm{Cr} 5 \mathrm{Ti}=\$ 400 / \mathrm{kg} ; \quad$ RAF steel $=\$ 50 / \mathrm{kg} ; \quad \mathrm{PCA}$ steel $=\$ 50 / \mathrm{kg}$;

SiC $($ blanket) $=\$ 100 / \mathrm{kg} ;$ SiC (other) $=\$ 30 / \mathbf{k g} ; \quad F e 1422=\$ 20 / \mathbf{k g}$;

Fe2Cr1V =\$20/kg; coils (tokamak) $=\$ 90 / \mathrm{kg} ; \operatorname{colls}(\mathrm{RFP})=\$ 50 / \mathrm{kg}$;

supporting structure $=\$ 25 / \mathrm{kg}$.

UNIT COSTS FOR COOLANT/BREEDER AND OTHER MATERIALS:

Liquid Li (unenriched) $=\$ 45 / \mathrm{kg} ; \mathrm{LiOZ}$ (unenriched) $=\$ 45 / \mathrm{kg} ; \mathrm{Bb}_{83} \mathrm{Li}_{17}$

$90 \%$ enriched) $=\$ 13 / \mathrm{kg} ; \mathrm{FLIBe}=\$ 70 / \mathrm{kg} ; \mathrm{Be}=\$ 500 / \mathrm{kg} ; \mathrm{LiF}-\mathrm{BeF}_{2}-\mathrm{ThF}_{4}=$

$\$ 50 / \mathrm{kg} ; \mathrm{Cd}=\$ 1600 / \mathrm{kg} ; \mathrm{BeO}=\$ 200 / \mathrm{kg} ; \mathrm{He}^{3}=\$ 100,000 / \mathrm{kg}$.

\section{COMPCNENT COSTS:}

Auxilliary power (tokamak) $=\$ 2.25 / \mathrm{W}$; auxilliary power (RFP) $=\$ 0.50 / \mathrm{W}$;

1 imiter $=\$ 60000 / \mathrm{m}^{2}$.

SCALING RULES FOR DIRECT COSTS BY CATEGORY:

Cost account

20 Land

21.1 Reactor bldg and hot cells

21.2 0ther bldgs and improvements

22.1 Reactor plant equip: heat trins

22.2 Reactor plant equip: other-1

22.3 Reactor plant equip: other-2.

23 Turbine plant equipment

24 Electric plant equipmerit

25 Misc plant equipment
Cost relation (million \$1986)

$\$ 5.0 \mathrm{M}$ (not scaled)

$\$ 174.4 \mathrm{M} \times\left(\mathrm{V}_{\mathrm{FPC}}\left[\mathrm{m}^{3}\right] / 2409\right)^{0.67}$

$\$ 120.6 \mathrm{M} \times\left(\mathrm{P}_{\mathrm{TH}}[\mathrm{MW}] / 4085\right) 0.50$

$\$ 100.3 \mathrm{M} \times\left(\mathrm{P}_{\mathrm{TH}}[\mathrm{MW}] / 4085\right)^{0.60}$

$\$ 162.4 \mathrm{M} \times\left(\mathrm{P}_{T H}[\mathrm{MN}] / 4085\right)^{0.60}$

$\$ 44.1 \mathrm{M} \times\left(\mathrm{V}_{\mathrm{FPC}}\left[\mathrm{m}^{3}\right] / 2409\right)^{0.67}$

$\$ 230.7 \mathrm{M} \times\left(\mathrm{P}_{E L}\left[\mathrm{MW} \mathrm{e}_{\mathrm{e}}\right] / 1200\right)^{0.8}$

$\$ 121.2 \mathrm{M} \times\left(\mathrm{P}_{E L}\left[\mathrm{MW} \mathrm{e}^{] / 1200)^{0.4}}\right.\right.$

$\$ 47.3 \mathrm{M} \times\left(\mathrm{P}_{\mathrm{EL}}\left[\mathrm{MW}_{\mathrm{e}}\right] / 1200\right)^{0.3}$

26 Main condensor and heat rejection \$59.1 $\left.\mathrm{M} \times\left(\mathrm{P}_{T H^{-}} \mathrm{P}_{\mathrm{EL}}[\mathrm{MW}]\right) / 2885\right)^{0.8}$ 


\section{FINANCIAL ASSUMPTIONS:}

Plant lead time $=6 \mathrm{yr} ;$ plant 11 fetime $=30 \mathrm{yr}$; indirect cost factor $=$ 0.375 ; contingency factor $=0.15 ;$ real cost of money $=0.0283 / \mathrm{yr}$; inflation $=0.06 / y r$ : interest during construction (real, for $s$-curve investment pattern) $=0.0856$; effective tax rate $=0.4816$; tax depreciation life (plant) $=10 \mathrm{yr}$ : tax depreciation life (replaceable blankets) $=5 \mathrm{yr}$ : fixed charge rate $=0.165$ (nominal $\$$ ), 0.0844 (constant $\$$ ).

\section{OPERATION AND MAINTENANCE ASSUMPTIONS:}

Capacity factor $=0.65$, except $V-M H D$ and $V-D H e^{3}$ tokamaks $=0.75$ owing to absence of turbines; blanket 1 ifetime $=20 \mathrm{mw}-\mathrm{yr} / \mathrm{m}^{2}$ of neutron fluence at the first wall (except $30 \mathrm{yr}$ for $D-\mathrm{He}^{3} / \mathrm{TOK}, 15 \mathrm{mw}-\mathrm{yr} / \mathrm{m}^{2}$ for RAF, $7 \mathrm{mw}-\mathrm{yr} / \mathrm{m}^{2}$ for P(A): $25 \%$ of auxilliary power supply replaced at same interval as blanket; annual coolant makeup $=2 \%$; radwaste management charge $=$ $1 \mathrm{mill} / \mathrm{kW}-\mathrm{hr}$; other operation and maintenance charges are $8.9 \mathrm{mills} / \mathrm{kW}-\mathrm{hr}$, with downward adjustments in cases with higher capacity factor He cooling and upward adjustment for extra guards (equal to fission plants) for hybrids.

power to the mass of the fusion power core--that is, mass power density (MPD, $\mathrm{kW}_{\mathrm{e}}$ /tonne)--as in Fig. 1. Also shown are the results of a similar iterative process for an RFP with the same liquid-lithlum/vanadium-alloy blanket type. In the RFP case, the lower limit on COE depends on the physically determined upper limit on peak neutron flux or heat flux at the first wall, with the actual COE minimum being diclated by the cost of frequent first-wall/blanket replacement (materials and downtime) at very high neutron wall loadings. The COE minimum for the tokamak case results from a capital-cost trade-off associated with low-power density at low fields and high-cotl masses at high fields.

The Case $1 \mathrm{LI} / \mathrm{V}$ blanket also served as the basis for using the Generomak model to examine the connection between physics and economics for a varlety of tokamak confinement assumptions ranging from the very conventional (low beta, 


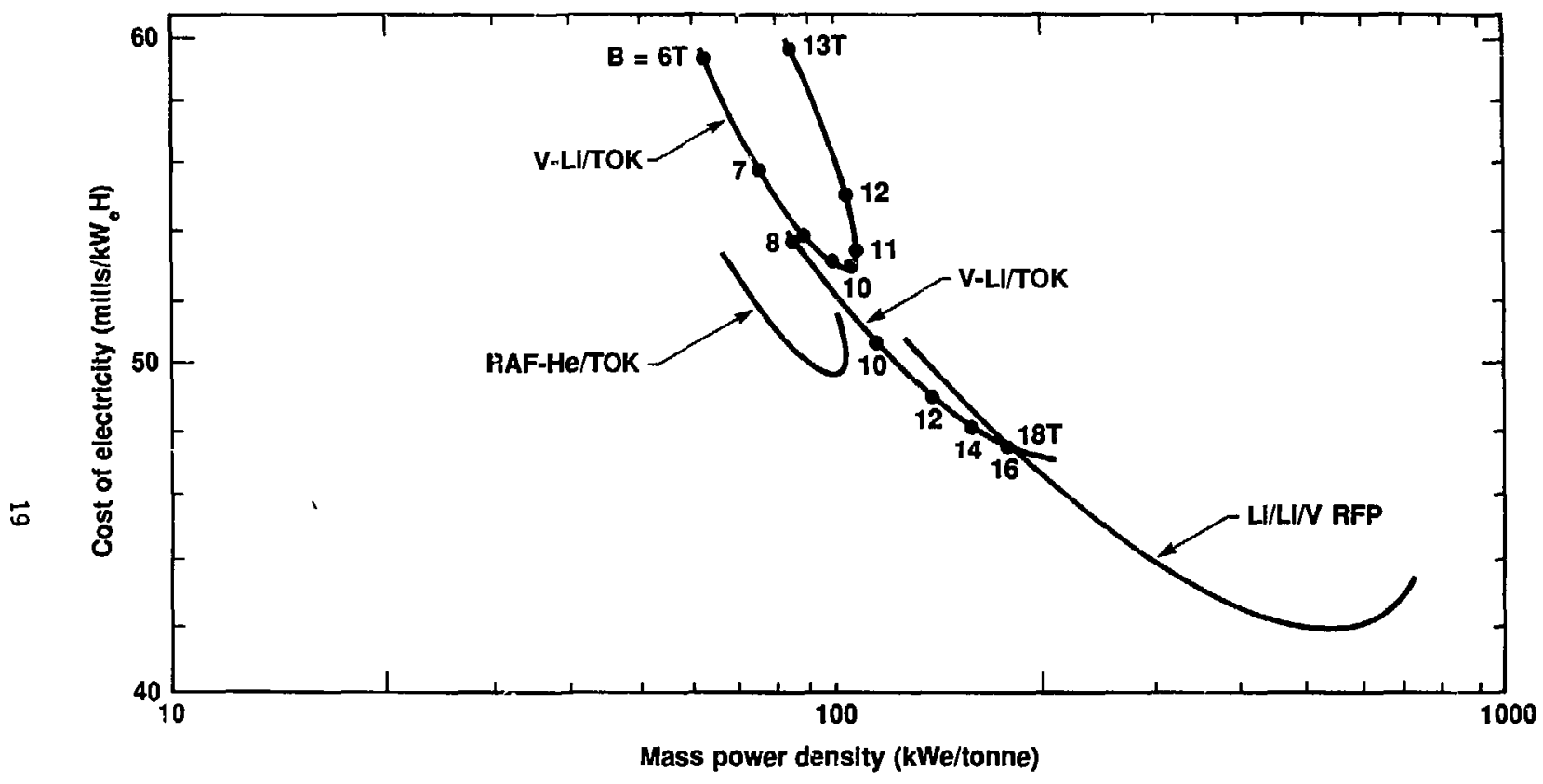

Figure 1. Cost if electricity vs mass power density for some ESECON cases. The curves show the locatton of the economic-optimum design point as the maximum toroidal magnetic field is varied in two tokamak cases and as the neutron wall loading is varied in the V-Li/RFP. The effect of an improved superconducting coll design on the COE/MPD relation for the point-of-departure $V$-LI/TOK is also shown. 
long pulsed) to the yet-to-be-achieved second-stability regime (high beta, low current). Some of these results are presented below in connection with our discussion of uncertainties, and more detail can be found in our main report. 1

For the fission cases, engineering characteristics and capital-cost estimates were taken from the analyses of the vendors or designers, 15, 35-38 modified in some instances according to the results of DOE reviews of these concepts. This information was then integrated into the NECDB methodology, with further modifications as necessary for consistency with the fusion calculations. For example, we use 6 years as the nominal design-andconstruction lead time for the fission cases as well as for the fusion ones to avoid blasing the comparisons with the assumption that future fission systems will suffer the sorts of construction delays that have been prevalent in recent experience. The engineering characteristics and econonic assumptions for the fission cases are sumarized in Table 3.

The results of the basic economic calculations are shown in Table 4. Here the "overnight" costs include the application of indirect and contingency factors but not interest during construction; they are the costs that would result if construction were instantaneous. The total capital costs are obtained by accounting for interest during the assumed 6-year construction period (adjusted to 1986 dollars). The additional fission case (11' PWR-ME) in Table 4 is the median-experience PWR and provides a second reference point rocted in reality. (The design-and-construction lead time for this case is 12 years and the indirect costs are 100\% instead of 37.5\%.) Particularly notewcrthy in these results is that the costs of electricity for the best experience and median experience PWRs bracket the range of costs estimated for the various fusion, hybrid-breeder, and advanced-fission cases.

All the costs estimated for fusion systems in Table 4 are based on the assumption that nuclear-grade construction is required throughout the plant, as has been the case with fission PWRs. The figures for the LSPB, PRISM, and MHTGR systems, on the other hand, incorporate some allowances for reduction of nuclear-grade requirement in consideration of the higher degree of passive safety that designers of these systems believe could be demonstrated in comparison with conventional fission plants. It is reasonable to suppose that those fusion systems with relatively low inventories of radioactivity and/or impressive passive barriers against release of these materials may also avoid the burdens of full nuclear-grade construction. A more systematic treatment 
Table 3. Fission cases: engineering characteristics, economic assumptions engineering characteristics.

\begin{tabular}{|c|c|c|c|c|c|c|c|}
\hline Case & $\begin{array}{l}\text { Plant } \\
\text { output } \\
\left(\text { MW }_{e}\right)\end{array}$ & $\begin{array}{l}\text { No. of } \\
\text { reactors } \\
\text { in plant }\end{array}$ & $\begin{array}{l}\text { Primary } \\
\text { fluid }\end{array}$ & $\begin{array}{l}\text { Reactor } \\
\text { exit } \\
\text { temp. } \\
\text { (of) }\end{array}$ & $\begin{array}{l}\text { Reactor } \\
\text { exit } \\
\text { press. } \\
\text { (psig) }\end{array}$ & $\begin{array}{l}\text { Thermal } \\
\text { conversion } \\
\text { effic. }\end{array}$ & $\begin{array}{l}\text { Enrichment } \\
(x)\end{array}$ \\
\hline 1 PWR-BPE & 1139 & 1 & $\mathrm{H}_{2} \mathrm{O}$ & $\overline{618}$ & 2250 & 0.339 & 3 \\
\hline 2 LSPB & 1320 & 1 & $\mathrm{Na}$ & 950 & atm & 0.377 & 24.4 \\
\hline 3 PRISM & 1245 & 9 & $\mathrm{Na}$ & 875 & atm & 0.325 & 25.9 \\
\hline 4 MHTGR & 558 & 4 & $\mathrm{He}$ & 1268 & 919 & 0.399 & 20 \\
\hline
\end{tabular}

\section{FINANCIAL ASSUMPTIONS:}

Same as for fusion except indirect cost factor $=0.31$ for MHTGR and 0.21 for PRISH (compare 0.375 for other fission and fusion cases), corresponding to $\langle 6-y r$ design-and-construction lead time claimed by designers for these modular plants.

FISSION FUEL-COST PARAMETERS:

$\mathrm{U}_{3} \mathrm{O}_{8}=\$ 50 / \mathrm{lb} ; \mathrm{Th}=\$ 35 / \mathrm{kg} ; \mathrm{Pu}=\$ 50 / \mathrm{g} ;$ conversion $=\$ 8 / \mathrm{kgU} ;$ enrichment $=$ $\$ 60 / \mathrm{SWU}$.

Fuel fabrication (per $\mathrm{kg}$ heavy metal): LWR (low-enriched $U$ ) $=\$ 240$;

LWR (U/Pu mixed oxide) =\$730; HTGR (low-enriched $U)=\$ 1750$;

HTGR $($ U233/Th) $=\$ 1150 ;$ LWR $($ U233 $/$ Th) $=\$ 1185 ;$ LMFBR (core) $=\$ 2250$; LMFBR (bTanicet) $=\$ 330$.

Spent-fuel shipping (per $\mathbf{k g}$ heavy metal): LWR $=\$ 45 ; \mathrm{HTGR}=\$ 300$;

LMFBR $=\$ 110$. 
Table 3. (continued)

Reprocessing (per kg heavy metal): LWR $(\mathrm{U} / \mathrm{Pu})=\$ 440 ;$ LWR $(\mathrm{U} 233 / \mathrm{Th})=\$ 625$; HTGR $=\$ 730 ; \quad$ LMFBR $=\$ 700$.

Radioactive-waste management $=1 \mathrm{mill} / \mathrm{kwhr}$.

OTHER OPERATION AND MAINTENANCE ASSUMPTIONS:

Capacity factor $=0.65$; nonfuel $08 M$ charges $=7.1 \mathrm{mil} \mathrm{ls} / \mathrm{kWhr}$ for PWR, $7.7 \mathrm{mills} / \mathrm{kWhr}$ for LSPB, $7.9 \mathrm{mills} / \mathrm{kWhr}$ for PRISM, $8.3 \mathrm{mills} / \mathrm{kWhr}$ for MHTGR.

of levels of safety assurance (LSA) in fusion and fission systems is offered below, along with a discussion of the economic ramifications of this issue. The nature and magnitude of the uncertainties in our cost estimates will also be discussed below. Suffice it to say here that these figures are of greater interest for their magnitudes relative to one another than for their absolute yalues. 
Table 4. Comparative costs without safety assurance credtits (1986\$).

\begin{tabular}{|c|c|c|c|c|c|c|c|}
\hline \multirow[b]{2}{*}{ Case } & \multicolumn{3}{|c|}{ Unit capital costs $\left(\$ / \mathrm{kW}_{\mathrm{e}}\right)$} & \multicolumn{4}{|c|}{ Cost of electricity $(\mathrm{mil} / \mathrm{kW}-\mathrm{hr})$} \\
\hline & Direct & $\begin{array}{l}\text { Over- } \\
\text { night }\end{array}$ & Total & Capital & $\begin{array}{l}\text { Fuel, } \\
\text { other } \\
\text { O\&H }\end{array}$ & $\begin{array}{l}\text { Fiss. } \\
\text { fuel } \\
\text { sales }\end{array}$ & Total \\
\hline $1 \mathrm{~V}-\mathrm{LI} / \mathrm{TOK}$ & 1378 & 2178 & 2365 & 35.1 & 18.1 & 0.0 & $\overline{53.1}$ \\
\hline 2 RAF-He/TOK & 1387 & 2193 & 2380 & 35.3 & 13.2 & 0.0 & 48.5 \\
\hline 3 RAF-LiPb/RFP & 349 & 1501 & 1630 & 24.2 & 13.5 & 0.0 & 37.7 \\
\hline $4 \mathrm{~V}$-Li/RFP & 963 & 1523 & 1655 & 24.5 & 12.8 & 乡.o & 37.3 \\
\hline $5 \mathrm{SiC}-\mathrm{He} / \mathrm{TOK}$ & 1621 & 2563 & 2785 & 41.3 & 13.4 & 0.0 & 54.6 \\
\hline $6 \mathrm{~V}$-FLIBE/TOK & 1184 & 1873 & 2035 & 30.1 & 17.8 & 0.0 & 47.9 \\
\hline 7 V-MHD/TOK & 873 & 1380 & 1500 & 19.2 & 16.1 & 0.0 & 35.4 \\
\hline $8 \mathrm{~V}-\mathrm{DHe}^{3} / \mathrm{TOK}$ & 1763 & 2787 & 3025 & 38.9 & 8.9 & 0.0 & 47.8 \\
\hline 9 RAF-LI/HYB & 1649 & 2608 & 2830 & 41.9 & 21.7 & $-23.2^{b}$ & 40.3 \\
\hline $10 \mathrm{SS}-\mathrm{He} / \mathrm{HYB}$ & 1343 & 2123 & 2305 & 34.1 & 21.7 & $-16.0^{b}$ & 39.8 \\
\hline 11 PWR-BPE & 740 & 1170 & 1270 & 18.8 & 14.6 & 0.0 & 33.4 \\
\hline 11' PWR-ME & 980 & 2260 & 2620 & 41.0 & 15.6 & 0.0 & 56.6 \\
\hline 12 LSPB & 1040 & 1645 & 1785 & 26.5 & ----16 & $7---C^{c}$ & 43.2 \\
\hline 13 PRISM $^{\mathrm{a}}$ & 996 & 1575 & 1710 & 25.3 & ---18. & $5-\ldots c$ & 43.8 \\
\hline 14 MHTGR $^{\mathrm{a}}$ & 885 & 1400 & 1520 & 22.6 & 19.4 & 0.0 & 42.0 \\
\hline
\end{tabular}

${ }^{a}$ Some safety-assurance credits were embedded in the vendor/designer estimates of PRISM and MHTGR capltal costs and remain in the cost figures shown here.

${ }^{b}$ These figures for hybrid fissile-fuel sales are based on MHTGR clients.

CFuel-sales credits for LSPB and PRISM are based on costs of reprocessing at central facilities (see Table 3 ) and sale of resulting plutontum at $\$ 50 / \mathrm{g}$. Reprocessing costs may be higher for on-site reprocessing proposed by PRISM designers. 


\section{SAFETY/ENVIRONMENT ANALYSIS}

ESECOM's analysis of environmental and safety characteristics included qualitaitive and, where possible, quantitative assessment of:

(a) possibilities and consequences of major releases of radioactivity from reactor accidents; (b) magnitude of the radioactive-waste burden;

(c) occupational and public exposures to radiation in routine operation; and (d) unwanted links to nuclear weaponry. Most of these analyses begin with the inventorles of various types of radioactivity, to which we now turn.

\section{DETERMINATION OF RADIOACTIVE INVENTORIES}

The largest quantities of radioactivity in fusion reactors are in the form of neutron-activation products, most of which are embedded in solid reactor materials. Smaller quantities may circulate with coolant, having been formed in coolant materials or mobilized from structure by corrosion, and still smaller quantities formed by air activation or outgassing from solid materals can be present in the plant atmosphere. Different subsets of these inventories play key roles in routine exposures of plant workers to radiation, in defining the potential for radiation doses to the public in the event of major accidents, and in shaping the radioactive-waste-management task.

ESECOM's calculations of activation-product inventories were carried out at LLNL using the TART, ORLIB, and FORIG computer codes and their associated data bases. 17,39-42 These codes operated on cylindrical approximations to our toroidal blanket configurations, in which the area of the cylindrical inner wall was equal to that of the first wall of the toroid being represented and the thicknesses of the cylindrical layers were chosen to give approximately the volumes implied by the toroidal blanket design.

The Monte Carlo calculations employed by the TART code to determine the neutron and gamma spectra in the various layers of the blanket, manifold/ reflector, and shield (and, in one case, magnets) used 20 samples with 5000 particles per sample. These spectrum calculations accounted for materials compositions down to the level of $0.1 \%$ by weight. The activation calculations performed by the ORLIB averaging code using the ACTL cross-section library took account of impurities to levels below $1 \mathrm{ppm}$ by weight. The constituent and impurity compositions used in these calculations came mainly from the Blanket Comparison and Selection Study (BCSS) (Ref. 13) and, in a few 
insiances, from the design groups working on particular blankets. These compositions are shown in Table 5.

The inventories resulting from such calculations depend not only on the incident neutron fluxes and layer thicknesses and compositions, but also on the total irradiation times. Based on a neutron fluence limit of $20 \mathrm{~mW}-\mathrm{yr} / \mathrm{m}^{2}$ at the first wall, it was assumed that solid blanket components in reactors with first-wall fluxes in the range of $3 \mathrm{mw} / \mathrm{m}^{2}$ were changed after each 6 fullpower yoars of operation, while those in reactors with first-wall fluxes $>$ ound $15 \mathrm{mw} / \mathrm{m}^{2}$ were changed after each full-power year of operation. Shields, magnets, and liquid constituents of blankets were assumed in most cases to be irradiated for 30 full-power years, as was the entire blanket of the very low neutron-flux $\left(0.09 \mathrm{MW} / \mathrm{m}^{2}\right) \mathrm{D}-\mathrm{He}^{3}$ tokamak.

For purposes of assessing accident potential and occupational hazards, reactor radioactivity inventories were evaluated at their maximum levels--that is, those attained just before blanket change-out. Radioactive-waste calculations were based on life-cycle waste quantities for 30 full-power years of operation, including all changed-out components. Component dimensions, irradiation times, and volumes for fusion Cases 1 through 6 and 8 are summarized in Table 6. (Because of lack of cross-section data for cadmium isotopes that are potentially dominant in the activation for Case 7--the V-MHD tokamak--activation calculations and the associated safety and environmental analyses were not perfoimed for this case.)

Estimates of tritium inventories in the fusion cases were based on the BCSS (Ref. 13) and on subsequent design studies, and included tritiun in structure, coolant, breeder, and neutron-multiplier materials. In addition, kilogram quantities of tritium (at $10 \mathrm{MCi} / \mathrm{kg}$ ) ordinarily would be kept in vault storage as an operational reserve or for subsequent transfer to start up new reactors. This inactive tritium inventory is not likely to be released in ordinary accidents (or even in extraordinary ones), although it might be releasable by sabotage, act of war, or natural disaster exceeding those for which the system was designed. A third type of tritium inventory exists in vacuum pumps and tritium fuel processing and purification systems, typically 100 to 200 grams. This inventory can be largely contained in separate compartments from the reactor. Vulnerability to release is generally thought to be intermediate between the tritium in the reactor blanket, structure, and coolant (the most vulnerable) and the tritium reserve fuel stored in a vault (the least vulnerable). Although ESECOM considered only the most vulnerable 
tritium (in the reactor) to be released in an accident, the additional tritium in the pumps and fuel processing equipment, even if released, would not be sufficient to significantly change any of the conclusions ESECOM derived from its accident analysis of fusion cases.

Fission-product inventorles for the PWR and LMFBR cases were derived from figures in the Reactor Safety Study of the U.S. Nuclear Regulatory Commission

Table 5. ESECOM alloy compositions (weight fraction).

VCrTi: $0.798 \mathrm{~V} ; 0.150 \mathrm{Cr} ; 0.050 \mathrm{Ti} ; 0.0003 \mathrm{Si} ; 0.0002 \mathrm{Al} ; 0.0001 \mathrm{~N}, 0$;

$0.00005 \mathrm{C}_{;} 0.00004 \mathrm{Fe} ; 0.00003 \mathrm{P} ; 0.00001 \mathrm{~S}$, Mo, Ta; $0.000004 \mathrm{NI}, \mathrm{Nb}$;

$0.000002 \mathrm{Cu}, \mathrm{As}, W ; 0.000001 \mathrm{Cl} ; 0.0000001 \mathrm{~K}$.

Fe2Cr1Y: $0.9513 \mathrm{Fe} ; 0.024 \mathrm{Cr} ; 0.015 \mathrm{~V} ; 0.003 \mathrm{Si}, \mathrm{Mn} ; 0.0011 \mathrm{C} ; 0.0005 \mathrm{Nt}$; $0.00043 \mathrm{Al} ; 0.0004 \mathrm{Cu} ; 0.0002 \mathrm{Mo} ; 0.00015 \mathrm{~N}, \mathrm{~S} ; 0.00007 \mathrm{P} ; 0.00003 \mathrm{Ti}$.

RAF : $0.8516 \mathrm{Fe} ; 0.11 \mathrm{Cr} ; 0.025 \mathrm{~W} ; 0.0053 \mathrm{Mn} ; 0.003 \mathrm{~V} ; 0.002 \mathrm{Si} ; 0.0015 \mathrm{C}$;

$0.001 \mathrm{Ti} ; 0.00013 \mathrm{P} ; 0.00008 \mathrm{Al} ; 0.00007 \mathrm{O} ; 0.00006 \mathrm{Ni} ; 0.00005 \mathrm{Co}$;

$0.00004 \mathrm{~S} ; 0.00003 \mathrm{Cu}, \mathrm{Sn} ; 0.00001 \mathrm{~B}, \mathrm{~N}, \mathrm{Zr} ; 0.000005 \mathrm{Sb}, \mathrm{Pb} ; 0.000004 \mathrm{Ta}$;

$0.000003 \mathrm{~K} ; 0.0000027 \mathrm{Mo} ; 0.000002 \mathrm{Ba}, \mathrm{Tb}, \mathrm{Ir}, \mathrm{Bi} ; 0.000001 \mathrm{Nb}, \mathrm{Cd}$;

$0.0000009 \mathrm{Ag}$.

L120: 0.5333 O; $0.4658 \mathrm{Li} ; 0.00037 \mathrm{~K} ; 0.00021 \mathrm{Ca} ; 0.0001 \mathrm{Cl}, \mathrm{Fe} ; 0.00008 \mathrm{~Pb}$; $0.00005 \mathrm{Na} ; 0.00002 \mathrm{Al}, \mathrm{Mn}, \mathrm{Ni} ; 0.00001 \mathrm{Si} ; 0.000006 \mathrm{Cu}$.

$\mathrm{Cu}: 0.9985 \mathrm{Cu} ; 0.0015 \mathrm{Zr} ; 0.000022 \mathrm{Fe} ; 0.000012 \mathrm{~S}, \mathrm{Ag} ; 0.000005 \mathrm{Ni}, \mathrm{As}, \mathrm{Sb}, \mathrm{Pb}$; $0.000002 \mathrm{Se} ; 0.000001 \mathrm{Sn}, \mathrm{Te}, \mathrm{Bi} ; 0.0000005 \mathrm{Mn}$.

LiPb: $0.9922 \mathrm{~Pb} ; 0.0068 \mathrm{LI} ; 0.001 \mathrm{Sr} ; 0.0005 \mathrm{P}, \mathrm{Zn} ; 0.0003 \mathrm{~S}, \mathrm{~K}, \mathrm{As}, \mathrm{Zr}$; $0.000260 ; 0.0001 \mathrm{Na}, \mathrm{Ca}, \mathrm{Fe}, \mathrm{Ba}, \mathrm{Bl} ; 0.00005 \mathrm{Al}, \mathrm{Cd} ; 0.00003 \mathrm{Ti}, \mathrm{V}, \mathrm{Co}, \mathrm{Mo}, \mathrm{Sb}$; $0.00002 \mathrm{Cl}, \mathrm{Cr} ; 0.00001 \mathrm{Be}, \mathrm{B}, \mathrm{N}, \mathrm{Mg}, \mathrm{Si}, \mathrm{Mn}, \mathrm{Ni}, \mathrm{Cu}, \mathrm{Ag}, \mathrm{Sn}$.

$\mathrm{PCA}: 0.6488 \mathrm{Fe} ; 0.16 \mathrm{Ni} ; 0.14 \mathrm{Cr} ; 0.02 \mathrm{Mn}, \mathrm{Mo} ; 0.005 \mathrm{Si} ; 0.003 \mathrm{Ti} ; 0.001 \mathrm{~V}$; $0.0005 \mathrm{~W} ; 0.0003 \mathrm{Al}, \mathrm{Co}, \mathrm{Nb} ; 0.0002 \mathrm{Cu}, \mathrm{As} ; 0.0001 \mathrm{~N}, \mathrm{P}, \mathrm{Ta} ; 0.00005$ 8,C,S,Zr,Sn; $0.00001 \mathrm{Sb}, \mathrm{Ba}, \mathrm{Tb}, \mathrm{Ir}, \mathrm{Pb}, \mathrm{Bl} ; 0.000003 \mathrm{~K} ; 0.000002 \mathrm{Cd} ; 0.000001 \mathrm{Ag}$.

SiC: 0.7005 Si; $0.2995 C_{i} 0.000011 \mathrm{Fe} ; 0.0000003$ Co. 
Table 5. (Continued)

PE16 Ni: $0.43 \mathrm{Ni} ; 0.35 \mathrm{Fe} ; 0.17 \mathrm{Cr} ; 0.03 \mathrm{Mo} ; 0.01 \mathrm{Al}, \mathrm{Ti} ; 0.005 \mathrm{Si}, \mathrm{Mn} ; 0.001 \mathrm{~V}$; $0.0005 \mathrm{~W} ; 0.0003 \mathrm{Co}, \mathrm{Nb} ; 0.0002 \mathrm{As}, \mathrm{Cu} ; 0.0001 \mathrm{~N}, \mathrm{P}, \mathrm{Ta} ; 0.00005 \mathrm{~B}, \mathrm{C}, \mathrm{S}, \mathrm{Zr}, \mathrm{Sn}$; $0.00001 \mathrm{Sb}, \mathrm{Ba}, \mathrm{Tb}, \mathrm{Ir}, \mathrm{Pb}, \mathrm{B1} ; 0.000003 \mathrm{~K} ; 0.000002 \mathrm{Cd} ; 0.000001 \mathrm{Ag}$.

FLiBe: $0.784 \mathrm{~F} ; 0.13 \mathrm{Be} ; 0.086 \mathrm{LI} ; 0.000166 \mathrm{Fe} ; 0.000026 \mathrm{Ni} ; 0.000019 \mathrm{Cr}$; $0.000005 \mathrm{~S} ; 0.000001 \mathrm{Mo}$.

NOTE: When a number is followed by more than one element, each of the elements listed is present at the indicated weight fraction.

(NRC) ${ }^{43}$ and an LMFBR safety study conducted in the Federal Republic of Germany, 44,45 scaled to $1200 \mathrm{MW}_{\mathrm{e}}$. As in the fusion cases, the inventories were evaluated both to give the maximum in the reactor at any one time (just before refueling in steady-state operation) and to give the 30-year 1ife-cycle quantities of radioactive wastes. Coolant activation and isotopes with halflives of a few seconds or less were not included. Fission-product and actinide inventories for the fusion-fission hybrid breeder cases were approximated by scaling from those calculated in earlier work for a somewhat similar blanket, ${ }^{46}$ and activation-product inventories for the hybrids were estimated from related pure-fusion cases using a scaling devised by Fetter. ${ }^{17}$

\section{ACCIDENT ANALYSIS}

To facilitate analysis of accident hazards associated with radioactive materials of differing degrees of inherent mobility, we divided the radioactive inventories of fusion and fission reactors alike into five mobility categories, as indicated in Table 7. In the case of fission, the categorizations are based on estimates of releasibility under accident conditions from the Reactor Safety Study, ${ }^{43}$ from more recent NRC and nuclearindustry reviews of the radioactive source term in light-water-reactor accidents, ${ }^{47,48}$ from preliminary analyses of the release from the Chernobyl accident, ${ }^{49}$ and from U.S. and German studies of LMFBR accidents. ${ }^{44,50}$ In the case of fusion, the categorizations are based in part on limited experimental data on releases from candidate fusion alloys under conditions that might be 
expected in accidents 20,21 and in part on generally avallable data on the melting points and bolling points of relevant elements and their oxides. The cacegorizations in Table 7 must be regarded as very approximate in any case, and differences of a single level should not be taken too seriously.

Table 6. Irradiation characteristics of fusion-reactor components.

\begin{tabular}{|c|c|c|c|c|}
\hline $\begin{array}{l}\text { Case (first-wall n } \\
\text { flux) and component }\end{array}$ & $\begin{array}{l}\text { Change-out } \\
\text { time (full- } \\
\text { power yr) }\end{array}$ & $\begin{array}{l}\text { Layer } \Delta r \\
\text { (cm)/Mat } 1 \\
\text { volume } \\
\text { fraction }(\%)\end{array}$ & $\begin{array}{c}\text { Component } \\
\text { volume } \\
\left(\mathrm{m}^{3}\right)\end{array}$ & $\begin{array}{l}\text { Life-cycle } \\
\text { volume } \\
\left(\mathrm{m}^{3}\right)\end{array}$ \\
\hline \multicolumn{5}{|c|}{ áse 1: $\quad V-L i / T O K\left(3.20 \mathrm{MW} / \mathrm{m}^{2}\right)$} \\
\hline First wall verTl & 6 & $5 / 20$ & 6.9 & 34 \\
\hline Inner blkt VCrTl & 6 & $35 / 7.5$ & 19 & 96 \\
\hline Mantfold VCrTi & 6 & $35 / 10$ & 28 & 140 \\
\hline Manifold Fe2Criv & 6 & $35 / 80$ & 230 & 1100 \\
\hline Shield Fe2Criv & 30 & $30 / 80$ & 220 & 220 \\
\hline
\end{tabular}

Case 2: RAF-He/TOK $\left(3.18 \mathrm{MW} / \mathrm{m}^{2}\right)$

First wall RAF

$6 / 12$

5

25

Inner blkt RAF

$57 / 15$

55

270

Inner blkt $\mathrm{L} 120$

$57 / 50$

330

1700

Manifold RAF

6

Shield Fe2Criv

30

$22 / 15$

37

190

$30 / 90$

220

220

Case 3: RAF-L1Pb/RFP $\left(16.6 \mathrm{~mW} / \mathrm{m}^{2}\right)$

First wall Cu

First wall RAF

Inner blkt RAF

Inner blkt LiPb

Shield Fe2cr1v

1
1
1
30
30

$1 / 50$

0.58

17
$1 / 20$

0.23

$60 / 11.7$

12

$60 / 88.3 \quad 86 \quad 86$

20

\section{7}

350

$10 / 90$ 
Table 6. (Continued)

Layer $\Delta r$

Change-out (cm)/Mat 1 Component LIfe-cycle

Case (first-wall $n$

flux) and component time (full- volume

power yr) fraction ( $(x)$ volume

$\left(m^{3}\right)$ $\left(\mathrm{m}^{3}\right)$

Case 4: $\mathrm{V-l.1/RFP}\left(14.6 \mathrm{MW} / \mathrm{m}^{2}\right)$

First wall VCrTi

Inner blkt VCrTi

Shield VCrTi

Shield Fe2Criv

Magnet $\mathrm{Cu}$

Magnet PCA

1

1

1

30

30

Case 5: SiC-He/TOK $\left(2.53 \mathrm{~mW} / \mathrm{m}^{2}\right)$

First wall SiC

Inner blkt SiC

Inner blkt Li20

Manifold SiC+

Shield Al+
6

6

6

6

30

Case 6: V-FLiBe/TOK $\left(3.70 \mathrm{MW} / \mathrm{m}^{2}\right)$

First wall VCrTi

Inner blkt VCrTi

6

Inner blkt FliBe

6

Shield PE16

30

Case 8: D-He ${ }^{3} /$ TOK $\left(0.09 \mathrm{MW} / \mathrm{m}^{2}\right)$

First wall vCrTi

Inner blkt VCrTi

Shield Fe2Criv

30

30

30
$1 / 100$

$49.1 / 16$

$49.1 / 39.8$

$28.9 / 52$

$108 / 89.1$
0.35

0.60

8.9

72

5.0

7.2
11

18

270

2100

5.0

7.2 
Table 7. Categorization of radioactive isotopes by mobility under accident conditions.

\section{Category Definition}

I: Elements gaseous or extremely volati ie under thermochemical conditions of normal operation.

II: Elements somewhat volatile under thermochemical conditions of normal operation.

III: Elements somewhat to highly volatile under conditions likely to be encountered in an accident.

IV: Elements somewhat volatile under conditions that may be encountered in severe accidents.

$V:$ Elements resistant to volatilization even under extreme accident conditions.

Fusion

Fission

$$
\mathrm{H}, \mathrm{C},{ }^{\star} \mathrm{N}, \mathrm{Ar}
$$

$\mathrm{Mg}, \mathrm{P}, \mathrm{Cl}, \mathrm{Ca}$, $\mathrm{Ag}, \mathrm{Cd}, \mathrm{Re}, \mathrm{Hg}$

$\mathrm{Na}, \mathrm{Mn}, \mathrm{As}, \mathrm{Sr}, \quad \mathrm{Sb}, \mathrm{Te}$ $\mathrm{Mo}, \mathrm{Cu}, \mathrm{Ni}, \mathrm{TC}$, $\mathrm{Tl}, \mathrm{Po}, \mathrm{Pb}$

$\begin{array}{ll}K, C o, V, P d, & S r, R u, B a, \\ I n, S b, W, T e & R h, C o, M o, \\ & \text { Tc }\end{array}$

Be,Al,Si,SC, Fe,Y,La, $\mathrm{Ti}, \mathrm{Fe}, \mathrm{Y}, \mathrm{Zr}, \quad \mathrm{Zr}, \mathrm{Nb}, \mathrm{Ce}$, $\mathrm{Nb}, \mathrm{Sn}, \mathrm{La}, \mathrm{Hf}, \mathrm{Pr}, \mathrm{Nd}, \mathrm{U}$, $\mathrm{Ta}, \mathrm{Bi}, \mathrm{Cr} \quad \mathrm{Th}, \mathrm{Np}, \mathrm{Pa}$ $\mathrm{Pu}, \mathrm{Am}, \mathrm{Cm}$

* From activation of air.

NOTES: These categorizations denote relative mobility of fusion elements compared with one another and of fission elements compared with one another; it should not be assumed that fusion elements in a given mobility cate/gory have the same likelihood of release, or the same release fraction in a severe accident, as elements in the same mobility category in the fission column.

Temperature ranges for fusion are defined as follows:

Normal operation: $T<800 \mathrm{~K}$

Likely to be encountered in an accident: $800 \mathrm{~K}<\mathrm{T}<1200 \mathrm{~K}$ May be encountered in severe accidents: $1200 \mathrm{~K}<\mathrm{T} \geqslant 1800 \mathrm{~K}$

We assume that the elements may come into contact with oxygen under accident conditions, so formation of volatile oxides has been taken into account.

Many of the categorizations for elements in fusion alloys are based on experimental data for $\mathrm{V} 15 \mathrm{Cr} 5 \mathrm{Ti}$ and $\mathrm{HTg}$ ferritic steel. Relative mobilities in different alloys will not necessarily be the same in all cases. 
Revisions in this or any similar scheme are inevitable as more data become available; this is especially so on the fusion side where available data are currently so scanty.

Given the radioactive inventories and the mobility-based classification scheme just described, it becomes possible to calculate the off-site doses that would result from release of $100 \%$ of the radioactive inventory in each mobility category for each design. One can then deduce how large the actual release fractions of these materials would have to be to produce any particular dose of interest. One can calculate, for example, what fraction of the radioactive inventory in a fusion-reactor first wall would have to be released to generate, under adverse weather conditions, an acute whole-body dose of $200 \mathrm{rem}$ at a distance of $1 \mathrm{~km}$ from the reactor (corresponding approximately to the threshold below which no early fatalities would be expected); and one can calculate these dose-threshold release fractions for each different mobility category in each reactor type. The higher these dosethreshold release fractions are, the better, because a large figure indicates that the threshold dose will not be exceeded unless a large fraction of the inventory escapes. (A dose-threshold release fraction exceeding unity means that not even a $100 \%$ release of the inventory would suffice to produce the threshold dose.)

Where estimates are available of the actual release fractions that are plausible for materials in different mobility categories under severe-accident conditions, these estimates can be compared with the dose-threshold release fractions calculated as iust described to clarify whetiner (and by how much) the threshold doses could be exceeded in credible events. (Estimates of maximum plausible release fractions in severe accidents are available for at least a few types of fission reactors, and ESECOM has made such estimates-necessarily in a very approximate way, but we belleve very conservatively--for three of our fusion cases.) Even where estimates of the maximum plausible release fractions are not available, as is the case for most fusion systems and for the more advanced fission systems, direct comparison of the dosethreshold re?ease fractions for the various mobility categories in different systems provides some basis for judgment about the relative potential of these systems to generate dangerous releases.

Table 8 summarizes our findings on inventories and dose-threshold release fractions for some of the fusion cases and for the PWR and LSPB fission cases. 
Table 8. Dose-threshold release fractions by component and mobility category.

Release fraction that would produce:

Case and 200 rem crit dose 25 rem 50 -yr ground mobility Inventories (MCi) from plume $1 \mathrm{~km}$ dose a $10 \mathrm{~km}$ categories First wall BOFC First wall BOFC First wall BOFC

Case 1: V-LI/TOK

$\begin{array}{lrccccc}\text { I } & 5 & 0.077 & 52 & 7100 & 15 & 260 \\ \text { I-II } & 10 & 6.0 & 6.3 & 5.0 & 0.78 & 0.82 \\ \text { I-III } & 10 & 60 & 5.1 & 0.027 & 0.55 & 0.00011 \\ \text { I-IV } & 95 & 670 & 3.7 & 0.027 & 0.021 & 0.00010 \\ \text { I-V } & 540 & 2400 & 0.036 & 0.015 & 0.0016 & 0.00009\end{array}$

Case 2: RAF-He/TOK

$\begin{array}{lcccccl}\text { I } & 1.7 & 0.040 & 160 & 2 \mathrm{e} & 56 & 4400 \\ \text { I-II } & 7.1 & 16 & 5.7 & 2.3 & 2.3 & 0.86 \\ \text { I-III } & 390 & 450 & 0.036 & 0.032 & 0.00011 & 0.00011 \\ \text { I-IV } & 510 & 670 & 0.035 & 0.028 & 0.00011 & 0.00010 \\ \text { I-V } & 1200 & 1300 & 0.033 & 0.327 & 0.00011 & 0.00010\end{array}$

Case 3: RAF-P'OLi/RFP

$\begin{array}{lcccccc}\text { I } & 0.51 & 0.032 & 510 & 4 \mathrm{e} 3 & 180 & 2200 \\ \text { I-II } & 21 & 20 & 1.9 & 0.63 & 0.70 & 0.076 \\ \text { I-III } & 120 & 480 & 0.031 & 0.011 & 0.00086 & 0.00019 \\ \text { I-IV } & 220 & 1300 & 0.028 & 0.011 & 0.00013 & 0.00017 \\ \text { I-V } & 2500 & 1600 & 0.028 & 0.010 & 0.00013 & 0.00010\end{array}$


Table 8. (Continued)

\section{Release fraction that would produce:}

200 rem crit dose 25 rem $50-y r$ ground

Case and mobility categories
Inventories (MCi)

First wall BOFC from plume [0 $1 \mathrm{~km}$

First wall BOFC dose a $10 \mathrm{~km}$

First wall BOFC

Case 4: V-Li/RFP

I

I-II

I-III

I-IV

I-V
5.0

6.5

6.5

38

180
0.07

51

17

14

8.1

0.099
$2 \mathrm{e} 4$

4

0.0121 .

0.011

0.0084
18

2.4

0.00010

1100

4600

0.031

0.0047
1.7

8.2

8.3

$8.0 \quad 230$

800

I-V

I-III

I-IV

2.1

14

15

230

1500
160

86

41

41

21
220

17

3.1

0.13

0.13

Case 6: V-FLiBe/TOK

I

I-I I

I-III

I-IV

I-V

Case 8: $\mathrm{V}-\mathrm{DHe}^{3} / \mathrm{TOK}$

I

I-II

I-III

I-IV

I-V
0.17

1.1

1.1

17

110

0.50

0.81

0.82

6.8

62

\section{$0.0116001 \mathrm{e} 5$}

0.96

1.2

16

220
41

32

19

0.20
560

38

22

14

0.21
56

55

8.4

2.9

2.9
0.00008

0.00008

350

0.17

0.00008
0.00008


Table 8. (Continued)

\begin{tabular}{|c|c|c|c|}
\hline \multirow[b]{2}{*}{$\begin{array}{l}\text { Case and } \\
\text { mob1lity }\end{array}$} & \multirow[b]{2}{*}{ Inventories (MC1) } & \multicolumn{2}{|c|}{ Release fraction that would produce: } \\
\hline & & $\begin{array}{l}200 \text { rem crit dose } \\
\text { from plume a } 1 \mathrm{~km}\end{array}$ & $\begin{array}{l}25 \text { rem } 50-y r \text { ground } \\
\text { dose a } 10 \mathrm{~km}\end{array}$ \\
\hline categories & Fission core & Fission core & Fission core \\
\hline
\end{tabular}

Case 11: PWR-BPE (fission)

$\begin{array}{lrlc}\text { I } & 380 & 0.38 & 28 \\ \text { I-II } & 1300 & 0.017 & 0.00013 \\ \text { I-III } & 1500 & 0.011 & 0.00012 \\ \text { I-IV } & 2600 & 0.0058 & 0.000086 \\ \text { I-V } & 5600 & 0.0025 & 0.000048\end{array}$

Case 12: LSPB (fission)

I

I-II

I-III

I-IV

I-V
360

1000

1200

2200

5300
0.67

0.024

0.015

0.0071

0.0031
63

0.00017

0.00016

0.000095

0.000042

NOTES: All figures scaled to a standard $1200-\mathrm{MW}_{\mathrm{e}}$ plant size.

BOFC $=$ balance of fusion core $=$ blanket other than first wall, manifold/reflector, shield, and magnets (if magnet activation is significant).

All of the tritium in the blanket is counted as if it were in the first wall, where it dominates the Category I inventory.

Dose-threshold release fractions greater than one mean that release of the entire inventory would not suffice to produce the threshold dose; these figuresthus represent multiples of the inventory.

The absence of cross-section data for certain cadmium isotopes made it impossible to perform accurate activation calculations for case 7 $(V-M H D / T O K)$, so no figures for this case are presented here. 
Two different threshold doses have been used here, critical-dose and chronicdose thresholds.

The critical dose threshold corresponds to a critical whole-body dose commitment of 200 rem delivered by passage of the radioactive plume to an individual standing $1 \mathrm{~km}$ from the release under meteorological conditions that tend to maximize this dose. Here critical is defined--as in the Reactor Safety Study ${ }^{43}$--to include all of the radiation dose delivered in the first 7 days after the exposure plus half the dose delivered in the 8th through 13th days. The mechanisms considered are external irradiation by suspended and ground-deposited material during plume passage, and internal irradiation from material inhaled while the plume is passing. A critical dose comitment of 200 rem represents the level below which no early fatalities would be anticipated. (Early fatalities are those resulting from acute radiation syndrome; when the dose is high enough to produce such fatalities, they occur within the first 60 days after the exposure.)

The chronic dose threshold corresponds to a 50-year whole-body dose of 25 rem from ground contamination at a distance of $10 \mathrm{~km}$ from the release. The calculation of this dose accounts for inhalation of resuspended material as well as for external irradiation by material on the ground, and it corrects for shielding attributable to surface roughness and to the exposed persons' being indoors part of the time. Potential doses from contamination of food and drinking water are not included. Under U.S. standards, a potential exposure of $25 \mathrm{rem}$ in 50 years from ground contamination would require either evacuation or extensive cleanup procedures.

All doses were calculated assuming weather conditions highly adverse in respect to the critical dose at the plant boundary (Pasquill $\mathrm{F}$ stability, $1 \mathrm{~m} / \mathrm{s}$ windspeed, Inversion layer at $250 \mathrm{~m}$, release at ground level with no thermal plume rise, and a deposition velocity of $0.01 \mathrm{~m} / \mathrm{s}$ ) and using the dose models developed by Fetter. 17

The results in Table 8 indicate that all of the fusion cases shown have substantial safety advantages over fission reactors based on release fractions required to exceed threshold doses--even without assuming that the physically plausible release fractions might be smaller for fusion. The point of departure V-Li/TOK fusion case, for example, has more than a two-order-ofmagnitude advantage over the LMFBR wfth respect to critical dose at $1 \mathrm{~km}$ in every mobility category from I to IV if one bases the comparison on the fusion first wall (which, with respect to after-heat power density, radioactivity 
concentration, surface-to-volume ratio, and susceptibility to overheating as a result of reconfiguration or exposure to fire, represents by far the most vulnerable part of the fusion inventory to release). Even the highest powerdensity fusion system (the RAF-LiPb/RFP) has a significant advantage over the LMFBR with respect to critical dose at $1 \mathrm{~km}$ from mobility categories $I$ through IV. The advantages of the low-activation and advanced-fuel fusion systems art much larger st 111.

If the whole balance of fuston core (BOFC) is included in the comparison, most of the fusion systems still retain an advantage of an order of magnitude or more over the fission cases with respect to critical-dose threshold release fractions in most mobility categories. With respect to chronic-dose threshold release fractions, as well, most of the fusion cases have significant advantages compared with fission whether the BOFC is included or not. The exceptions here are cases 2 and 3 , in which the manganese activation in the ferritic-stee 1 blanket produces high potential for ground contamination, and Case 4 , in which the manganese activation in the shield and cobalt-60 in the magnet supports pose similar ground-contamination potential. In general, the potential for significant ground contamination from fusion-reactor accidents ij0-year ground doses well in excess of 25 rem at distances of tens of kilometers) is considerably greater than the potential for early fatalities. In nearly ail cases, the main contributors in this respect are manganese and cobalt isotopes in mobility categories III and IV.

Table 9 gives a component-by-component breakdown of the critical-dose threshold release fractions in the fusion cases and indicates which specific isotopes are mainly responsible for the dose potential in each mobility category. These figures underline the safety attractions of some of the more advanced fusion cases--the SiC-He, V-FLiBe, and $\mathrm{D}-\mathrm{He}^{3}$ tokamaks. It is apparent that these systems cannot generate a prompt fatality off-site at all unless one can imagine an event that would release a substantial fraction of the Category $V$ isotopes from the first wall (in the cases of the $V$-FLiBe and $\mathrm{D}-\mathrm{He}^{3}$ tokamaks) or a substantial fraction of the Category IV isotopes from the shield (in the case of the SiC-He tokamak).

When one takes the next step of comparing the release fractlons needed to generate threshold doses with the fractions that may be physically plausible for isotopes in the different mobility categories in the fusion and fission cases, the advantage of fusion widens. Tlis is shown in Table 10, where FSECOM's estimates of maximum physicaily plausible release fractions for the 
Table 9. Critical-dose threshold release fractions and dominant isotopes. The figures shown are the fraction (or multiple) of the inventory in the stated component and mobility category that would produce a critical whole-body dose of 200 rem at $1 \mathrm{~km}$ from the release under pessimistic assurptions.

\begin{tabular}{lllll}
\hline & First Wall & Rest of inner blanket & Manifold/refiector & Shield \\
Case and & Threshold & Threshold & Threshold & Threshold \\
mobility & :elease Dominant release Dominant & release Dominant release Dominant \\
category & fraction isotopes fraction isotopes fraction isotopes fraction isotopes
\end{tabular}

\begin{tabular}{cllll}
\hline Case 1: & V-LI/TOK & & & \\
I & 50 & H3 & 2 e4 & H3 \\
I-II & 6 & Ca45, Ca47 & 8 & Ca45, Ca47 \\
I-III & 5 & Ca45, Na24 & 6 & Ca45, Na24 \\
I-IV & 4 & Ca45, Na24 & 5 & Ca45, Na24 \\
I.V & 0.04 & Sc48 & 0.04 & Sc48
\end{tabular}

\begin{tabular}{llrl}
\multicolumn{1}{l}{1 e4 } & H3 & \multicolumn{1}{l}{3 e5 } & H3 \\
10 & P32,Ca45 & 400 & P32 \\
0.03 & Mn56, Mn54 & 0.6 & Mn56 \\
0.03 & Mn56, Mn54 & 0.6 & Mn56 \\
0.02 & Mn56, Mn54 & 0.4 & Mn56, Fe59
\end{tabular}

Case 2: RAF-He/TOK

$\begin{array}{ll}\text { I } & 200 \\ \text { I-II } & 6 \\ \text { I-III } & 0.04 \\ \text { I-IV } & 0.04 \\ \text { I-V } & 0.03\end{array}$

H3

Re186,Re188

Mn56, Mn54

$\operatorname{Mn} 56, \operatorname{Mn} 54$

Mn56, Mn54

3 Re186, Re188

$0.03 \operatorname{Mn} 56, \operatorname{Mn} 54$

0.03 Mn56, Mn54

$0.03 \mathrm{Mn56}, \mathrm{Mn} 54$

3 e6

0.9 Mns6, Mn54

$0.3 \mathrm{~W} 187, \mathrm{Mn} 56$

4e3 Ar41

0.6 P32, Re188

0.01 Po210, Mn56

0.01 Po210, Mn56

0.01 Po210,Mn56
Re188, Re186

Cu64, Mn56

Cu64, Mn56

Cu64,Mn56

\subsection{3}

H3

$I$
$I-I I$
$I-I I I$
$I-I V$
$I-V$

$\mathrm{H} 3$

Ca45,Ca47

Ca45, Na24

$1-V$

0.1 Sc48

$\begin{array}{ll}6 \mathrm{e} 4 & \mathrm{H} 3, \mathrm{N13} \\ 10 & \mathrm{Ca} 45 \\ 7 & \mathrm{Ca} 45, \mathrm{Na24} \\ 6 & \mathrm{Ca} 45, \mathrm{Na24} \\ 0.04 & \mathrm{Sc} 48\end{array}$

$\begin{array}{ll}3 e 4 & H 3 \\ 400 & \text { P32 } \\ 0.7 & \operatorname{Mn} 56, \operatorname{Mn} 54 \\ 0.5 & \operatorname{Mn} 56, \operatorname{Mn} 54 \\ 0.4 & \operatorname{Mn} 56, F e 59\end{array}$

$\begin{array}{rl}5 e 6 & H 3 \\ 400 & \text { P32 } \\ 0.7 & \operatorname{Mn56} \\ 0.7 & \operatorname{Mn56} \\ 0.6 & \operatorname{Mn56,Fe59}\end{array}$

$\begin{array}{ll}2 \mathrm{e} 4 & \mathrm{H3}, \mathrm{N} 13 \\ 7 & \mathrm{P32} \\ 0.01 & \text { Mn56, Cu64 } \\ 0.01 & \text { Mn56, Cu64 } \\ 0.01 & \text { Mn56, Cu64 }\end{array}$


Table 9. (Continued)

\begin{tabular}{|c|c|c|c|c|c|}
\hline & First Wall & Rest of inner blanket & Manifold/reflector & Shield & \\
\hline $\begin{array}{l}\text { Case and } \\
\text { mobility } \\
\text { category }\end{array}$ & $\begin{array}{l}\text { Threshold } \\
\text { release Dominant. } \\
\text { fraction isotopes }\end{array}$ & $\begin{array}{l}\text { Threshold } \\
\text { reiease Dominant } \\
\text { fraction Isotopes }\end{array}$ & $\begin{array}{l}\text { Threshold } \\
\text { release Dominant } \\
\text { fraction isotopes }\end{array}$ & $\begin{array}{l}\text { Threshold } \\
\text { release } \\
\text { fraction }\end{array}$ & $\begin{array}{l}\text { Dominant } \\
\text { i sotopes }\end{array}$ \\
\hline
\end{tabular}

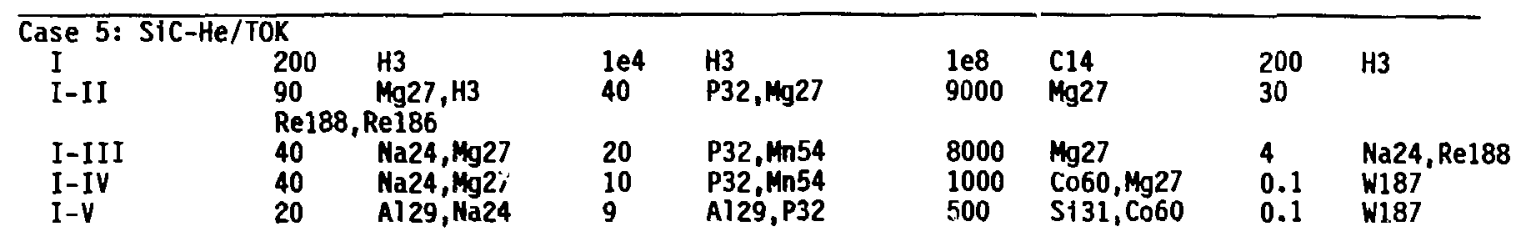

Case 6: V-FLIBE/TOK

$\begin{array}{lllllllll}\text { I } & 2000 & \text { H3 } & 1 e 5 & \text { H3 } & \text { NA } & \text { NA } & 2 \text { (e8 } & \text { H3 } \\ \text { I-II } & 40 & \text { Ca45, Ca47 } & 40 & \text { Ca45,P32 } & \text { NA } & \text { NA } & 3 e 5 & \text { P32, Ca45 } \\ \text { I-III } & 30 & \text { Ca41, Na24 } & 20 & \text { Ca45, Na24 } & \text { NA } & \text { NA } & 500 & \text { Mn56, Mn54 } \\ \text { I-IV } & 20 & \text { Ca45, Na24 } & 8 & \text { Ca45, Ma24 } & \text { NA } & \text { NA } & 100 & \text { Co60, Mn56 } \\ \text { I-V } & 0.2 & \text { Sc48 } & 0.2 & \text { SC48 } & \text { HA } & \text { NA } & 100 & \text { Co60, Mn56 }\end{array}$

Case 8: D-He3/TOK

\begin{tabular}{|c|c|c|c|c|c|c|c|}
\hline $\begin{array}{l}I \\
I-I I \\
I-I I I \\
I-I V \\
I-V\end{array}$ & $\begin{array}{l}500 \\
100 \\
80 \\
60 \\
0.6\end{array}$ & $\begin{array}{l}\text { H3 } \\
\text { Ca45, H3 } \\
\text { Ca45, Na24 } \\
\text { Ca45, Na24 } \\
\text { Sc48 }\end{array}$ & $\begin{array}{l}1 e 6 \\
1 e 3 \\
800 \\
700 \\
6\end{array}$ & $\begin{array}{l}\mathrm{H} 3 \\
\text { Ca45 } \\
\text { Ca45, Na24 } \\
\text { Ca45, Na24 } \\
\text { Sc48 }\end{array}$ & $\begin{array}{l}\text { MA } \\
\text { MA } \\
\text { NA } \\
\text { NA }\end{array}$ & & $\begin{array}{l}\text { H3 } \\
\text { H3, P32 } \\
\text { Mn54, Mn56 } \\
\text { Mn54, Mn56 } \\
\text { Mn54, Mn56 }\end{array}$ \\
\hline
\end{tabular}


Table 10. Estimates of maximum plausible release fractions.

\begin{tabular}{ccccc}
\hline $\begin{array}{l}\text { Mobility } \\
\text { Category }\end{array}$ & V-Li/TOK & RAF-He/TOK & V-LiT/RFP & $\frac{\text { Fission }}{\text { LWR, LMFBR }}$ \\
\hline I & 1.0 & 1.0 & 1.0 & 1.0 \\
II & 0.1 & 0.7 & 0.7 & $0.2-0.7$ \\
III & 0.05 & $0.1-0.7$ & 0.2 & $0.2-0.4$ \\
IV & $5 e-4$ & $0.01-0.1$ & $2 e-3$ & $0.05-0.1$ \\
V & $5 e-5$ & $1 e-4$ to le-3 & $2 e-4$ & $0.003-0.05$
\end{tabular}

NOTES: The time-temperature scenarios assumed in estimating the fuston release fractions are as follows:

V-Li/TOK: Lithiam-air fire + decay heat produce $1300^{\circ} \mathrm{C}$ for 10 hours followed by 40 hours at $900^{\circ} \mathrm{C}$.

RAF-He/TOK: Decay heat produces $900^{\circ} \mathrm{C}$ for 50 hours.

V-Li/RFP: Lithium-air fire + decay heat produce $1500^{\circ} \mathrm{C}$ for 10 hours followed by 40 hours at $1200^{\circ} \mathrm{C}$.

$V-L i$ and RAF-He tokamaks and the V-Lf RFP are compared with corresponding estimates for fission. The fusion release fractions are based on analyses at MIT of maximum attainable temperatures in these systens, combined with data from INEL on volatilization from these alloys at those temperatures, and with no credit for the effects of active release-suppression measures or containment buildings. The fission release fractions have been compiled from Refs. 43 and 47-50.

\section{LEVELS OF SAFETY ASSURANCE (LSA)}

The fission and fusion communities have given considerable attention to the concept of inherent or passive safety. There is as yet no generally accepted technical definition of inherent safety, however, and if one were agreed upon there would be a danger of its being used, too simplistically, to divide the world of reactors into just two categories--those that possess this property and those that do not. We have found it useful to work with a more highly differentiated classification that defines four LSA, based in substantial part on the work of Piet. ${ }^{51}$ These levels are based on differences 
in the extent and nature of dependence on passive vs active design features for assurance of public safety--more specifically, for precluding any off-site early fatalities from release of radioactivity.

By passive design features we mean combinations of materials properties and configurations of structural components such that natural processes of energy removal (conduction, natural convection, radiation) suffice to $1 \mathrm{fmit}$ accident sequences and the resulting radioactivity releases. Relevant materials properties include inventorfes of radioactivity, masses, heat capacities, strength vs temperature, melting points, vapor pressures (as functions of temperature), and susceptfbflity to formation of volatile oxides. By active design features, we mean pumps, valves, switches, sensors, and the like, as well as (more controversially) contaminment bufldings.

We had two main reasons for categorizing contaminment buildings with active rather than passive means of assuring safety. First, containment buildings are typically complicated systems with many penetrations controlled by active means, and they can fall in many ways. Second, if one were to assert that a sufficiently stout containment building justifies the appellation of passive safety whatever the characteristics of the reactor inside, the concept of passive safety would lose most of its meaning: it would not offer any useful distinctions among degrees of "goodness" in the safety properties of the reactors themselves.

As discussed above, our quantitative threshold for avoidance of early fatalities off-site is a critical whole-body dose of 200 rem at the plant boundary, assumed to be at $1 \mathrm{~km}$ from the point of the release. If the "fencepost" critical dose does not exceed $200 \mathrm{rem}$, not only are no early fatalities from acute radiation syndrome to be expected among members of the public, but it can be shown as well that the total population exposure resulting from lower doses at larger distances will not exceed a few million person-rem. This figure implies an eventual number of excess cancer deaths in the range of a few hundred among the millions of people receiving a measurable dose, or considerably less than $0.1 \%$ of the cancer fatalities occurring in this population from other causes. (The dose of 200 rem to the hypothetical most-exposed individual translates to a 2 to $4 \%$ chance of dying of cancer, which is to be compared with an overall chance of 20 to $25 \%$ that a given individual in an industrial society will die of cancer from some other cause.)

The four LSA are arranged so that moving from Level 1 (the highest or most desirable level) to Level 4 (the lowest or least desirable level) 
shrinks, at each step, the range of accident conditions in which materials properties and passive heat removal alone suffice to assure public safety, thus expanding the range of accident conditions that must be prevented by passive design features (Levels 2 and 3) or active ones (Level 4). More specifically:

1. In a Level 1 reactor, safety is assured by passive mechanisms of release 1 imitation no matter what the accident sequence. The radioactive inventories and material properties in such a reactor preclude a fatal release regardless of the reactor's condition.

2. In a Level 2 reactor, safety is assured by passive mechanisms of release $11 \mathrm{mitation}$ as long as severe reconfiguration of large-scale geometry is avolded, and escalation to fatality-producing reconfigurations from less severe initiating events can plausibly be precluded by passive design features. In such a reactor, natural heat-transfer mechanisms suffice to keep temperatures below those needed--given $i t s$ radioactivity inventories and material propertles--to produce a fatal release unless large-scale geometry is badly distorted.

3. In a Level 3 reactor, safety is assured by passive mechanisms of release $11 \mathrm{mitations}$ as long as severe violations of small-scale geometry--such as a large break in a major coolant pipe--are avoided, and escalation to fatality-capable violations from less severe initiating events can plausibly be precluded by passive design features. In such a reactor, sufficiency of natural heat-transfer mechanisms to keep temperatures low enough--given its radioactivity inventories and materials properties--to avoid a fatal release can only be assured while the coolant boundary is substantially intact.

4. In a Level 4 reactor, there are credible inftiating events that can only be prevented from escalating to fatality-capable boundary violations or reconfigurations by means of active safety systems.

Achlevement of Level 1 is most readily apparent when it is based on inventory alone--that is, when one can show that the complete release of the radioactive inventory of the reactor would not produce a cricical dose of 200 rem at the plant boundary. In cases where the inventory is too large to meet this condition, characterization of the reactor as Level 1 could still, in principle, be justified if persuasive information about the properties of the materials in which the radioactivity is embedded and about the quantities of energy that could be brought to bear on those materials showed conclusively that moblization of a suffictent fraction of the inventory to produce a 
critical dose of 200 rem at the plant boundary is impossible. In cases where this determination is not clear cut, however, Level 1 should not be claimed.

To warrant classification of a design as Level 2, it must be demonstrated that preservation of the large-sca!e geometrical aspects of the design in an accident is sufficient to ensure public safety without resort to active systems and that passive design features make failure of the large-scale geometric aspects required for safety incredible. For example, if maintenance of a pool geometry is necessary to provide cooling for radioactive components, then the integrity of that pool must be assured by passive means for all credible circumstances.

For classification as Level 3, it must be demonstrated that preservation of large-scale and small-scale geometric integrity together is sufficient to assure pubilic safety without resort to active systems and that passive design features are sufficient to preserve the features of geometry needed to maintain this condition. For example, if failure of a piping system could drain required coolant or prevent required natural circulation and if such failure could lead to mobilization of sufficient radioactivity to cause an off-site early fatality, then failure of that system must be made incredible by passive means. Level 3 designs must tolerate, without resort to active systems, all anticipated faults such as station blackout, relfef-valve failures, pump-seal failures, and so on.

For Level 4 designs, maintenance of the critical safety-related aspects of large- and/or small-scale geometry cannot be assured by passive means, or, even if assured, is not sufficient to preclude off-site early fatalities without reliance on containment or other active measures for release suppression. For such designs, active safety systems must be provided and shown to be of very high reliabllity if public safety is to be considered assured. This approach, which is the one employed in contemporary fissionreactor practice, requires a tremendous amount of safety analysis and testing as well as the acquisition of multiple active safety systems that are expensive in themselves. It is inherently difficult to analyze the responses of active systems to a wide range of low-probability events, and st11l more difficult to prove the adequacy of such analyses to the public and to licensing officials. Certainly Level 4 designs can be made sufficiently safe; but the costs of assuring their adequate safety tend to be high, and the demonstrability of adequate safety to the relevant audiences may be so difficult as to cause a further set of costs and burdens (through, e.g.. 
prolonged licensing procedures, public hearings and lawsuits, and siting restrictions).

The definitions of the four LSA are presented in compact form in Table 11. Table 12 summarizes the LSA assignments arrived at by ESECOM for our reference cases. For each of the reference cases we show three values of the LSA, as follows:

1. The optinistic concept evaluation represents the highest safetyassurance potential of the concept in question. It is obtained by assuming favorable resolution of the uncertainties in the rudimentary safety analysis we used to make these assignments. This favorable resolution could result from better data on materials propertles, from better modeling of accident conditions, from consideration of design features we did not take into account, or from a combination of these.

2. The nominal design estimate represents our best estimate, albeit leaning to the conservative side, under the prevalling 1 imitations of design deta1l and safety-relevant data. Among other conservatisms mentioned below, we have tended to resolve any Committee disagreements about the nominal rating in favor of the more pessimistic value.

3 . The conservative concept evaluation represents the lower-bound LSA concept. It is obtained by assuming unfavorable resolution of the main uncertainties in our analysis.

We define a concept in this connection to have the same choice of blanket materials and basic geometry as the corresponding ESECOM reference case, but allow the possibility of changes in shieid materials and high-heat-flux components in considering the potential for improvement.

The procedure by which the LSA assignments in Table 12 were derived involves comparing the critical-dose threshold release fractions for various reactor components and mobility categories with the mobilization fractions that seem conceivable in the kinds of temperature transients predicted or postulated for the varlous designs in different classes of accidents. The dominant safety concerns in the different cases are listed in compact form in Table 12. The details of our assumptions and analyses concerning stored energy sources, patterns of release, resulting temperature transients, and molilization of activated materials--based largely on work at MIT and INEL-can be found in our main report, ${ }^{1}$ together with a fuller explanation of how these findirss were integrated in the assignment of LSA values. 
Table 11. The meaning of ESCCOM's ISA. The entries under each accident class indicate the basis of assurance that accidents in the class will not lead to an early fatality off-site.

\begin{tabular}{|c|c|c|c|c|}
\hline \multirow[b]{2}{*}{ LSA } & \multirow[b]{2}{*}{$\begin{array}{c}\text { Concise } \\
\text { description }\end{array}$} & \multicolumn{2}{|c|}{ Accident class } & \multirow[b]{2}{*}{$\begin{array}{c}\text { Transient without } \\
\text { violation of geometry } \\
\text { (e.g. LOFA) }\end{array}$} \\
\hline & & $\begin{array}{l}\text { Large-scale } \\
\text { reconfiguration }\end{array}$ & $\begin{array}{c}\text { Small-scale } \\
\text { violation of geometry } \\
\text { (e.g., LOCA) }\end{array}$ & \\
\hline I & $\begin{array}{l}\text { Inherent } \\
\text { safety }\end{array}$ & $\begin{array}{l}\text { If event occurs, material } \\
\text { properties }^{a} \text { suffice to } \\
\text { prevent fatal release. }\end{array}$ & $\begin{array}{l}\text { If event occurs, material } \\
\text { properties suffice to } \\
\text { to prevent fatal release. }\end{array}$ & $\begin{array}{l}\text { If event occurs, material } \\
\text { properties suffice to } \\
\text { prevent fatal release. }\end{array}$ \\
\hline II & $\begin{array}{l}\text { Large-scale } \\
\text { passive } \\
\text { protection }\end{array}$ & $\begin{array}{l}\text { Reconfiguration severe } \\
\text { enough to lead to } \\
\text { off-site fatality is made } \\
\text { incredible using passive } \\
\text { passive design features. }\end{array}$ & $\begin{array}{l}\text { If event occurs, material } \\
\text { material properties and } \\
\text { passive mechanisms }{ }^{b} \\
\text { suffice to prevent fatal } \\
\text { release or escalation to } \\
\text { next class. }\end{array}$ & $\begin{array}{l}\text { If event occurs, material } \\
\text { material properties and- } \\
\text { passive mechanisms suffic } \\
\text { to prevent fatal release. }\end{array}$ \\
\hline III & $\begin{array}{l}\text { Small-scale } \\
\text { passive } \\
\text { protection }\end{array}$ & $\begin{array}{l}\text { Reconfiguration severe } \\
\text { enough to lead to off- } \\
\text { site fatality is made } \\
\text { incredible using } \\
\text { passive design features. }\end{array}$ & $\begin{array}{l}\text { Violation severe enough } \\
\text { to lead to off-site } \\
\text { fatality is made } \\
\text { incredible using passive } \\
\text { design features. }\end{array}$ & $\begin{array}{l}\text { If event occurs, material } \\
\text { properties and passive } \\
\text { mechanisms suffice to } \\
\text { prevent fatal release or } \\
\text { escalation to next class. } \\
\text { class. }\end{array}$ \\
\hline
\end{tabular}


Table 11. (Continued)

\begin{tabular}{|c|c|c|c|c|}
\hline \multicolumn{5}{|c|}{ Accident class } \\
\hline LSA & $\begin{array}{c}\text { Concise } \\
\text { description }\end{array}$ & $\begin{array}{l}\text { Large-scale } \\
\text { reconfiguration }\end{array}$ & $\begin{array}{c}\text { Small-scale } \\
\text { violation of geometry } \\
\text { (e.g., LOCA) }\end{array}$ & $\begin{array}{c}\text { Transient without } \\
\text { violation of geometry } \\
\text { (e.g. LOFA) }\end{array}$ \\
\hline
\end{tabular}

IV Active There are events in one or more of these categories protection that, if they occur, require active systems ${ }^{c}$ to preclude an off-site fatality, and that cannot be made incredible by passive design measures alone.

Materials properties include inventories of radioactivity, heat capacities, melting points, vapor pressures versus temperature, and susceptibijlty to formation of volatile oxides, and are evaluated in the context of the energy sources that could be present.

b Passive mechanisms include natural convection, conduction, and radiation. The sufficiency of these mechanisms may depend on large-scale geometry and/or on the integrity of coolant boundaries.

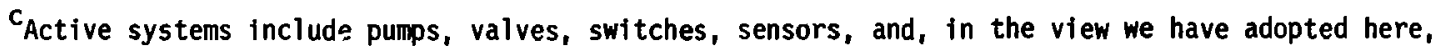
containment buildings (some of the penetrations in which are managed by active means).

Although reactors classified at Levels I, II, or III would not need active systems to provide assurance against early fatalities off-site, they would presumably be equipped with such systems for protection of plant investment and abatement of other consequences of accidents. 
Table 12. Levels of safety assurance for ESECOM reference cases.

\begin{tabular}{|c|c|c|c|c|c|}
\hline \multicolumn{2}{|r|}{ Case } & $\begin{array}{l}\text { Level of sa } \\
\text { Optimistic } \\
\text { concept } \\
\text { evaluation }\end{array}$ & $\begin{array}{l}\text { fety assur } \\
\text { Nominal } \\
\text { design } \\
\text { est fmate }\end{array}$ & $\begin{array}{l}\text { ance } \\
\text { Conser- } \\
\text { ative } \\
\text { concept } \\
\text { evaluation }\end{array}$ & Dominant safety concerns \\
\hline 1 & $V$-LI/TOK & 2 & 3 & 4 & $\begin{array}{l}\text { Lithium-air fire + decay } \\
\text { heat, Mn moblifization from } \\
\text { mant fold }\end{array}$ \\
\hline 2 & RAF-He/TOK & 2 & 2 & 3 & $\begin{array}{l}\text { LOFA }^{a} \text { and LOCA with decay } \\
\text { heat, Mn mobilization from } \\
\text { blanket }\end{array}$ \\
\hline 3 & RAF-PbLi/RFP & 3 & 4 & 4 & $\begin{array}{l}\text { PbL1 reaction, high decay } \\
\text { heat, Cu from ist wall, Po } \\
\text { from PbLi }\end{array}$ \\
\hline 4 & V-Li /RFP & 3 & 4 & 4 & $\begin{array}{l}\text { Lithlum-air fire plus high } \\
\text { decay heat, Mn from shleld, } \\
\text { Cu from magnets }\end{array}$ \\
\hline 5 & SiC-He/TOK & 1 & 1 & 2 & $\begin{array}{l}T \text { release, water-air } \\
\text { reaction with mobilization } \\
\text { of } w \text { from shield }\end{array}$ \\
\hline 6 & V-FLIBe/TOK & 1 & 2 & 2 & $\begin{array}{l}\text { Decay heat, } y \text {-air reactions, } \\
\text { Sc mobflization from blanket }\end{array}$ \\
\hline 8 & $V-\mathrm{DHe}^{3} /$ TOK & 1 & 2 & 2 & $\begin{array}{l}V \text {-air reactions, } S c \\
\text { mobilization from first } \\
\text { wall, T release }\end{array}$ \\
\hline 9 & RAF-Li/HYB & 3 & 4 & 4 & $\begin{array}{l}\text { Lithium-air fire, LOCA/LOFA, } \\
\text { mobilization of FP, } \\
\text { actinides }\end{array}$ \\
\hline 10 & SS-He/HYB & 3 & 4 & 4 & $\begin{array}{l}\text { LOCA/LOFA, worse heat } \\
\text { transfer than Case 9, } \\
\text { simflar releases }\end{array}$ \\
\hline 11 & PWR-BPE & 4 & 4 & 4 & $\begin{array}{l}\text { LOCA/LOFA, loss-of-power } \\
\text { transtent, mobilization of } \\
\text { FP }\end{array}$ \\
\hline
\end{tabular}


Table 12. Levels of safety assurance for ESECOM reference cases.

\begin{tabular}{|c|c|c|c|c|}
\hline Case & $\begin{array}{l}\text { Level of sa } \\
\text { Optimistic } \\
\text { concept } \\
\text { evaluation }\end{array}$ & $\begin{array}{l}\text { fety assur } \\
\text { Nominal } \\
\text { design } \\
\text { estimate }\end{array}$ & $\begin{array}{l}\text { ance } \\
\text { Conser- } \\
\text { ative } \\
\text { concept } \\
\text { evaluation }\end{array}$ & Dominant safety concerns \\
\hline 12 LSPB & 4 & 4 & 4 & $\begin{array}{l}\text { Sodium-air fire, core } \\
\text { transient mobilization of } \\
\text { FP, actinides }\end{array}$ \\
\hline 13 PRISM & 3 & 3 & 4 & $\begin{array}{l}\text { Sodium-alr fire, core } \\
\text { transient mobilization of } \\
\text { FP, actinides }\end{array}$ \\
\hline 14 MHTGR & 3 & 3 & 4 & $\begin{array}{l}\text { Core transients, } C \\
\text { reactions, mobilization of } \\
\text { FP }\end{array}$ \\
\hline
\end{tabular}

$a_{\text {LOFA }}=$ loss-of-flow accident
$b_{\text {LOCA }}=$ loss-of-coolant accident
$c_{F P}=$ fission products

We believe we have erred rather consistently on the side of conservatism--that is, in the direction of overstating the potential releases--in our analyses and LSA assignments. The main conservatisms have been: the assumption that activated components are heated to the combustionzone temperature in lithium fires rather than to the (lower) pool or air temperature; the neglect of heat removal by natural convection of air in thermal-transient calculations; ignoring any possibility of mitigating measures during postulated temperature transients of many hours' duration; and neglect of demobilization of activated material by condensation and plate-out within the reactor building. The actual quantities of activated material released in even the most serlous fusion reactor accidents are likely to be considerably smaller than we have estimated here.

ROUTINE EMISSIONS AND EXPOSURES

As is the case with the fission fuel cycle, the normal operation of fusion power facilities will entail small emissions of radioactivity to the 
environment--hence some exposure of members of the public to radiation--as well as routine exposures of workers to radioactivity and radiacion at plant sites. As a basis for comparison, routine exposures from the contemporary LWR fuel cycle to members of the public in the current generation are in the range of 500 to 1500 person-rem (whole-body equivalent) per $G W_{e} / y r$ : 25 to $70 \%$ from reprocessing plants (if plutonium recycle is practiced), 25 to $70 \%$ from uranium mining and milling, 7 to $20 \%$ from reactor operations, and less than $1 \%$ from other fuel-cycle operations including uranium enrichment, fuci fabrication, and radioactive-waste management. ${ }^{52,53}$ (Population doses in person-rem are the sum of all the individual doses.) Exposures predicted to occur in future generations as a result of current operations of the nuclearfuel cycle are in the range of 5000 person-rem per $G W_{e}-y r$, spread out over the next $20000+$ years, from emissions to 5770-year half-life carbon-14, and a dose as high as a million-person rem per $\mathrm{GW}_{\mathrm{e}}-\mathrm{yr}$, spread out over the next several hundred thousand years, from leakage of radon from uranium-mill tallings if these are not managed so as to avoid this dose. 52,53

Routine worker exposures from the LWR fuel cycle fall in the range of 1000 to 4000 person-rein per $6 W^{-y r:} 50$ to $70 \%$ at reactors, 2 to $50 \%$ at reprocessing plants, 5 to $20 \%$ in mining and milling of urantum, and less than $1 x$ at other fuei-cycle steps ( $f: \leqslant 1$ fabrication and enrichment, waste management). ${ }^{52,53}$ Early experience with high-temperature gas reactors (HTGRs) and LMFBRs suggests that the worker doses at such reactors may be much lower. The range of values for reprocessing is so large that experience with this technology has been limited and highly varied; the lowest figures are based on projections for large, modern plants that have not yet operated. Because there is even less experience with radioactive waste management at commerclal scale (including the decommissioning of facilities at the end of their useful lives), the estimates cited for public and worker exposures from this activity must also be considered to be rather uncertain.

Using the usual linear hypothesis relation of one excess cancer death per 5000 to 10000 person-rem, the 500 to 1500 person-rem public dose to the current generation translates to 0.05 to 0.3 excess death per $\mathrm{GW}_{\mathrm{e}}-\mathrm{yr}$. The routine dose to the most exposed individual member of the public falls well below MRC guidelines of $5 \mathrm{mrem} / \mathrm{yr}$ each from gaseous and aqueous effluents, corresponding to less than a tenth of natural background radiation and an incremental probability of cancer death, on a strict interpretation of the 1 near hypothesis, on the order of $10^{-6}$ per year. Average individual worker 
doses fall well below the NRC limit for routine occupational exposure of $5 \mathrm{rem} / \mathrm{yr}$; the worker population dose trans?ates under the linear hypothesis to 0.1 to 0.8 excess cancer deaths per $G W_{e}-y r$.

The significance of the doses to future generations, accumulated over huge time scales, has been questioned on the grounds that the dose rates involved are at all times tiny fractions of natural background radiation-indeed, tiny fractions of the geographic variations in the natural background--and any associated excess cancer deaths would likewise represent infinitesimal perturbations in the pattern of cancer deaths from other causes. It seems likely, nonetheless, that concern over these very long time scale, very low dose-rate exposures will lead to more stringent regulations governing carbon-14 emissions and management of uranium-mill tailings. (The quantity of tailings generated per $\mathrm{GW}_{\mathrm{W}} \mathrm{e}^{-\mathrm{yr}}$ would be reduced by about a hundred-fold with the advent of breeding fuel cycles, in any event.)

Fusion-pcwer technology, as contemplated, would have no counterpart to fission's sources of routine emissions and exposures in uranium mining and milling, nor any real counterpart to fission's reprocessing-plant emissions and exposures. The main fusion analog to reprocessing is tritium recovery, which is integral to reactor operations in current designs. Some reprocessing of particularly valuable activated structural, breeder, or neutron-multipifer material might be contemplated in future fusion systems, however. Concernifig exposures associated with waste management, quantitative estimates for fusion would necessarily be even more uncertain than those for fission; to the extent that the indices of waste hazard sumarized in the next section have any relevance to the potential for worker and public exposures, however, one may argue that such exposures should be smaller for fusion systems than for fission. The main focus of emissions control in fusion, then, presumably will be the power plant itself.

It is reasonable to suppose in any case that all fusion-power operations will be subject to the same standards governing routine exposures to workers and the public as apply in the fission industry. Observing these individual maxima will lead in the case of fusion--as it has with fission--to average exposures that are considerably smaller.

The key uncertainty that arises from lack of operating experience alid design detail on the fusion side is what capital and operating costs will be associated with keeping occupational and public exposures from fusion reactors within whatever guidelines are in force. The best we can do at this stage of 
fusion's development is to call attention to those characteristics of fusion power plants that will tend to determine those costs and to distinguish tentatively between aspects that seem amenable to inexpensive solutions and those that seem more problematical, hence potentially more expensive or at: least more demanding of engineering innovation to avoid undue expense.

The most important such characteristics with respect to occupational exposures are: (a) the ease or difficulty of tritium control in a given fusion-reactor design; (b) the magnitude and spatial distribution of gammaemitting activation products in reactor components; and (c) the nature of the distributed gamma source associated with coolant activation and coolant transport of activated corrosion products. The first and third items are also major deteminants of potential emissions to the environment outside the plant, and hence of public exposures. Finally, an emission source of little significance to occupational exposures but potentially a major contributor to the long-term, global population dose is (d) carbon-14 produced by neutron reactions on nitrogen, oxygen, and carbon in structural materials, coolants, breeders, and plant atmosphere.

\section{Tritium}

Although analyzing tritium behavior and control without very detailed reactor designs is extremely difficult, we offer in Table 13 a tentative characterization of the tritium-control issue for the ESECON reference designs. The levels of potential difficulty of tritium control presented in the table are calibrated against fission experience as follows: low corresponds to the magnitude of the tritium-control task in LMFBRs and HTGRs (where matters are simplified by the use of a primary coolant other than water): medium corresponds to the magnitude of the task in LWRs and heavywater reactors (e.g., CANDU); and high refers to cases likely to prove nore difficult than any fission experience. Much of the basis for these evaluations is the analysis of tritium-control issues provided in the Blanket comparison and Selection Study, ${ }^{13}$ augmented by more recent experimental results. 20,21 other useful surveys of the literature of tritium-control in fusion reactors are found in Refs. 18 and 19. 
Table 13. Tritiun-Control Issues in ESECOM reference cases.

\begin{tabular}{|c|c|c|c|c|}
\hline & $\begin{array}{l}\text { Active } \\
\text { tritium } \\
\text { inventory } \\
\text { (grams) }\end{array}$ & $\begin{array}{l}\text { Dominant } \\
\text { location } \\
\text { of } \\
\text { tritium }\end{array}$ & $\begin{array}{l}\text { Diffi- } \\
\text { culty } \\
\text { of } \\
\text { control }\end{array}$ & Key issues, conments \\
\hline$V-1,1 /$ TOK & 500 & $\begin{array}{l}\text { coolant/ } \\
\text { breeder }\end{array}$ & Low & $\begin{array}{l}\text { High } T \text { solubility in lithium } \\
\text { implics low mobility; higher than } \\
\text { expected T implantation in } V \\
\text { alloy may pose problens. }\end{array}$ \\
\hline RAF-He/TOK & 160 & Breeder & $\begin{array}{l}\text { Low to } \\
\text { ned tum }\end{array}$ & $\begin{array}{l}\text { T removal from primary loop may } \\
\text { be difficu?t; losses into steam } \\
\text { generator high unless in } \\
\text { hellum is oxidized rapidly. }\end{array}$ \\
\hline RAF-PbL1/RFP & 60 & Coolant & $\begin{array}{l}\text { Medium } \\
\text { to high }\end{array}$ & $\begin{array}{l}\text { Low } T \text { solubility in PbL1 means } \\
\text { high mobllity. }\end{array}$ \\
\hline$V$-LI/RFP & 500 & $\begin{array}{l}\text { Coolant/ } \\
\text { breeder }\end{array}$ & Low & Sane as $V$-L1/TOK. \\
\hline SIC-He/TOK & 160 & Breeder & $\begin{array}{l}\text { Low to } \\
\text { meditum }\end{array}$ & Similar to RAF-He/TOK. \\
\hline$V$-FLIBe/TOK & 15 & Structure & Medtum & $\begin{array}{l}\text { Low tritium solubility in FLiBe } \\
\text { poses problems; a chemical "fix" } \\
\text { has been proposed. }\end{array}$ \\
\hline$V$-MHD/TOK & $\begin{array}{l}\text { Not est1- } \\
\text { mated }\end{array}$ & Structure? & Medtun? & $\begin{array}{l}\text { FLiBe breeder has low } T \text { solubtT- } \\
\text { ity. MHD blanket not well } \\
\text { characterized as to } T \text { control. }\end{array}$ \\
\hline$v$-OHe ${ }^{3} /$ TOK & 60 & Coolant & $\begin{array}{l}\text { Low to } \\
\text { medium }\end{array}$ & $\begin{array}{l}\text { Less } T \text { handling since it need not } \\
\text { be bred, but water as coolant } \\
\text { gives some } T \text { difficulties. }\end{array}$ \\
\hline RAF-LI/HYB & 1000 & $\begin{array}{l}\text { Coolant/ } \\
\text { breeder }\end{array}$ & Low & $\begin{array}{l}\text { Similar to other 11quid 1ithium } \\
\text { systems. }\end{array}$ \\
\hline SS-He/HYB & 200 & structure & $\begin{array}{l}\text { Low to } \\
\text { medium }\end{array}$ & $\begin{array}{l}\text { Similar to other hellum-cooled } \\
\text { systems. }\end{array}$ \\
\hline
\end{tabular}


We have used the Remote Maintenance Rating Code ${ }^{17}$ to compute surface contact dose rates from semi-infinite slabs with the activation-product composition of the ESECON fusion-reactor components (first wall, blanket, manifold/reflector, shield, and in some cases magnets) at several times of interest--shutdown and 1 hour, 1 day, 1 week, 1 month, 1 year, and 30 years after shutdown. As in our accident analysis, the activation levels correspond to maximum irradiation for the respective components--that is, just before component change-out (e.g., after an irradiation of about $20 \mathrm{mw}-\mathrm{yr} / \mathrm{m}^{2}$ for first-wall and blanket components) or the assumed plant decomissioning (after 30-full-power years). The results are summarized in Table 14. These results of the semi-infinite-slab-approximation tend to overstate the actual dose rates to be expected from finite components. On the other hand, some locations in the reactor will be subject to the radiation fields from more than one component. In any case, the figures in Table 14 have the mertt of having been calculated in a consistent fashion, and they can give at least a rough indication of the magnitude of the problems to which shielding, remotemaintenance equipment, and 1 imited access will have to provide the solutions. The remote-maintenance equipment and $t \in c h n i q u e s$ needed to cope with these problems have only begun to be developed. Success in this endeavor will be important not only in minimizing occupational exposures to radiation during maintenance, but also in keeping the costs of maintenance of fusion reactors to tolerable levels. Finally, the systems and capabilities developed for remote maintenance presumably will have considerable bearing on the ease or difficulty of decomissioning fusion reactors at the end of their useful lives--a problem whose potential for generating bo, th costs and occupational exposures is not yet well understood for either fission or fuston systems.

\section{Coolant Activity}

Radioactive material occurs in coolants because of neutron-activation of constituents of the coolant itself and because of corrosion of activated (or 
Table 14. Contact dose rates from activated components.

Case and component
Contact dose rate (mrem/hr) vs time after shutdown

$\begin{array}{llllllll}\mathrm{t}=0 & 1 \mathrm{hr} & 1 \mathrm{~d} & 1 \mathrm{wk} & 1 \mathrm{mo} & 1 \mathrm{yr} & 30 \mathrm{yr}\end{array}$

Case 1: V-L1/TOK

\begin{tabular}{|c|c|c|c|c|c|c|c|}
\hline $\begin{array}{l}\text { First wall V15Cr5Ti } \\
\text { Inner blkt V15Cr5Ti } \\
\text { Manifold V15Cr5T1 } \\
\text { Manifold Fe2Cr1V } \\
\text { Shield Fe2Cr1V }\end{array}$ & $\begin{array}{l}1.2 \mathrm{e} 10 \\
6.6 \mathrm{eg} \\
3.2 \mathrm{eg} \\
4.5 \mathrm{e} 8 \\
6.2 \mathrm{e} 7\end{array}$ & $\begin{array}{l}5.9 \mathrm{eg} \\
1.7 \mathrm{eg} \\
9.1 \mathrm{e} 7 \\
3.1 \mathrm{e} 8 \\
2.3 \mathrm{e} 7\end{array}$ & $\begin{array}{l}4.2 \mathrm{eg} \\
1.2 \mathrm{e} 9 \\
6.5 \mathrm{e} 7 \\
4.8 \mathrm{e} 7 \\
2.1 \mathrm{e} 6\end{array}$ & $\begin{array}{l}6.1 \mathrm{e} 8 \\
1.8 \mathrm{e} 8 \\
1.2 \mathrm{e} 7 \\
4.5 \mathrm{e} 7 \\
1.9 \mathrm{e} 6\end{array}$ & $\begin{array}{l}1.6 \mathrm{e} 8 \\
5.3 \mathrm{e} 7 \\
4.3 \mathrm{e} 6 \\
4.1 \mathrm{e} 7 \\
1.4 \mathrm{e} 6\end{array}$ & $\begin{array}{l}8.6 \mathrm{e} 6 \\
3.0 \mathrm{e} 6 \\
2.9 \mathrm{e} 5 \\
1.7 \mathrm{e} 7 \\
3.2 \mathrm{e} 5\end{array}$ & $\begin{array}{l}6.1 \mathrm{e} 2 \\
1.7 \mathrm{e} 2 \\
2.9 \mathrm{e} 1 \\
7.8 \mathrm{e} 3 \\
3.6 \mathrm{e} 3\end{array}$ \\
\hline
\end{tabular}

Case 2: RAF-He/TOK

First wall RAF

Inner blkt 1 RAF

$1.3 \mathrm{e} 10$

9.7eg

$1.8 \mathrm{eg}$

$1.7 \mathrm{eg}$

$1.6 \mathrm{e} 9$

$7.4 \mathrm{e} 8$

$5.8 \mathrm{e} 4$

Inner blkt 1 L120

2. 4 eg

$3.4 \mathrm{e} 8$

$3.1 e 8$

$2.9 \mathrm{e} 8$

$1.4 \mathrm{e} 8$

$3.3 e 4$

Inner blkt 2 RAF

$1.4 \mathrm{e} 8$

$1.5 \mathrm{e} 6$

4.7e5

$2.4 \mathrm{e} 5$

$9.2 \mathrm{e} 4$

2.9e2

Inner b1kt 2 L120

8.7e7

$2.9 e 5$

$2.1 \mathrm{e} \quad 1.4 \mathrm{e} 7$

$1.2 \mathrm{e} 7$

$5.8 \mathrm{e} 6$

1.7 e4

$1.4 \mathrm{eg} \quad 1.2 \mathrm{e} 8$

4.4e4, 8.0e3

$6.9 \mathrm{e} 3$

$2.1 \mathrm{e} 3$

9.3e0

$3.4 \mathrm{e} 7$

$1.3 e 7$

$1.9 \mathrm{e} 7.0 \mathrm{e} 6$

$5.8 \mathrm{e} 6$

$2.8 e 6$

$2.8 \mathrm{e} 4$

Shield Fe2Criv

1. 1 e 6

$3.2 \mathrm{e} 5$

$1.0 \mathrm{e} 3$

Case 3: RAF-PbL1/RFP

First wall Cu

First wall RAF

1.3e11

4.7e10

$1.5 \mathrm{e} 102.7 \mathrm{eg}$

2. $6 e 9$

$2.3 \mathrm{eg}$

$5.0 \mathrm{e} 7$

$7.6 \mathrm{e} 10$

$5.5 \mathrm{e} 10$

$6.5 \mathrm{e} \quad 4.9 \mathrm{eg}$

4. 5 eg

2. 0 e9

$6.4 \mathrm{e} 5$

$3.7 e 9$

$4.1 \mathrm{e} 9$

$5.6 \mathrm{e} 8$

$3.9 \mathrm{e} 8$

$1.8 \mathrm{e} 8$

$3.0 \mathrm{e} 4$

Inner blkt PbL!

4. $3 \mathrm{e} 8$

$2.4 \mathrm{e} 7$

$1.8 \mathrm{e} \quad 9.7 \mathrm{e} 6$

6.9 e6

5. 0 e6

$8.6 \mathrm{e} 5$

shield Fe2Criv

$1.6 \mathrm{e} 71.4 \mathrm{e} 7$

1.0e7

$1.4 \mathrm{e} 6$

$6.2 \mathrm{e} 2$

Case 4: V-LI/RFP

First wall V15Cr5Ti

Inner blkt V15Cr5Ti

$8.2 \mathrm{e} 10$

$4.3 \mathrm{e} 10$

3.0010

$4.4 e 10$

$1.4 \% 10$

$3.0 \mathrm{e} 10 \quad 4.4 \mathrm{eg}$

$1.1 \mathrm{eg}$

$5.7 \mathrm{e} 7$

$1.8 \mathrm{e} 3$

$1.8 \mathrm{e} 10$

$6.0 \mathrm{e} 8$

$\begin{array}{ll}4.3 \mathrm{e} 8 & 7.3 \mathrm{e} 7\end{array}$

$4.0 \mathrm{e} 8$

2. $2 \mathrm{e} 7$

4. 0e2

Shield Fe2Cr1V

$2.6 \mathrm{eg}$

$1.8 \mathrm{eg}$

1. $9 \mathrm{e} 8$

$2.5 \mathrm{e} 7$

1. 7 e6

$3.1 \mathrm{e} 1$

$6.7 e 8 \quad 5.7 e 8$

$1.6 \mathrm{e} 8 \quad 1.5 \mathrm{e} 6$

$1.5 \mathrm{e} 8$

$6.1 \mathrm{e} 7$

$7.4 \mathrm{e} 3$

Magnet PCA

$5.6 \mathrm{e} 8 \quad 4.4 \mathrm{e} 8$

$6.0 \mathrm{e} \quad 5.4 \mathrm{e} 7$

$1.4 e 6$

1. 1 e6

2. $7 \mathrm{e} 4$

4. 0e7

8. 7 e5

Case 5: SiC-He/TOK

First wall SiC

Inner blkt $\mathrm{SIC}$

Inner blkt L120

$5.2 \mathrm{e} 10 \quad 1.4 \mathrm{e} 7$

2.7 e6

5. 0e4

$4.4 \mathrm{e} 4$

$2.5 e 4$

3. $5 \mathrm{e} 2$

$9.5 \mathrm{e} 91.2 \mathrm{e} 6$

$8.4 \mathrm{e} 4$

$1.6 \mathrm{e} 4$

1. 5 e4

$1.1 \mathrm{e} 4$

$2.0 \mathrm{e} 2$

4.1e9 $1.4 \mathrm{e} 6$

2. $5 \mathrm{e} 5$

$9.8 \mathrm{e} 4$

3.1e2

$1.2 \mathrm{e} 8 \quad 2.1 \mathrm{e} 4$

1.0e4

$1.0 \mathrm{e} 4$

$8.7 \mathrm{e} 3$

1.9e2

Shield all matls

$1.2 \mathrm{e} 78.6 \mathrm{e} 6$

$4.3 \mathrm{e} 6 \quad 6.6 \mathrm{e} 4$

$3.2 \mathrm{e} 3$

4.8e2

$2.4 \mathrm{e} 0$

Case 6: V-FLIBe TOK

First wall V15Cr5Ti

Inner blkt V15Cr5T1

$2.2 \mathrm{e} 10$

$8.5 e 9$

$6.0 \mathrm{eg}$

8.7e8

$2.2 \mathrm{e} 8$

$1.2 \mathrm{e} 7$

$7.7 \mathrm{e} 2$

$2.2 \mathrm{eg} \quad 3.5 \mathrm{e} 8$

$2.5 \mathrm{e} 8 \quad 3.7 \mathrm{e} 7$

1.0e7

$6.0 \mathrm{e} 5$

2. $5 \mathrm{el}$

Inner blkt FLIBe

$3.8 \mathrm{e} 9 \quad 1.5 \mathrm{e} 5$

$5.1 \mathrm{e} 4 \quad 4.8 \mathrm{e} 4$

4. $3 \mathrm{e} 4$

1. $5 \mathrm{e} 4$

$1.0 \mathrm{e} 2$

Shleld PE16

$1.4 \mathrm{e} 5 \quad 1.1 \mathrm{e} 5$

7.0e4

$6.5 \mathrm{e} 4$

$5.8 \mathrm{e} 4$

$2.7 e^{4}$

5. $5 \mathrm{e} 2$ 
Table 14. (Continued)

Case and component

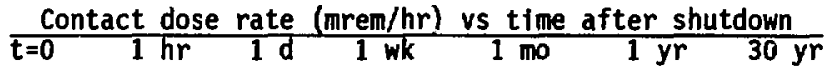

Case 8: $\mathrm{V}$-DHe ${ }^{3} / \mathrm{TOK}$

First wall V15Cr5Ti

Inner blkt V15Cr5Ti

Shield Fe2Criv
$5.0 \mathrm{e} 8$

2. $4 \mathrm{e} 7$

$1.1 \mathrm{e} 5$
$1.1 \mathrm{e} 8$

1.1e7

$8.3 e 4$
$7.7 e 7$

7.7e6

$2.1 \mathrm{e} 4$
1. 1 e7

$1.1 e 6$

$2.0 \mathrm{e} 4$ 2.9e6

$3.2 \mathrm{e} 5$

$1.6 \mathrm{e} 5$

$1.6 \mathrm{e} 1$

$1.9 \mathrm{e} 4$
$1.8 \mathrm{e} 4$

$8.8 \mathrm{e} 3$
$1.6 \mathrm{e} 0$

$7.5 \mathrm{e}-1$

activatable) material from the coolant-system walls. (In the case of fusionfission hybrid systems, migration of fission products and actinides from the fuel into the coolant is an additional source of coolant activity.) This radioactive material, entrained in the coolant or deposited subsequently on the walls of pipes and in pumps and valves, poses threats to workers mainly during routine maintenance of coolant systems and during cleanup of coolant spills. Migration of coolant-borne activation products to other parts of the plant following spilis may also lead to emissions to the environment outside the plant and hence to public exposures.

Problems of coolant-borne activity have been less thoroughly studied in the fusion community than either tritium problems or activation embedded in structure, and the data base from which to form judgments about the relative hazards of coolant activity in different fusion-reactor designs is rather scanty. The characierization provided in Table 15 is based mainly on reviews in Refs. 11, 13, 16, and 54-57. Here again, the indicated levels of potential difficulty are calibrated against fission experience: low corresponds to the level of precautions and countermeasures necessary in the fission system that is least troublesome from the standpoint of coolant activation, namely the HTGR; medium corresponds approximately to the greater level of effort required to cope with coolant activity in LWRs and LMFBRs; and high corresponds to a level of difficulty and complexity greater than that ancountered in fission systems.

\section{Carbon-14}

The main carbon-14 production reactions of concern in fusion reactors appear to be ${ }^{14} \mathrm{~N}(n, p){ }^{14} \mathrm{C}$ on $n /$ trogen in the plant atmosphere or present as 
Table 15. Occupational exposure problems from coolant activity.

\begin{tabular}{|c|c|c|c|c|c|}
\hline $\begin{array}{l}\text { Coolant/ } \\
\text { structure }\end{array}$ & $\begin{array}{l}\text { Re levant } \\
\text { ESECOM } \\
\text { cases }\end{array}$ & $\begin{array}{l}\text { Inventory } \\
\text { (Ci) }\end{array}$ & $\begin{array}{l}\text { Fraction } \\
\text { deposited } \\
\text { on walls }\end{array}$ & $\begin{array}{l}\text { Contact } \\
\text { dose rate } \\
\text { (rem/hr) }\end{array}$ & $\begin{array}{l}\text { Overall } \\
\text { magnitude } \\
\text { of problem }\end{array}$ \\
\hline Li/steel & 9 & $7 e 5$ & $?$ & $----16,000$ & Medium to high \\
\hline IV & 1,4 & $7 e 5$ & $?$ & $?$ & Medium? \\
\hline $\mathrm{He} / \mathrm{steel}$ & 2,10 & $3 \mathrm{e} 4$ & $99.9 \%$ & $\langle 0.1 /-\ldots$ & Low \\
\hline /SiC & 5 & $?$ & $99+x ?$ & $?$ & Low \\
\hline H2O/steel & none & $2 \mathrm{e} 5$ & $99.9 \%$ & $>0.1 / 300$ & Medi um \\
\hline IV & 8 & $?$ & $99+x ?$ & $?$ & Medi um? \\
\hline$/ \mathrm{Cu}$ & 3 & $?$ & $99+\% ?$ & $?$ & Medium to high \\
\hline PbLi/stee 1 & 3 & $6 e 8$ & $?$ & $100 / 90,000$ & High \\
\hline FLIBe/V & 6,7 & $7 e 7^{c}$ & $?$ & $0.1 / 2,000$ & Low to medium \\
\hline
\end{tabular}

${ }^{a}$ Inventory values from calculatigns performed for the BCSS (Ref. 13) assuming wall loading of $5 \mathrm{~mW} / \mathrm{m}^{2}$ for 2 years.

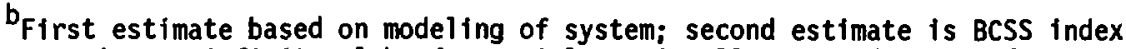
assuming an infinite slab of material continually exposed at the first wall.

$\mathrm{C}_{\text {The }} \mathrm{FLiBe}$ inventory decays within a day to $6 \mathrm{e} 5 \mathrm{Ci}$, owing to the 110 -minute half-life of the initially dominant F-18.

impurities in reactor materials, ${ }^{17} 0(n$, alpha $){ }^{14} \mathrm{C}$ on the trace isotope oxygen-17 in oxygen, ${ }^{13} \mathrm{c}(\mathrm{n}, \mathrm{gamma}){ }^{14} \mathrm{C}$ on the carbon-13 isotope in carbon, and a two-step chain in which this last reaction occurs on carbon- 13 produced from the dominant isotope in oxygen by $\left.{ }^{16} 0(n, a) p h a\right){ }^{13} c$. The long-term population dose commitment from carbon-14 is probably in the range of 500 person-rem per curle released, ${ }^{18}$ extended over a few times the 6000-year half-1ife of this isotope. The activation calculations performed by ESECOM indicate production of carbon-14 in blanket and shield materials at rates of up to hundreds of curies per year. Most of this carbon-14 presumably remains immobilized in the structural materials in which it was formed, where because of its weak beta 
emission its contribution to short-term radiological hazards compared to other activation products is very small. The question of the mobility of carbon-14 formed in different materials needs more attention, however. The large quantities of carbon-14 formed in $\mathrm{Lf}_{2} \mathrm{O}$ solid breeder material from $n$-alpha reactions on the oxygen may be of particular concern. This production is much larger than from the $\mathrm{H}_{2} \mathrm{O}$ in water-cooled fusion reactors, apparently because of the effectiveness of lithium in slowing down fast neutrons through the reaction

$$
{ }^{7} \mathrm{Li}+n \text { (fast) } \rightarrow \mathrm{T}+{ }^{4} \mathrm{He}+n \text { (slow) }
$$

It is possible that spectal systems for capturing carbon-14 will be required in fusion reactors that use 11 thium-oxide or lithium-aluminate breeders.

Based on the foregoing considerations and on the more detafled treatments in our main report, ${ }^{1}$ we provide in Table 16 a summary of the relative difficulties that may be expected in connection with managing the four main aspects of routine emissions and exposures in ESECOH's reference fusion reactors. We reemphasize that high degrees of difficulty may or may not translate into significant extra costs. The applicácition of engineering ingenuity to difficult tasks may lead in some cases to inexpensive solutions. A relevant reference point is the cost of controlling routine emissions in fission power plants: Such controls in current LWRs account for at most a few percent of both capital costs and operating costs, and these costs in newer fission systems are expected to be comparable or lower.

\section{RADIOACTIVE WASTES}

The size of the radioactive-waste-management task was characterized quantitatively using the concept of intruder dose developed by the U.S. NRC in connection with its "10CFR61" criteria for shallow burial of fission-reactor wastes. 58 The intruder dose is the highest dose that could be received, between 100 years and 1000 years after shallow burlal of the wastes, by (a) a worker excavating the site and constructing a dwelling there or (b) a farmer cultivating the site and eating the food grown there. Qualification for shallow burial requires--under specified assumptions about site design and waste form and packaging--that the calculated intruder dose not exceed $0.5 \mathrm{rem} / \mathrm{yr}$. 
Table 16. Relative difficulty of managing routine emissions and exposures for the ESECOM reference cases: A summary.

\begin{tabular}{|c|c|c|c|c|}
\hline Case & $\begin{array}{l}\text { Tritlum } \\
\text { (workers, } \\
\text { publ|c) }\end{array}$ & $\begin{array}{l}\text { Structural } \\
\text { activation } \\
\text { (workers) }\end{array}$ & $\begin{array}{l}\text { Coolant } \\
\text { activity } \\
\text { (workers, } \\
\text { public) }\end{array}$ & $\begin{array}{l}\text { Carbon-14 } \\
\text { (publ ic) }\end{array}$ \\
\hline$V-L I / T O K$ & Low & High & Medium? & Medi um? \\
\hline RAF :le/TOK & Low to medium & High & Low & High \\
\hline RAF-PbLi/RFP & Medium to high & Very high & Hfgh & Medium \\
\hline$V$-L1/RFP & Low & High & Med l um? & Med I um? \\
\hline SiC-He/TOK & Low to medium & Low to medium & Low & High \\
\hline V-FLiBe/TOK & Medi um & Medi um & Low to medium & Low \\
\hline V-MHD/TOK & Medium? & $\mathrm{NE}^{\mathrm{a}}$ & NE & Med I um? \\
\hline $\mathrm{V}-\mathrm{OHe} \mathrm{H}^{3} / \mathrm{TOK}$ & Low to medium & Medium & Low? & Low? \\
\hline RAF-LI/HYN & Low & High? & High? & NE \\
\hline
\end{tabular}

$a_{\text {NE }}=$ not evaluated.

ESECOM used computer codes developed by Fetter ${ }^{17}$ for applying the 10CFR61 methodology (with correction of several errors in the original NRC work) to fusion as well as fission wastes. The results permitted us to characterize the wastes with four different indices: the life-cycle volume of the radioactive wastes from each $1200-M W_{e}$, 30-year 11 fetime power plant; the intruder dose averaged for these wastes; the Annualized Intruder Hazard Potential (the sum of the products of intruder dose times annual waste volume for each reactor component), and the Deep Disposal Index (for the life-cycle wastes, the sum of the products of the volumes of components with intruder doses exceeding 0.5 rem times the ratios by which this threshold is exceeded).

In using the shallow-burial scenarto and the intruder-dose concept as the basis for its scheme for characterizing radioactive-waste burdens, ESECOM does not intend to suggest that shallow burial is necessarily the best strategy for managing fusion wastes, or that fusion systems whose wastes do not meet the 
present shallow-burial criteria are hopelessly handicapped. We simply belfeve that this calculational approacli provides a consistent and illuminating way to rank the size of the radfoactive-waste-management task for different systems.

The results of using this approach for some of our fusion and fission cases are shown in Table 17. The RAF cases reflect the benefit of using a

Table 17. Radioactive waste Indices for ESECOM fusion reference cases.

\begin{tabular}{|c|c|c|c|}
\hline $\begin{array}{l}\text { Life-cycle } \\
\text { waste } \\
\text { volume }\left(m^{3}\right)\end{array}$ & $\begin{array}{l}\text { Intruder } \\
\text { dose } \\
\text { (rem) }\end{array}$ & $\begin{array}{l}\text { Annualized } \\
\text { intruder } \\
\text { hazard } \\
\text { potential } \\
\left(\mathrm{R}-\mathrm{m}^{3} / \mathrm{yr}\right)\end{array}$ & $\begin{array}{l}\text { Deep } \\
\text { disposal } \\
\text { inģex } \\
\left(\pi^{3}\right)\end{array}$ \\
\hline
\end{tabular}

Case 1: V-L1/TOK

First wall VCrTi

Inner blkt VCrTf

Manifold VCrTi

Manifold Fe2Criv

Shield Fe2Criv

Total (average)

Case 2: RAF-He/TOK

First wall RAF

Inner blkt 1 RAF

Inner blkt $1 \mathrm{LA}_{2}{ }^{0}$

Inner blkt 2 RAf

Inner blkt $2 \quad \mathrm{Lt}_{2} \mathrm{O}$

Manifold RAF

Shfeld FezCriv

Total (average)

Case 3: RAF-PbLI/RFP

First wall $\mathrm{Cu}$

First wall RAF

Inner blkt RAF

Inner blkt $\mathrm{Pb} \mathrm{L}$

shield Fe2Criv

Total (average)

Case 4: V-L1/RFP

First wall VCrTi

Inner blkt VCrTi

Shteld VCrTi

Shield Fe2Criv

magnet $\mathrm{Cu}$

magnet $\mathrm{PCA}$

Total (average)
34

96

140

1100

220

1590

0.60

0.47

0.31

0.20

0.079

$(0.22)$

0.66

0.26

0.011

0.066

5.6e-4

0.054

0.044

$(0.039)$

2415

17

7

350

86

20

480

9.0
0.8
0.16
190
0.039
$(34)$

0.57

0.45

0.29

0.19

2100

50

7.2

2419

$\begin{array}{rl}10 & 0.57 \\ 72 & 0.45 \\ 180 & 0.29 \\ 2100 & 0.19 \\ 50 & 5.3 \\ 7.2 & 56\end{array}$

$(0.48)$
0.69

1.5

1.5

7.6

0.57

12

41

0

0

0

0

41

\subsection{5}

1.2

0.48

0.31

$5.8 \mathrm{e}-3$

0.33

0.33

3.2

\section{3}

0.18

1.8

540

0.026

550

33

33

0

0

0

0

0

0

33

Ag108m, Nb94

Ag108m, Nb94

Ar39, C14

Ag108m, Nb94

C14, Ar39

Ag108m, Nb94

Tc99, 14

Nb94,A126

Nb94, Tc99

Tc99,Nb94

TC99,C14

Tc9g, C14 
Táble 17. (Continued)

\begin{tabular}{|c|c|c|c|c|c|}
\hline & $\begin{array}{c}\text { Life-cycle } \\
\text { waste } \\
\text { volume }\left(m^{3}\right)\end{array}$ & $\begin{array}{l}\text { Intruder } \\
\text { dose } \\
\text { (rem) }\end{array}$ & $\begin{array}{l}\text { Annualized } \\
\text { intruder } \\
\text { hazard } \\
\text { potengtial } \\
(\mathrm{R}-\mathrm{m} / \mathrm{yr})\end{array}$ & $\begin{array}{l}\text { Deep } \\
\text { disposal } \\
\text { index } \\
\left(m^{3}\right)\end{array}$ & $\begin{array}{l}\text { Dominant } \\
\text { i sotopes }\end{array}$ \\
\hline $\begin{array}{l}\text { Case 5: SiC-He/TOK } \\
\text { FIrst wall SiC } \\
\text { Inner blkt SiC } \\
\text { Inner blkt Li } 0 \\
\text { Manifold all matl } \\
\text { Shield all matl } \\
\text { Total (average) }\end{array}$ & $\begin{array}{r}34 \\
290 \\
1200 \\
620 \\
970 \\
3114\end{array}$ & $\begin{array}{l}0.018 \\
3.9 \mathrm{e}-4 \\
0.011 \\
1.1 \mathrm{e}-4 \\
2.5 \mathrm{e}-3 \\
(0.0053)\end{array}$ & $\begin{array}{l}0.021 \\
3.8 \mathrm{e}-3 \\
0.42 \\
2.3 \mathrm{e}-3 \\
0.08 \\
0.53\end{array}$ & $\begin{array}{l}0 \\
0 \\
0 \\
0 \\
0 \\
0\end{array}$ & $\begin{array}{l}\text { Al26 } \\
\text { A126, C14 } \\
\text { Ar39, C14 } \\
\text { C14,Be10 } \\
\text { A126 }\end{array}$ \\
\hline $\begin{array}{l}\text { Case 6: V-FLiBe/TOK } \\
\text { First wall VCrTi } \\
\text { Inner blkt VCrTi } \\
\text { Inner blkt FLiBe } \\
\text { Shield PE16 } \\
\text { Total (average) }\end{array}$ & $\begin{array}{l}4.2 \\
97 \\
460 \\
75 \\
636\end{array}$ & $\begin{array}{l}1.1 \\
0.2 \\
2.4 e-3 \\
0.036 \\
0.044\end{array}$ & $\begin{array}{l}0.15 \\
0.64 \\
0.037 \\
0.091 \\
0.92\end{array}$ & $\begin{array}{l}9.2 \\
0 \\
0 \\
0 \\
9.2\end{array}$ & $\begin{array}{l}\mathrm{Nb94}, \mathrm{Al} 26 \\
\mathrm{Nb} 94, \mathrm{Al} 26 \\
\mathrm{C} 14, \mathrm{Tc99} \\
\mathrm{Nb94} \text {, Tc99 }\end{array}$ \\
\hline $\begin{array}{l}\text { Case 8: } \mathrm{D}-\mathrm{He}^{3} / \mathrm{TOK} \\
\text { First wall VCrTi } \\
\text { Inner blkt VCrTi } \\
\text { Shield } \mathrm{Fe} 2 \mathrm{Cr} 1 \mathrm{~V} \\
\text { Shield } \mathrm{Pb} \text { and } \mathrm{B}_{4} \mathrm{C} \\
\text { Total (average) }\end{array}$ & $\begin{array}{r}23 \\
24 \\
920 \\
264 \\
1231\end{array}$ & $\begin{array}{l}0.083 \\
5.7 e-3 \\
8.3 e-5 \\
6.3 e-8 \\
(2.4 e-4)\end{array}$ & $\begin{array}{l}0.064 \\
4.6 e-3 \\
2.5 e-3 \\
5.5 e-7 \\
0.071\end{array}$ & $\begin{array}{l}0 \\
0 \\
0 \\
0 \\
0\end{array}$ & $\begin{array}{l}\mathrm{Nb94}, \mathrm{A} 126 \\
\mathrm{Nb94}, \mathrm{A} 126 \\
\mathrm{Tc} 99, \mathrm{Nb94} \\
\mathrm{Pb} 205, \mathrm{~B} 1208\end{array}$ \\
\hline $\begin{array}{l}\text { LSPB (fission) } \\
\text { fiss prod, actinides } \\
\text { cladding, channels } \\
\text { reactor vessel, etc }\end{array}$ & $\begin{array}{c}120 \\
120 \\
200\end{array}$ & $\begin{array}{r}.000 \\
11 \\
\text { NC }\end{array}$ & $\begin{array}{rr}40,000 & 8,200 \\
44 & \\
N C & \end{array}$ & $\begin{array}{r}0,000 \\
2600 \\
\text { NC }\end{array}$ & $\begin{array}{l}\text { Am241, Cs135 } \\
\text { Nb94, Tc99 }\end{array}$ \\
\hline
\end{tabular}

NC $=$ not calculated

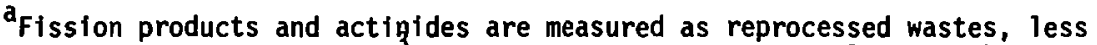
cannisters, occupying $4 \mathrm{~m}$ per $1200-M W$ reactor-yr. Volume of the radionuclides, without the chemical malrix they are embedded in during reprocessing is 10 times smaller. Reactor vessel and related components $_{3}$ add about $200 \mathrm{~m}^{3}$ of activated waste $\left(40-50000 \mathrm{c1} / \mathrm{m}^{3}\right)$ at the time of decomisstoning; we did not compute the intruder dose and related indices. The average activation w111 be less than that of the cladding and fuelchannel material removed from the core each year; the indices may be smaller than those listed in the cladding-channel category. 
modification of the usual HT-9 ferritic steel in which tungsten has been substituted for molybdenum; this substitution eliminates the major source of the niobium-94, molybdenum-93, and technetium-99 activation products that otherwise would dominate the waste hazard from HT-9. Based on the two indices that we consider most 11 luminating--the Annualized Intruder Hazard Potential and the Deep Disposal Index--Table 17 shows that the worst fusion cases are superior to fission by more than two orders of magnitude and the better fusion cases enjoy even larger margins. In a 11 but one of the fusion designs, the intruder dose averaged for all the 11 fe-cycle wastes falls below the $0.5 \mathrm{rem} / \mathrm{yr}$ threshold, meaning that this mixture would qualify for shallow burial under the current regulatory philosophy.

If, as many experts argue, the management of fission-power wastes proves to entafl only modest contributions to fuel-cycle radiation exposures (on the order of the estimates cited in the preceding section) and to the monetary cost of electricity (on the order of the $1 \mathrm{mil}$ per $\mathrm{kW}-\mathrm{hr}$ we have assumed here), then it should be safe to conclude from the indices presented in Table 17 that waste management $m_{1}, 1$ also have only very modest effects on the overall environmental and economic costs of electricity from fusion. In other words, our assumption for the ESECON economic calculations that fusion waste management will cost the same mil per kW-hr as fission waste management, should be conservative. If, on the other hand, the management of fission wastes should turn out to pose much more serious problems than the foregoing estimates suggest--as some critics of fission energy continue to assert may be the case--the margins between fusion and fission indicated in Table 17 are large enough to make plausible that fusion might escape these difficulties.

Concerning fusion hybrid breeders and the associated fuel cycles, we did not perform separate calculations of waste burdens. To first order, one would suspect from the dominance of fission-energy generation in a system of fission reactors supplied with fissile fuel by a hybrid breeder, and from the comparison of fusion and fission waste characteristics in Table 17, that the wastes from such a system would be dominated by those from the fission clients. Some closer attention may be warranted, however, to possible differences in the quantities of actinides associated with the wastes from a hybrid-fueled fission energy system. 
Just as countries that openly operate nuclear-weapons programs can use weapons-dedicated or dual-purpose (energy-weapons) fission facilities to produce the needed nuclear-weapons materials, it would also be possible to design fusion reactors to maximize trittum production for use in natural weapons programs and to design fusion-fission hybrid reactors to produce large quantities of weapons-grade plutonium for such purposes. ${ }^{9,59}$ we do not consider these purely weapons-dedicted forms of fusion technology further here. We focus instead on ways in which pursuit of fusion technologies for energy-generation purposes may contribute to providing nuclear weapons capabilities to countries or groups that have not been able or willing to acquire such capabilities by other means; and we compare this problem with the corresponding one for fission energy technologies.

The main concern about facilitating nuclear weapons proliferation by fission energy technologies has been that these technologies would spread access to fissile materials--most importantly plutonium and highly enriched uranium. Lack of access to these materials has long been considered the principal technical barrier to the acquisition of fission weapons. $52,53,60,61$ The potential vulnerability of a fission fuel cycle therefore can be characterized most compactly in terms of quantitatives of fissile material present at the point(s) in the fuel cycle where the physical, chemical, and isotopic barriers to its removal and use in nuclear weapons are lowest. A yardstick against which to measure the quantities of fissile material involved is the critical mass required to fashion a nuclear explosive. This information is provided in Table 18 for representative fission fuel cycles and for the RAF-LI/HYB fusion-fission hybrid breeder (Case 9) considered by ESECOM. Fission fuel-cycle flows are from the American Physical Society fuelcycle study published by 1978 (Ref. 53) and from information provided to ESECOM for denatured high-temperature gas (HTG) fuel; critical masses are from the same study and from Willrich and Taylor.

The rankings of "Relative Weapons Potential" shown in Table 18 are based on the nature of the barriers to diversion for weapons use at the indicated point(s) of greatest vulnerability, most importantly the need for isotopic enrichment, the need for chemical separation of plutonium from uranium or U-233 from thorium, the presence or absence of fission products, and the sophistication required in weapon design and fabrication using the indicated 
Table 18. Fissile materials in fission and fusion-hybrid fuel cycles.

Point (s) of
greatest

Quant1ty of of fissile material

vulnerability (per reactor-yr)
Main remaining

technical

Relevant barrier to

critical use in nuclear

mass

explosives
Relative

weapons

potential

\begin{tabular}{|c|c|c|c|c|c|}
\hline $\begin{array}{l}\text { PWR (once- } \\
\text { through) }\end{array}$ & $\begin{array}{l}\text { spent-fuel } \\
\text { storage }\end{array}$ & $\begin{array}{l}250 \mathrm{~kg} \mathrm{Pu}(69 \% \text { fis- } \\
\text { s1le) in } 26,000+\mathrm{kg} \\
U+\text { fission prod }\end{array}$ & $\begin{array}{l}5-10 \mathrm{~kg} \\
\text { fisstle } \\
\mathrm{Pu}\end{array}$ & $\begin{array}{l}\text { chemical separ- } \\
\text { ation from } U \& \\
\text { fisston products }\end{array}$ & Low/medi um \\
\hline $\begin{array}{l}\text { PWR (self } \\
\text { generated } \\
\text { Pu recycle) }\end{array}$ & $\begin{array}{l}\text { reprocessing } \\
\text { plant output }\end{array}$ & $\begin{array}{l}440 \mathrm{~kg} \text { Pu (61\% } \\
\text { f1sstle), possibly } \\
\text { mixed with U }\end{array}$ & $\begin{array}{l}5-10 \mathrm{~kg} \\
\text { f1ssile } \\
\mathrm{Pu}\end{array}$ & $\begin{array}{l}\text { chemical separ- } \\
\text { atopm from U } \\
\text { if present }\end{array}$ & $\begin{array}{l}\text { Medium/ } \\
\text { high }\end{array}$ \\
\hline \multirow{2}{*}{$\begin{array}{l}\text { HIGR (U235/ } \\
\text { Th232/U233 } \\
\text { fuel cycle) }\end{array}$} & $\begin{array}{l}\text { enrichment } \\
\text { plant output }\end{array}$ & $\begin{array}{l}350 \mathrm{~kg} \mathrm{93.5 \%} \\
\text { enrlched U235 }\end{array}$ & $\begin{array}{l}15-20 \mathrm{~kg} \\
\mathrm{U} 235\end{array}$ & $\begin{array}{l}\text { no significant } \\
\text { barrier }\end{array}$ & Very high \\
\hline & $\begin{array}{l}\text { repiocessing } \\
\text { plant output }\end{array}$ & $\begin{array}{l}190 \mathrm{~kg} \text { U233, } \\
50 \mathrm{~kg} \text { U235 }\end{array}$ & $\begin{array}{l}5-10 \mathrm{~kg} \\
\mathrm{U} 233\end{array}$ & $\begin{array}{l}\text { no signtficant } \\
\text { barrier }\end{array}$ & Very high \\
\hline $\begin{array}{l}\text { LMFBR } \\
\text { (natural U } \\
\text { feed) }\end{array}$ & $\begin{array}{l}\text { reprocessing } \\
\text { plant output }\end{array}$ & $\begin{array}{l}2350 \mathrm{~kg} \text { Pu (80\% } \\
\text { fissile), possibly } \\
\text { mixed with U }\end{array}$ & $\begin{array}{l}5-10 \mathrm{~kg} \\
\text { f1ssile } \\
P U\end{array}$ & $\begin{array}{l}\text { chemical separ- } \\
\text { ation from } i \\
\text { If present }\end{array}$ & HIgh \\
\hline $\begin{array}{l}\text { RAF-L1/HYB } \\
\text { (LWR } \\
\text { clients) }\end{array}$ & $\begin{array}{l}\text { reprocessing } \\
\text { plant output } \\
\text { with Th }\end{array}$ & $\begin{array}{l}3300 \mathrm{~kg} \mathrm{U233} \\
\text { probably m1 xed }\end{array}$ & $\begin{array}{l}5-10 \mathrm{~kg} \\
\text { U233 }\end{array}$ & $\begin{array}{l}\text { chemical separ- } \\
\text { ation from Th } \\
\text { if present }\end{array}$ & HIgh \\
\hline
\end{tabular}

NOTE: Critical masses are for metals and vary with Isotopic composition and reflector. Critical masses of oxides are significantly but not prohibitively higher. "Coprocessing" so that fissile output from reprocessing is mixed with nonfissile urantum or thorfum isotopes (meaning subsequent isotopic separation would be necessary in order to use material for weapons) is generally possible but not convenient. Hybrid breeder serves some 13 1-GW cllent LWRs, so fissile flow per system GW is much smaller than shown. LMFBR would serve 1 to 2 client LWRs (most plutonfum produced is recycled to the LMFBR itself).

material. With respect to sophistication in weapon design and fabrication, we have assumed the following ranking of materials from eastest to most difficult $53,61,62$; U-235, U-233, plutonlum with fissile content about $75 x$, plutonium with fissile content below 75\%. The "Relative Weapons Potential" rankings in Table 18 do not take into account physical security barriers (guards, monitoring systems, possible collocation of factlities to minimize 
transport of fissile materials, and so on) as opposed to the technical ones built into the choice of fuel cycle.

The annual flow of plutonfum from a hybrid breeder operating on the Pu-239/U-238 fuel cycle would be similar to the U-233 figure shown for ESECON's RAF-Li/HYB case in Table 18. The fissile content of hybrid plutonium would be in the vicinity of 90\%--even higher than that for LMFBRs--and hence particularly well suited for use in nuclear explosives. 22 on the other hand, hybrid plutonium would contain more Pu-236 than that from LWRs or LMFBRs, leading to penetrating gamma emissions from the U-232 decay chain and tending to decrease the attractiveness of the material for bomb makers.

If the U-233/Th-232 fuel cycle had large antidiversion advantages over the Pu-239/U-238 alternative, this would constitute an important additional benefit derived from the ability of hybrid breeders to make the U-233/Th-232 cycle economically more attractive than with pure-fission breeders as the source of the U-233. A number of reviews have concluded, 53,59,62-64 however, that the antidiversion advantages sometimes claimed for the U-233/Th-232 fuel cycle--based mairily on radiological hazards to bomb makers and on the possibility of denaturing the $\mathrm{U}-233$ to be used client reactors with U-238--are the modest usefuliness at best, tend to be offset by corresponding disadvantages, and come at substantial cost in money and convenience.

Fusion-energy systems other than fusion-fission hybrid breeders would not ordinarily produce or contain fissile materials, so the weapcis-linkage concern that is most acute for fission energy systems--that the technology would provide access to this 1 imiting ingredient for producing fission weapons--would be far less acute for such fusion systems. The only remnant of this particular concern in pure-fusion reactors would be that fertile material not ordinarily present could be introduced into the reactor and exposed there to fusion neutrons to breed fissile isotopes--either openly or clandestinely.

If a government or major industrial concern in possession of a fusion reactor were to decide to undertake such a step openly, they certainly would be able to produce significant quantities of high-quality fissile material in a rather short time. In the Brookhaven study of proliferation and safeguards issues in futurc technologies, ${ }^{22}$ it was estimated that insertion of uraniumcarbide breeder modules at the first wall in the Starfire fusion reactor would yield about $14 \mathrm{~kg}$ of fissile plutonium per square meter per year, and that dissolving urantum in the reactor coolant could yield $160 \mathrm{~kg}$ of fissile plutonium per year. On the other hand, it would be extremely difficult if not 
impossible for a government or industrial concern to achieve significant fissile material production clandestinely in an ostensibly pure-fusion reactor subject to frequent international monitoring of the sort that can be readily envisioned based on fission practice. The modifications to the fusion reactor and its operating procedures needed to make and extract fissile material would be easy to detect, especially given that one is looking for fertile or fissile material in an environinent where none is expected (in contrast to looking for small discrepancies in large inventories, as is the case in monitoring fission or fusion-fission fuel cycles). Similarly, the necessary modifications would be too extensive and too obvious to escape detection by the operators of the plant if an attempt at clandestine fissile-materials production were being made by a subgroup of insiders; and because of the need for prolonged access as well as easily observed modifications of systems and procedures, outsiders would have no chance at all.

The next question that arises is whether the diversion of tritiun from fusion reactors for use in thermonuclear weapons poses problems analogous to those of diversion of fissile material frum fission reactors for use in fission weapons. It is true that tritium is used in a number of modern thermonuclear warhead designs ${ }^{65}$; that the inventortes and throughputs of tritium in large D-T fusion rectors (typically kilograms in inventory and hundreds of grams per day in throughput) are more than large enough to be significant in the weapons context [the total tritium inventory in the U.S. weapons stockpile has been estimated to be about $70 \mathrm{~kg}$ (Ref. 66)]; and that fusion reactors could be rather readily modified to maximize net tritium output for weapons purposes. For these reasons, commercial fusion reactors presumably w1ll be subject to materials accounting procedures and other safeguards designed to minimize the chance that reactor tritium will be misused for weapons. There are, nonetheless, some strong arguments for regaruing the tritium safeguards issue as fundamentally less problematical for fusion than the fissile-material issue is for fission. Most importantly, tritium acquisition is not the 1 imiting ingredient on thermonuclear-weapon construction in the way that fissile materials are the 1 imiting ingredient on fission-weapon construction. Both the needed fission-bomb trigger and the technical insights required for design and fabrication of thermonuclear weapons are more important barriers than access to fusion fuels, and while access to tritium is conventent in thermonuclear-weapon construction, it is not necessary. 
The spread of highly weapons-specific types of knowledge--as distinct from the spread of particular facilities and materials usable for weaponry-has not been given much weight in recent years as a liability of fission energy systems, in large part because the knowledge needed to build fission weapons (and most certainly those parts of this knowledge that are derivable from nuclear-power technology) is already so widespread. In the case of thermonuclear weaponry, by contrast, the much greater scientific and technological sophistication required is not so widespread, and the question logically arises whether the spread of fusion-energy technology would spread important insights relevant to thermonuclear weapons.

The major powers declassified their research programs on magneticconfinement approaches to fusion energy in 1958, and they have maintained their field as an area of declassified and indeed highly internationalized research ever since. This strongly suggests that the important insights about thermonuclear weaponry have nothing in comon with MFE. As is well known, however, there are connections between research in inertial-confinement fusion and insights relevant to the design and effects of thermonuclear weapons, 22,67 and these connections have been the basis for classification of many aspects of research on inertial confinenent since the inception of such work. Because inertial-confinement fusion is not within the province of ESECON and classification barriers would prevent a full discussion in any case, the weapons linkages of inertial-confinement fusion are not considered further here.

It needs to be emphasized, finally, that judgments about the weight to be given to unwanted weapons linkages in comparing fission and fusion energy options are very difficult because much of the weapons risk is dependent on institutional and political rather than technical factors. Little can be said now about the nature of these nontechnical elements 30 or 40 years in the future when large-scale usè of fusion may have become a real possibility--the institutional and political incentives and restraints relating to acquiring nuclear weapons could be very different in the future--and without such Information any estimates of the absolute impact of the weapons-linkage issue on either the fission or the fusion side must be highly speculative. 
In assessing the overall environmental and safety implications of any energy source, attention must be given to all associated activities, not only the operation of the power plant itself and the management of power-plant wastes. Previous studies of the fuel cycles of coal, fission, fusion, and renewable energy sources have indicated that aside from emissions and accident risks from power-plant operations (and, in the fission case, reprocessingplant operations) and aside from weapons linkage, the biggest eneigyassoclated risks to health and safety tend to be those of more-or-iess routine accidents in fuel and materials acquisition, processing, manufacturing, and transport. For the most part, these hazards fall more heavily on workers than on the public. Of the public risks in these categories, the largest usually arise from transporting fuels and materials. Because the occupational hazards are also largely dependent on the quantity of fuel and nonfuel materials being handled, a crude but useful index for comparing other fuel-cycle impacts, both occupational and public, is the total mass associated with consiructing and operating the various fuel cycles.

Estimates of these masses for fusion- and nonfusion-energy cycles are sumarized in Table 19, with very rough figures for worker deaths in materiais-related accidents, public deaths resulting from the transport of materials, and emissions of particulate matter in materials-related activities (as an index of air-pollution impact). These figures were adapted from a number of recent reviews $2,18,68-70$; a particularly detailed discussion of the conceptual and methodological issues arising in such calculations is found in Raf. 66.

Materials-related hazards in the indicated magnitudes have not excited much public or regulatory interest in the past and probably will not do so in the future. The main exceptions are the relatively high worker risks that come from coal mining (and, to a lesser extent, uranium mining) and the rather high public risk that comes from coal transport. Even this last problem, which objectively speaking is a rather serious impact of coal use, seems to be percelved more as a hazard of soclety's transport and transportation systems than of its energy system.

In any case, the materials-related hazards of fusion appear to be in the same range as those of fission and the most widely used renewable electricity sources of the present t1me, hydropower and wind, and well beiow those of 
Table 19. Materials requirements and impacts in energy cycles.

\begin{tabular}{|c|c|c|c|c|c|c|}
\hline \multirow[b]{2}{*}{$\begin{array}{l}\text { Energy } \\
\text { cycle }\end{array}$} & \multicolumn{3}{|c|}{$\begin{array}{l}\text { Thousands of tons of } \\
\text { materials per } \mathrm{GW}_{\mathrm{e}}^{-y r}\end{array}$} & \multicolumn{2}{|c|}{$\begin{array}{l}\text { Accidental deaths } \\
\text { from materials } \\
\text { activities, } \\
\text { per GW } \mathrm{e}^{-\mathrm{yr}}\end{array}$} & \multirow{2}{*}{$\begin{array}{l}\text { Particulate } \\
\text { emissions } \\
\text { from materjals } \\
\text { activities } \\
\text { tons/GW } \text {-yr }^{-y}\end{array}$} \\
\hline & $\begin{array}{l}\text { Total } \\
\text { metals }\end{array}$ & Concrete & $\begin{array}{c}\text { Fuel } \\
\text { (as ore) }\end{array}$ & Workers & Public & \\
\hline Coal & $1-2$ & & $5-7$ & $3,500^{b}$ & $1-3$ & $0.5-3 \quad 50-400$ \\
\hline Fission & $1-2$ & $8-13$ & $200^{C}$ & $0.3-1.3$ & $0.03-0.06$ & $80-800$ \\
\hline Hydropower & $1-2$ & $13-70$ & -- & $0.15-0.3$ & $0.03-0.2$ & $130-2500$ \\
\hline Wind & $5-15$ & $6-50$ & -- & $0.1-0.4$ & $0.03-0.3$ & $70-4500$ \\
\hline Fuston & $2-4$ & $10-20$ & $3.5^{d}$ & $0.3-0.7$ & $0.03-0.1$ & $100-2500$ \\
\hline
\end{tabular}

Materials activities include mining, processing, manufacturing, and transport.

bigure is for bituminous coal; range for lower-rank coals extends to about 2 times higher.

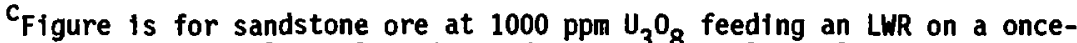
through fuel cycle. Plutonitum and uranium recycle could reduce figure by 25 to $30 \%$. Use of fast breeder reactors could reduce it fifty- to one-hundredfold.

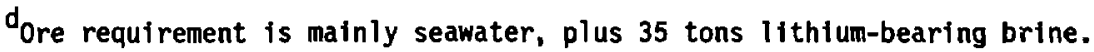

coal. As a yardstick for assessing the meaning of 0.1 public death per GW-yr (the upper-limit public risk from transport of fusion materials), it is of interest that this figure amounts to about $0.001 \%$ of the risk from all causes--and $0.02 \%$ of the risk from all accidents-- in a representative population of 1 million U.S. citizens whose annual electricity consumption amounts to about $1 \mathrm{GW}-\mathrm{yr}$.

With this perspective, it is clear that the modest differences among different fusion systems in the hazards related to bulk materials requirements are not important. Occupational hazards of particularly toxic materials, such as beryllifum, might be another matter; but they seem unlikely to be as difficult to handle as the radiological occupational hazards considered above, and we did not examine them. For further discussion of chemical hazards in 
fusion reactors as well as of exposures to electric and magnetic fields (which also seem not to pose very difficult problems) see Ref. 18.

\section{SYNTHESIS}

In this section we treat the interaction of safety, environmental, and economic charazteristics, and we discuss some of the uncertainties and omissions that bear on the interpretation of our results. We defer until the final section, "Findings in Brief," our comments on the Implications of this study for directions in research and development on MFE.

\section{INTEGRATION SAFETY, ENVIRONMENT, AND ECONOMICS}

A premise of this study has been that environmental and safety characteristics of fusion reactors may significantly affect the cost of electricity from this energy source, and that early attention to the specific ways in which safety and environment could influence fusion's economics may be useful in steering the development of fusion tocinology in directions that enhance positive influences (reduce costs) and minimize negative ones.

The most obvious economic ranifications of environmental and safety issues in nuclear energy technologies would seen to be the construction and operating costs assoclated with specific safety-related or environmentalcontrol subsystems--that $1 s$, subsystems whose functions are to prevent accidents, or to abate their consequences, or to prevent or reduce routine exposures of workers and the puisilc to radioactivity and radiation. But tabulating the construction and operating costs of safety and environmentalcontrol subsystems is difficult because of the complexity and degree of integration typical of power plants of any kind. Many components and subsystems have multiple functions, so that it is not always clear what shoulu be classified as a safety or environmental-control subsystem and what should not. Most of the components in the plant are related to safety and environment in the looser sense that fallure or improper functioning of the components could have safety or environmental consequences, which means in turn that safety and environmental factors must be taken into account in the design of the components and may well affect the costs of their construction and operation. And it is in the nature of a complex, integrated system that 
the presence and characteristics of safety and environmental-contral subsystems invariably will influence costs of other parts of the plant.

The problem of sorting out the economics of safety and environment is further compounded by the multiplicity of approachrs to assuring safety and low routine exposures, some integrated into the design at the most basic level (e.g., passive safety based on materials compositions and certain large-scale geometric arrangements) and others added on as discrete subsystems (e.g., containment sprays and filtering systems). Added on approaches to safety and environmental control are by their nature associated with identifiable costs; designed in approaches may also add to costs in compar!son to systems of comparable performance without the designed-in safety/environmental features, but this is not necessarily so, and in any case there may be offsetting gains in the form of reduced requitrements for added-on systems.

There are, finally, some indirect but sometimes very large impacts of safety and environmental characteristics on economics that exert themselves through the processes of siting, licensing, and regulation. That is, as fission experience has demonstrated, if the safety and environmental characteristics of a plant or class of plants allow significant pub?ic uncertainty about their acceptability, the result can be difficulties and delays in siting and licensing, redesigns and retrofits during construction, and safety/environment-related shutdowns once commercial operation has commenced--all of which can be staggeringly expensive. These problems can arise even if a plant is, objectively, extremely safe; difficulty in demonstrating its safety can be enough to cause the problems.

The combination of difficulties just described has made it difficult to analyze what share of power-generating costs should be attributed to safety and environment, even the case of fission. Obviously, making such an estimate for fusion power technology at the present state of its development would be even less feasible. Charged, nonetheless, with the task of somehow 11 luminating this issue, ESECOM has used a mixture of quantitative and qualitative approaches to provide some partial insights.

On the quantitative side, we have assumed that high LSA, as described above, could be the basis for reduced requirements for nuclear grade materials and components compared to the requirements imposed in fission power-plant construction today. Much more than any extra quality or reliability actually built into such "N-stamped" materials and components, it is the layers of documentation and certification required to establish the pedigree of these 
items and to accompany their installation in the power plant that account for the large cost increases assoctated with them (for example, a factor of 6 in cost for something as simple as piping). The conceptual basis for the N-stamp requirements in fission plants is the need for a wide range of components to function reliably under accident conditions if unacceptable public radiation exposures are to be prevented. Thus we belleve that in fusion (or fission) reactor designs providing the same assurance more simply--for example, by virtue of fundamental materials properties and passive heat-transfer mechanisms in configurations that can be maintained without active safety systems--the layers of assurance provided by $\mathrm{N}$-stamp certification of many plant components would not be required.

To apply this idea to the ESECOM fusion-reactor reference cases, we made use of a set of cost-reduction factors developed by J. Perkins in the course of the Minimars study ${ }^{71}$ to estimate the potential cost savings associated with use of nonnuclear-grade materials and components. These cost-reduction factors are broken down into the standard cost accounts used in ESECOM's Generomak/NECDB economic model. They are shown in Table 20. The result of applying them account by account to a given fusion reference design represents a hypothetical minimum plant capital cost that would apply if no nuclear-grade materials and components were required in constructing that plant. The difference between this figure and the unadjusted capital cost (see Table 4) of a reactor is its hypothetical maximum safety assurance credit in our scheme.

This maximum credit amounts to about $30 \%$ of the unadjusted capital cost for the point-of-departure tokamak; since different designs have different distributions of their unadjusted costs among cost accounts, however, this percentage reduction varies slightly from case to case. As a check on our results, we repeated some of our calculations using a set of safety-assurance cost-reduction factors derived independently in a recent inertial-confinement fusion-reactor study. ${ }^{72}$ Although the factors differed in detail, the overall cost reductions calculated were very similar.

It may be argued that, inasmuch as no fusion system is 11kely to be able to avoid nuclear-grade requirements entirely, such a figure tends to overstate the savings avallable even to systems with $L S A=i$. On the other hand, potential savings from reduced licensing and construction times, from higher capacity factors attributable to fewer safety-related shutdowns, and, perhaps, from increased flexibility in siting--none of which savings we attempted to 
Table 20. Cost-reduction factors for complete avoidance of $\mathrm{N}$-stamp requirements. Figures multiply unadjusted costs to give costs if no nuclear-grade requirements applied. Entries denoted DDC are design-dependent composites of other categories.

Account number and description Multiplier

\begin{tabular}{lll}
\hline 20 & Land and land rights & 1.0 \\
21 & Structures and site facilities & DDC \\
211 & Site improvements and facilities & 0.68 \\
212 & Reactor building & 0.68 \\
213 & Turbine building & 0.68 \\
214 & Reactor maintenance building & 0.68 \\
215 & Tritium building & 0.68 \\
216 & Electrical equipment building & 0.68 \\
217 & Other buildings and structures & 0.68 \\
22 & Reactor plant equipment & DDC \\
221 & Reactor system & DDC \\
221.1 & Vacuum vessel/first wall & 0.5 \\
221.2 & Blankets & 0.5 \\
221.3 & Nuclear shields & 0.5 \\
221.4 & Structure & 0.67 \\
222 & Magnet system & 0.69 \\
223 & Auxiliary plasma heating & 1.0 \\
224 & Vacuum-vessel pumping system & 1.0 \\
225 & Magnet power conditioning & 1.0 \\
226 & Heat transport & 0.4 \\
227 & Plasma fuel handling & 1.0 \\
228 & Instrumentation and control & 1.0 \\
229 & Reactor maintenance equipment & 1.0
\end{tabular}


Table 20. (Continued)

\begin{tabular}{lll}
\hline Account & number and description & Multiplier \\
\hline 23 & Turbine plant equipment & 1.0 \\
24 & Electric plant equipment & 0.57 \\
25 & Hiscellaneous plant equipment & 0.77 \\
26 & Heat rejection system & 0.8 \\
& Total direct cost & DDC \\
& Indirect costs & 0.80 \\
& Total plant capital cost & DDC
\end{tabular}

$a_{\text {Multiplier for indirect-cost fraction of direct cost. }}$

quantify--would add to those from reduced nuclear-grade construction. The size of further possible savings from elimination of some active safety systems in reactors $w 1$ th $L S A=1,2$, or 3 is very difficult to estimate; even where active systems are not needed for assurance against off-site fatalities, some of these systems presumably will still be desirable for protection of plant investment against smaller but nonetheless potentially costly accidents.

In any case, we did not assume that each fusion reactor design was entitled to the maximum hypothetical cost reduction calculated by the scheme described above. Instead, the savings actually credited were scaled to the LSA assigned to the design. Designs with $L S A=1$ received $100 \%$ of the maximum credit, those with $L S A=2$ received 50\%, those with $L S A=3$ received $25 \%$, and designs with $L S A=4$ recelved no safety-assurance credit. (Recall that Level 4 corresponds to contemporary fission-reactor practice and hence to the contemporary $\mathrm{N}$-stamp requi rements and construction costs that were the basis of the unadjusted cost calculations.)

The adjusted capital costs obtalned by following this prescription were then combined with the calculated operating costs (assumed independent of LSA) to obtain COE figures. These are shown in Table 21 for ESECOM's ten fusion and hybrid-breeder reference cases; figures in each case are given for all three LSA evaluations--optimistic, nominal, and conservative--and the unadjusted figures (no safety-assurance credit) are shown for comparison. As can be seen 
Table 21. Cost of electricity with safety-assurance credits.

\begin{tabular}{|c|c|c|c|c|c|}
\hline \multicolumn{2}{|c|}{ Case } & \multirow{2}{*}{$\begin{array}{l}\frac{\operatorname{COE}(\mathrm{m} / 11 \mathrm{~s} / \mathrm{kWh})}{\text { Optimistic }} \\
\begin{array}{l}\text { concept } \\
\text { evaluation }\end{array} \\
46.2\end{array}$} & \multirow{2}{*}{$\begin{array}{c}\text { If safety-z } \\
\begin{array}{l}\text { Nominal } \\
\text { design } \\
\text { estimate }\end{array} \\
49.7\end{array}$} & \multirow{2}{*}{ 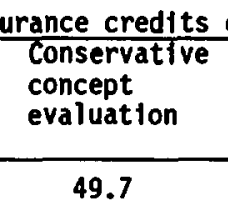 } & \multirow{2}{*}{$\begin{array}{c}\begin{array}{c}\text { Correspond to } \\
\text { No safety } \\
\text { assurance } \\
\text { credit }\end{array} \\
53.1\end{array}$} \\
\hline 1 & V-L1-TOK & & & & \\
\hline 2 & RAF-He-/TOK & 42.6 & 42.6 & 45.6 & 48.5 \\
\hline 3 & RAF-PbL1/RFP & 35.7 & 37.7 & 37.7 & 37.7 \\
\hline 4 & $V$-LI-RFP & 35.2 & 37.3 & 37.3 & 37.3 \\
\hline 5 & SIC-He/TOK & 40.3 & 40.3 & 47.5 & 54.6 \\
\hline 6 & V-Fl1Be/TOK & 38.0 & 42.9 & 42.9 & 47.9 \\
\hline 7 & V-MHD/TOK & 31.0 & 35.4 & 35.4 & 35.4 \\
\hline 8 & $V-\mathrm{DHe}^{3} / \mathrm{TOK}$ & 34.9 & 41.3 & 41.3 & 47.8 \\
\hline \multirow[t]{3}{*}{9} & RAF-LI/HYB & & & & \\
\hline & W LWR clients & 39.1 & 39.4 & 39.4 & 39.4 \\
\hline & w MHTGR clients & 40.1 & 40.3 & 40.3 & 40.3 \\
\hline \multirow[t]{3}{*}{10} & SS-He/HYB & & & & \\
\hline & W LWR cillents & 38.4 & 38.8 & 38.8 & 38.8 \\
\hline & w MHTGR clients & 39.4 & 39.8 & 39.8 & 39.8 \\
\hline
\end{tabular}

from Table 21, the effect of these adjustments is to narrow the range of $C O E$ values spanned by the reference cases, as well as to lower the average figure. The reason for the narrowing is that the fusion cases with higher unadjusted costs tended to earn better safety-assurance ratings, which is not surprising given that their higher unadjusted costs tended to result from advanced materials or from relatively low-power densities, both of which can contribute to the possibility of passive protection against major releases.

In addition to this necessarily very approximate approach to quantifying the potential benefits of achieving high LSA, we also attempted to qualitatively characterize some potential cost impacts of safety and environimental issues that are resistant to quantification at the present state of knowledge about fusion technology. Specifically, we identified a set of such issues that w11l have some bearing on reactor design, construction, and operation, but whose resolution is not clear enough to permit incorporation of 
engineering detal1s, operating procedures, and corresponding costs into the formal engineering/economic model ESECOM used. Two of these issues--seismic restraints and safety systems for chemically reactive coolants--relate to accident prevention/control; two others--tritium-control systems and remote maintenance--relate to control of radiological hazards in routine operation. These are not the only issues of this kind, of course, but they are surely four of the most important.

For each reference design, we assigned a potential economic impact rating of High, Medium, Low, or None to each of the four safety/environment issues, indicating its potential for leading to costs beyond those embedded in ESECON's nominal costing evaluation: we consider High to represent a potential impact equivalent to a $20 \%$ increase in plant capital cost, Medium a 10\% increase, and Low a 5\% increase. Obviously these are very approximate categorizations. Indeed, we emphasize that we do not know that these costs will materialize at all; clever engineering solutions might be able to reduce or avoid them. We have used this scheme simply as a way of drawing attention to the possible magnitudes associated with safety/environment-related cost uncertainties that no one is really in a position to pin down more precisely. The ratings, which are based on safety and environmental considerations summarized above and treated in more detafl in our main report, ${ }^{1}$ as well as on engineering judgment concerning the technical problems involved, 1,13 appear in Table 22. If the four areas are considered together, the designs with the highest combined potential cost impacts (as percentages) are seen to be Cases $1,3,4$, and 9, while those with the lowest are Cases 5, 6, and 8 .

It has been widely supposed that there will be trade-offs between attractive economics and safety characteristics, partly on the basis of the economic costs of added-on safety systems and partly on the assumption that high-power density is as inimical to safety as it is fivorable to low cost. Our work suggests that the relations are more complicated than this. As already noted above, LSA values of 1,2 , or 3 associated with basic materials properties and passive energy-removal mechanisms may lead to substantial savings through reduced $\mathrm{N}$-stamp requirements, even if elaborate active safety systems remain desirable to protect plant investment. As for the putative economics/safety trade-off associated with power density, that relation is also complicated. Depending on details of confinement schisme, magnet capabilities, and materials properties (among other factors), the economic optinum power density may occur at levels below those where significant 
Table 22. Potentfal cost impacts of some other safety/environment issues. High means a potential impact on COE equivalent to that of a $20 \%$ increase in plant capital costs, medium 10\%, low 5\%. Potentlal impacts may be reducible or avoldable by means of engineering innovations.

\begin{tabular}{llllll}
\hline & & $\begin{array}{l}\text { Seismic } \\
\text { restraints }\end{array}$ & $\begin{array}{l}\text { Reactive- } \\
\text { coolant } \\
\text { protection }\end{array}$ & $\begin{array}{l}\text { Tritium- } \\
\text { control } \\
\text { systems }\end{array}$ & $\begin{array}{l}\text { Remote } \\
\text { Maintentance }\end{array}$ \\
\hline 1 & V-Li/TOK & Medium & Medium & Low & High \\
2 & RAF-He/TOK & Low & None & Medium & Medium/high \\
3 & RAF-PbLi/RFP & Medium & Low & Medium & High \\
4 & V-Li/RFP & Medium & Medium & Low & High \\
5 & SiC-He/TOK & Low & None & Medium & Low/medium \\
6 & V-FLiBe/TOK & Low & None & Medium & Medium \\
7 & V-MHD/TOK & Low & Low & Medium & Medium/high \\
8 & V-DHe $3 / T O K$ & Low & None & Low & Medium \\
9 & RAF-Li/HYB & Medium & Medium & Low & High \\
10 & SS-He/HYB & Medium & None & Medium & High \\
& & & & & \\
\hline
\end{tabular}

adverse impacts on LSA would occur. Generalizations on this point are unrelfable, as detalled technical specificasions and a rather rigorous analysis of the thermal transients that could be encountered in realistic accidents are required to clarify the question for any given design. Also, compactness (associated with high power density or simplified magnetic topology, such as the RFP) may offer advantages for maintenance and accidentrecovery, translating into economic benefits.

It is possible, finaliy, that there is an economics/safety trade-off assoclated with plant scale, wherein very large plants are favored by the scaling laws of fusion plasmas and other economies of scale, while safety assurance is impertled at very large scale by the size of the radioactivity inventories present in a single device. Here, too, as the longer analysis in our main report suggests, the situation is more complicated than it first appears. Even without bringing safety into the picture, the economic-optimum scale is influenced by many factors, some of them poorly understood even for 
fission plants and necessarily more so for fusion. The extent to which modularization, multiplexing, mass production, and learning effects could change the usual conceptions about nuclear-plant scale economies is unclear and needs further investigation; information being accumulated in the study of this issue for fission plants will eventually be helpful in assessing fusion's prospects, but attention will also have to be given to possible differences in the amenability of fission and fusion systems to modularization, inutiplexing, and factory fabrication. The implications of all this for safety represent largely uncharted ground, and the already overambitious scope of this study in relation to the avallable resources left us little room even to begin mapping it.

UNCERTAINTIES AND OMISSIONS

We have mentioned in the foregoing summary many of the uncertainties that inevitably arise in a study of this kind. Most of them are attributable at least in part to the early stage of development of fusion technology. Some are connected with our assumptions about the performance of fusion $p l$ asmas and the surrounding systems; some affeci our assessments of environmental and safety characteristics: and most influence one way or another our estimates of monetary costs.

It is useful to separate the uncertainties that affect our economic estimates into four classes, as follows:

1. Physics uncertainties, such as those associated with plasma performance, current-drive efficiency, maximum magnetic field strength, and so on;

2. Materials uncertainties, having to do with the key properties of structural materials in regard to strength at temperature, fabricability, maintenance of performance under neutron bombardment, and so on:

3. Technology uncertainties (Inciuding aspects related to environment and safety), such as those connected with tritium management, remote maintenance, energy conversion, and so on;

4. Institutional uncertainties, having to do with management practices, regulatory environment, interest rates, and so on.

The uncertainties in the physics and materials categories can easily be large enough, in the fusion cases, to become feasibility issues; that is, if the outcomes are unfavorable enough, particular approaches (and perhaps 
fusion-electric systems in general) will not even be close to competitive. Put another way, it is not hard to show that outcomes still within the realm of possibility for combinations of these variables could drive up the cost of electricity to 2 times or more the nominal values estimated here. Most of us think that is unlikely, but it cannot be ruled out. (It can be added that the economic attractiveness of fusion hybrid breeders is less sensitive to such uncertainties than is the case for pure-fusion systems, both because the hybrid breeders are less demanding of fusion performance and because the impact of their cost on COE is diluted by the economics of the client reactors.)

In the technology category, the range of uncertainty is probably smaller: in the least well developed cases the cumulative uncertainty from all such effects may extend to $50 \%$ or so greater than our nominal COE values, and in the least uncertain cases perhaps to $25 \%$ or so greater than the nominal values: St111, it 1 s concelvable that very adverse outcomes on combinations of major issues such as remote maintenance and tritium management could drive up costs by more than these tentative figures suggest.

In the institutional category, finally, it should be clear from fission experience that combinations of these management/regulatory/financial aspects can be responsible for cost impacts in the range of a multiplicative factor of 2. Many of these aspects would tend to affect different fuston designs--and indeed fission as well as fusion systems--approximately equally, although as al ready noted this might not be so for regulatory factors related to safety.

We present in Table 23 a necessarily judgmental evaluation of the relative sizes of the physics, materials, and technology uncertainties in the 14 ESECOM fusion, hybrid, and fission reference cases. The table was compiled by polling the members of ESECOM at a meeting in December 1986. The cholces for each reactor type and uncertainty class were Negligible, Low, Medium, or High. The "votes" of the members were averaged numerically using a scale from 0 for Negligible to 3 for High. The fission PWR-BPE again serves as a calibration of this scale: it receives zeroes (negligible uncertainties) in each of these three categories. (It should be noted that the institutional uncertainties affecting the COE for PWRs would not be zero.) The pure-fusion system with the lowest across-the-board physics, materials, and technology uncertainties is the RAF-He/TOK; it is also the most attractive of the relatively low-uncertainty cases from the safety/environment standpoint. 
Table 23. Judgmental relative uncertainties in ESECON reference cases. Values obtained by averaging ratings of Negligible, Low, Medium, and High made by individual members of ESECOM. Numerical scale for averaging was Negligible $=0$, Low $=1$, Medlum $=2$, High $=3$.

\begin{tabular}{rlccc}
\hline & & \multicolumn{3}{c}{ Averaged uncertainty ratings } \\
\cline { 3 - 5 } & Case & Physics & Materials & Technology \\
\hline 1 & V-LI/TOK & 1.7 & 2.3 & 2.0 \\
2 & RAF-He/TOK & 1.7 & 1.3 & 1.8 \\
3 & RAF-PbLI/RFP & 2.3 & 1.8 & 2.6 \\
4 & V-LI/RFP & 2.3 & 2.3 & 2.6 \\
5 & SIC-He/TOK & 1.7 & 3.0 & 2.3 \\
6 & V-FLIBE/TOK & 1.7 & 2.5 & 2.3 \\
7 & V-MHO/TOK & 2.3 & 2.8 & 2.8 \\
8 & V-DHe $3 /$ TOK & 3.0 & 2.3 & 2.3 \\
9 & RAF-LI/HYB & 1.1 & 1.8 & 2.0 \\
10 & SS-He/HYB & 1.1 & 2.0 & 2.0 \\
$1:$ & PWR-BPE & 0.0 & 0.0 & 0.0 \\
12 & LSPB & 0.1 & 0.6 & 1.0 \\
13 & PRISH & 0.1 & 0.6 & 0.9 \\
14 & MHTGR & 0.0 & 0.7 & 0.8 \\
& & & & \\
\hline
\end{tabular}

A more detalled characterization of economic uncertainties in the materials and technology levels was undertaken in connection with calculating tne COEs for the fusion cases. (For this purpose, as already noted, the main physics incertainties were assumed to have been resolved with rather favorable outcomes--typically $10 \%$ beta, plasma safety factor of 2.3, maximum field of 10 tesla at the coils, coil current density greater than $20 \mathrm{MA} / \mathrm{m}^{2}$, and so on.) For each cost account and major subaccount used in calculating capital costs (e.g., turbine-plant equiprient, nuclear-1sland/coils), and for each heading under operating costs (e.g., blanket replacement, other fuel-like expenditures), an economic uncertainty rating of Low, Medium, or High was assigned by consensus after comittee discussion of the associated engineering and materials issues. This was done for each design, after accounting for the 
safety-assurance credits corresponding to the nominal LSA evaluations. The ratings and the rationales for them can be found in our main report. It then became possible to compute for each design the fractions of the COE that are associated with low-uncertainty, medium-uncertainty, and high-unceriainty elements.

The results of this breakdown of COE according to uncertainty level are presented in Table 24. Figure 2 presents in graphical form the cost comparisons among all the ESECOM reference cases, using ple diagrams placed at the nominal COEs of the fusion designs to convey the uncertainty distributions from Table 24. Shaded bars denote the range from optimistic to conservative evaluations of LSA, and dotted arrows emphasize the existence of unquantified

Table 24. Distribution of COE by degree of uncertainty. Evaluations performed for nominal LSA.

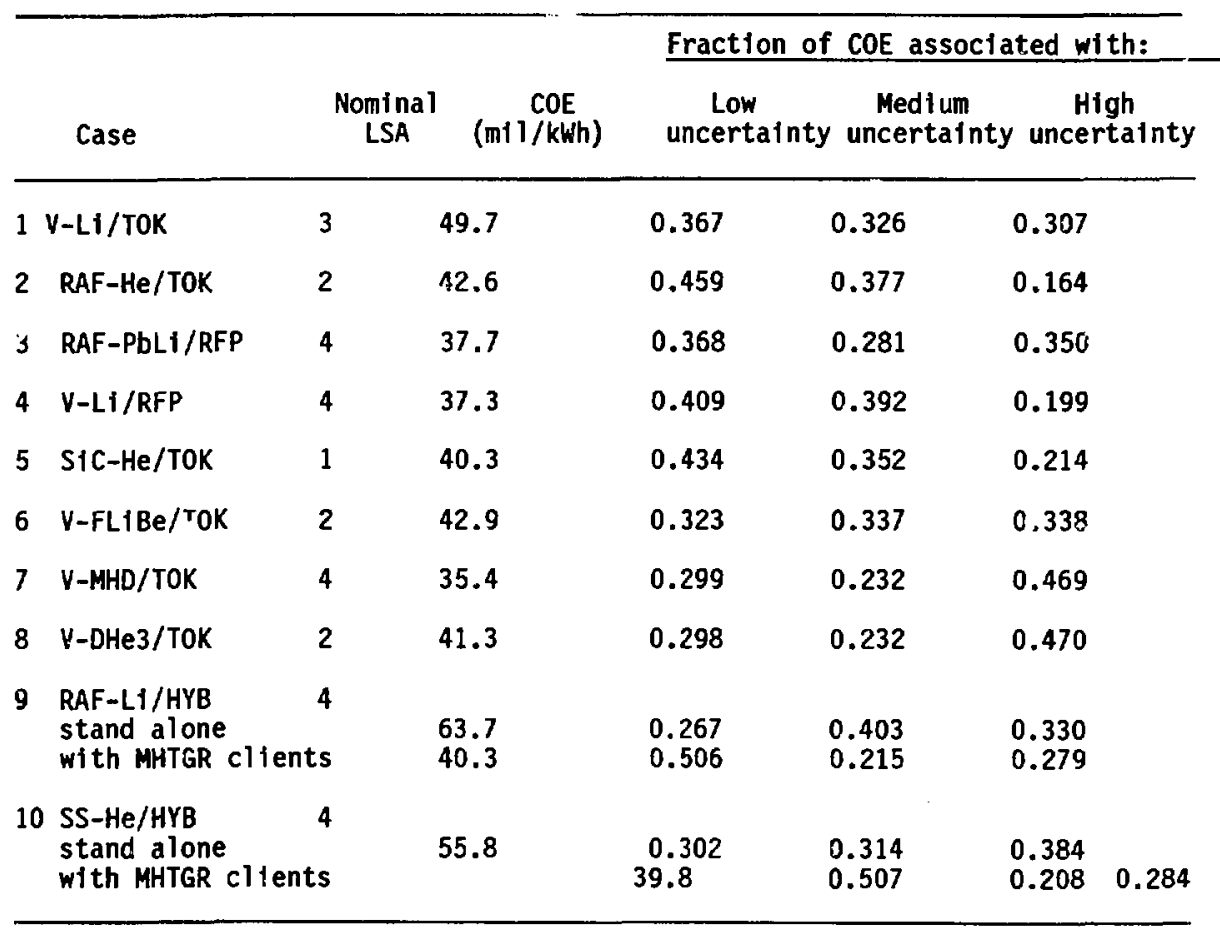




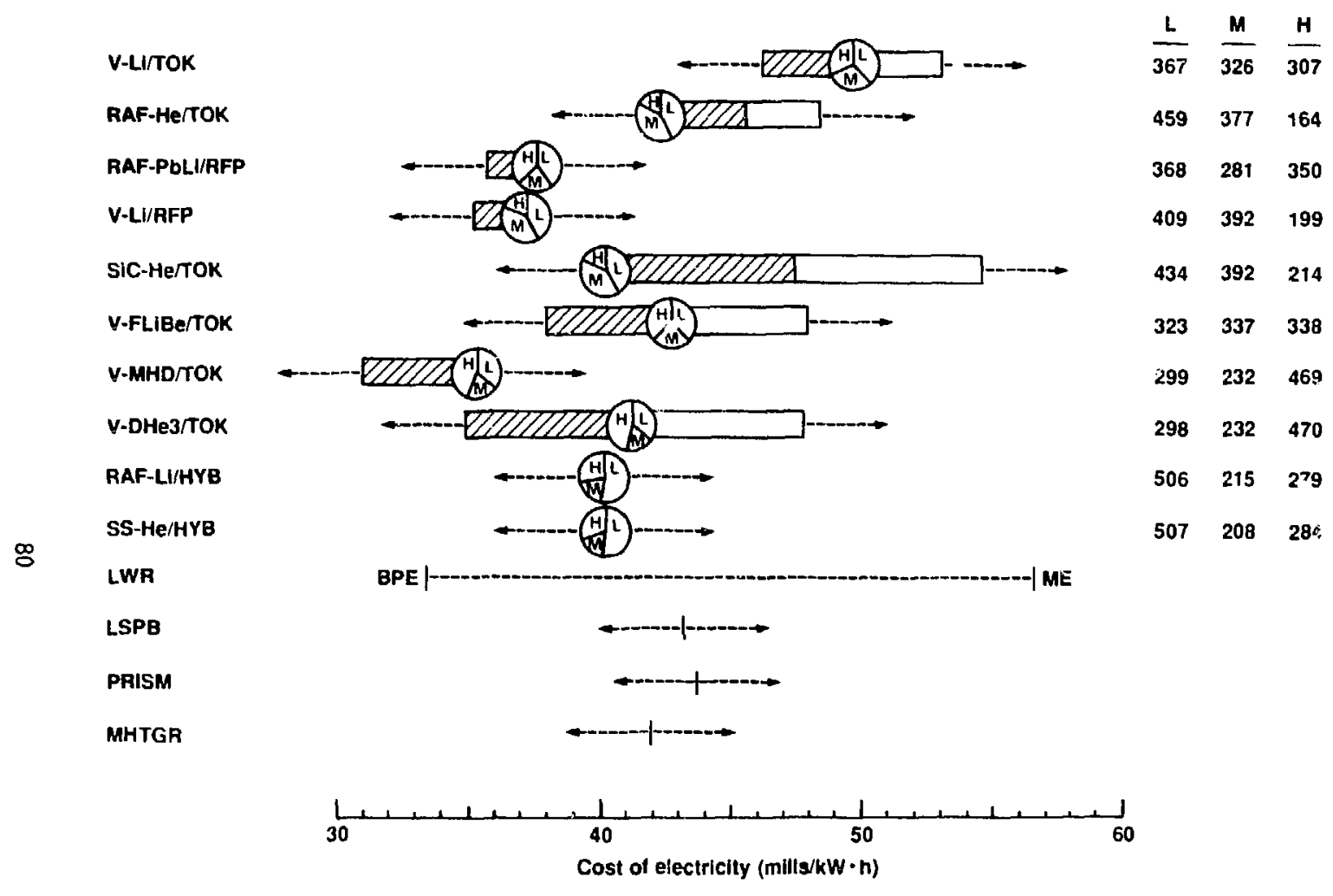

Figure 2. COE estimates for ESECON cases with and without safety assurance credits. $L, M$, and $H$ represent low, medium, and high cost uncertalnties determined by assigning these designations to each cost account for each design. (See Table 24.) Where the conservative LSA rating is less than 4, a blank bar extends to the COE that would obtain at LSA $=4$ (that is, without safety-assurance credits). 
uncertainties assoctated with, for example, physics and institutional factors. Fission COEs are not broken down by uncertainty level because the disaggregated cost estimates needed to do so were not avallable to us for all the fission cases.

Although the emphasis in the preceding discussion has been on the possibility that fusion economics could be worse than ESECOM's estimates indicate, the economic uncertainties do cut in both directions. It is true that we have picked some key parameters (such as beta and current drive efficlency) toward the optimistic end of the ranges that are plausible based on present understanding, so that the uncertainties may not be symmetric; on the other hand, it is impossible to account in any comprehensive way for the array of potential discoveries that have not yet been made and that could extend the range in the optimistic direction.

Indicative of such possibilities is the concept of the second stability regime for tokamaks. Information that became available late in our study ${ }^{73}$ made it possible for us to explore in at least a prefiminary way, using the Generomak model, the potential impact on tokamak economics if the second stability regime actually turns out to be realizable. COE reductions in the range of 15 to $20 \%$ for the ESECOM point-of-departure V-LI/TOK were estimated for this eiventuality. Ancther possibility with the potential for significant positive effects on MFE economics is advanced superconducting magnets. ESECOM's sensitivity studies indicated that application of the advanced magnets assumed for the $\mathrm{D}-\mathrm{He}^{3}$ case to the point-of-departure tokamak could reduce $C O E$ for the latter case by about $13 \%$. These and some other results of our modeling of the sensitivity of COE to physics and technology assumptions are shown in Table 25.

The rapid pace of developments, late in our study, relating to highertemperature superconductors ${ }^{74}$ raises further magnet-related possibilities for savings, ranging from reduced refrigeration costs (a small-percentage effect) to substantiaily more compact designs (with conceivable savings in the 20 to $30 \%$ range). Much more work on the higher-temperature superconductors will be required before the 11kelihood of achieving these possibilities can be evaluated with any confidence.

Still other possibilities simply weie not considered by ESECOM at all. For example, there exists a range of possible compact confinement schemes with inproved magnet topology and field utilization and the potential for significant cost reductions; these extend beyond the RFP and include concepts 
Table 25. Sensitivity of COE to variations in parameters. All figures are for variations on nominal values for point-of-departure V-L1/TOK.

Troyon coefficient, $\beta \mathrm{B}_{\phi} \mathrm{a} / \mathrm{I} \phi=0.04$

- Decrease from 0.04 to 0.03 , giving $\rho=0.075$

- Make proportional to $1 / k$, with $k=2.5$, $\beta \mathrm{B}_{\phi} \mathrm{a} / \mathrm{I}_{\phi}=0.016, \beta=0.04$

- Increase from 0.04 to 0.12 by schieving second stability regime, giving $\beta=0.20$

Plasma safety factor, $q_{1}=2.3$

- Increase from 2.3 to $4 . n$

-- by decreasing $\beta$ to 0.057

-- by decreasing $A$ from 4 to 2.7

Plasma elongation, $k=2.5$

- Reduce from 2.5 to 2.0 with $A=3$

Current drive efficiency, $\gamma=2.7 \mathrm{~A} / \mathrm{m}^{2} \mathrm{~W}\left(I_{\phi} / \mathrm{P}_{O D}=0.2 \mathrm{~A} / \mathrm{W}\right)$

- Limit $\gamma$ to $0.4 \mathrm{~A} / \mathrm{m}^{2} W$

- Limit $\gamma$ to $0.5 \mathrm{~A} / \mathrm{m}^{2} W$ but increase plasma $T$ to $25 \mathrm{keV}$

- Sustain full $I_{\phi}=15.7$ MA with bootstrap currents

Coil current density, $\mathrm{J}_{\phi C}=20.4 \mathrm{~mA} / \mathrm{m}^{2}$

- Improved coll design with $f_{\phi c}=58 \mathrm{MA} / \mathrm{m}^{2}, B_{\phi C}=18 \mathrm{~T}$

Blanket unit cost, $190 \$ / \mathrm{kg}$

- Decrease by 50 percent

Plant Lead Time, $Y=6 \mathrm{yr}$

- Decrease fry 6 to $5 \mathrm{yr}$ 
such as the Spheromak, field-reverse configurations, and the dense Z-pinch. 75 These approaches were not amenable to investigation in the framework of our study, but they deserve attention. Another possikility not considered here is spin-polarization of fuel nuclei to increase their reaction rate. This technique has been rather extensively studied, ${ }^{75}$ although its feasibility is still unclear. If it works, it could increase the reaction rate in D-T systems by a factor of perhaps 1.5 , reducing the beta required for a given power density by the square root of that factor. The economic trade-off between the resulting cost savings and the added costs associated with accomplishing the polarization cannot be evaluated given current knowledge. A still less well understood possibility we did not analyze is "cold nuclear fusion" based on muon catalysis of the fusion reactions. Conceivably this process, which has been demonstrated at temperatures between a few kelvin and a few hundred degrees centigrade, can be macie energetically and economically attractive, but if so the technology would be so different from that of MFE that our current study would be of little relevance in judging its potentlal.

\section{FINDINGS IN BRIEF}

Our most important and general conclusions follow under the first subheading. More detafled conclusions and recommendations are summarized in the subsequent subsections.

THE POTENTIAL OF MAGNETIC FUSION ENERGY

Our analysis indicates that magnetic fusion energy systems have the potential to achieve costs-of-electricity comparable to those of present and future fission systems, coupled with significant safety ard environmental advantages. This conclusion is based on (a) assumptions about plasma performance and engineering characteristics that are optimistic but defensible extrapolations from current experience, and (b) consistent application of an elaborate set of engineering/economic and safety/environment models to a range of fusion and fission reference cases, with the known characteristics of fission light-water reactors as a benchmark. Fusion's putential economic 
competitiveness does not depend on translating safety and environmental benefits into cost credits, but it would be enhanced if that occurs. The most Important potentlal advantages of fusion with respect to safety and environment are:

1. High demonstrability of adequate public protection from reactor accidents (no early fatalities off-site), based entirely or largely on lowradioactivity inventories and passive barriers to release rather than on active safety systems and the performance of containment butldings;

2. Substantial anelioration of the radioactive-waste problem by eliminating or greatly reducing the high-level-waste category that requires deep geologic dtsposal;

3. Diminution of some important links with nuclear weaponry (easier safeguards against clandestine use of energy facilities to produce fissile materials, no inherent production or circulation of fissile materials subject to diversion or theft).

These advantages are potentially large enough to make a difference in public acceptability of MFE, as compared with fission.

The timing and intensity of the need for MFE w11l ciepend on future patterns of U.S. and world energy demand, as well as on the characteristics of other energy sources avallable to meet those demands. Future energy demand and the characteristics of alternatives to fusion in the t1m frame when it might be available--starting 20 to 30 years hence--are clouded by uncertainty. Given the potential damages to society from insufficient energy supply or excessive economic and environmental costs of obtaining $1 t$, however, and given the absence of any long-term energy source that is both reasonably assured technologically and free of potentfally serious economic or environmental lfabilities, it would be linprudent to assume that fusion energy would not be needed.

If fforts to continue to increase the efficiency of energy end use worldwide are less successful than hoped, if the expansion of coal use is constrained by the carbon-dioxide problem and other environmental 11abilities, if fission energy cannot be expended owing to concerns about safety and links to nuclear weaponry, and if large-scale use of sunlight and blomass energy is impeded by high monetary costs or environmental impacts, then the need for fusion energy could be early and acute. Even if such severe problems with the alternatives do not materialize, fusion might offer sufficient benefits in th combination of fuel avallability, economic cost, versatilfty, and 
environmental safety characteristics to displace otherwise acceptable energy sources for significant societal advantage. Fusion's long-term potential inçludes a number of applications--among them synfuels production, isotope production, waste processing, and space propulsion--that may contribute to its attractiveness but were not evaluated by ESECOM.

Neither the economic competitiveness nor the environmental and safety advantages of fusion will materialize automatically. Economic competitiveness depends on attaining plasma and engineering performance--such as high beta, efficient current drive, and ease of maintenance consistent with high capacity factor--that are not yet assured. Achieving the potential environmental and safety advantages depends in large measure on designs specifically tallored to do so and on the use of low-activation materials whose practicality for fusion applications remains to be demonstrated. Research is needed to clarify these possibilities, and a commitment to pursuing fusion's highest potential is needed to ensure that the results of such research are embodied in the mainstream of fusion development.

In a world where large-scale use of fission energy had been deewed acceptable, fusion hybrid breeder reactors producing fuel for fission-reactor clients would have the potential to Inprove system economics (and, concelvably, system safety and proliferation resistance) compared to purefission systems, while providing a fusion-technology stepping stone toward pure-fusion electricity generation. The COE uncertainties of hybrids are lowe han for other fusion systems because cost and performance variations in the fusion breeder itself are distributed over a large number of fission client reactors with less uncertain economics. On the other hand, whether and when hybrids will be attractive at all depends strongly on very uncertain aspects of the world energy future, including the public acceptability of large-scale use of fission, the cost of uranium, and the characteristics of advanced fission breeders.

Although the technological feasibility of MFE has not yet been fimly established and the characteristics of a practical reactor therefore remain unclear in detail, it is completely appropriate--indeed essential--to undertake a systematic and cont'nuing assessiment of fusion's potential to achieve attractive combinations of environmental, safety, and economic characteristics. Doing so at a relatively early stage of fusion's development has the advantage of steering R\&D efforts in the directions of greatest promise, before one approach or the other has become locked in. 
It is essential, in this connection, that sufficient R\&D be devoted early to determining which of a varlety of confinement schemes, structural materials, blanket types, and fuel-cycle/energy-conversion combinations can actually be made practical. Otherwise, the set of realistic possibilities for attractive combinations of environmental, safety, and economic characteristics will not be known, incurring the risk that fusion either will be developed in suboptimal directions or will not appear to be attractive enough to be developed at all.

TECHNOLOGY AND ECONOMICS

The fusion cost estimates we have derived necessarily embody many uncertainties. Experience suggests that even our estimates for fission-energy costs, based on better understood systems, should not be considered very accurate. The magnitudes of these cost estimates relative to one another are wre informative than their absolute values. Although the overall COE uncertainties for our fusion and advanced fission reference cases probably exceed the typical differences between cases, we belfeve our use of consistent calculational techniques for all the cases justifies some confidence in our conclusion that MFE has the potential to be generally competitive with fission energy. Similarly, we have confidence that our relative COE figures convey real insights about the economic effects of particular types of design changes.

The uncertainties with the biggest effects on our estinates of $\operatorname{COE}$ for the fusion-electric cases are assoclated with achieving the assuned beta and current-drive efficiency and with attaining plant reliability and maintainability characteristics compatible with reasonable capacity factors. These are cruclal issues for MFE competitiveness, they pose particular difficulties in tokamaks, and they will need much more experimental and design work before answers can be offered with high confidence. At the same time, it should be emphasized that improvements in some areas--for example, magnets-can offset shortfalls in others.

ESECON'S ten fusion and hybrid-breeder reference cases were chosen to explore the implications of different cholces of power densities, coolant/breeder combinations, structural materials, energy conversion schemes, and fuel cycles within a linited number of case studies. We do not claim, nor should it be assumed, that any one of these designs embodies the best 
combination of choices that could be made based on current knowledge. Using ESECOM's findings and other recent work, it should be possible to generate new designs with improved performance by combining some of the best features of different reference cases.

The design characteristics offering the most important potential benefits for fusion COE are:

1. Compactness (including but not linited to high mass power density). wich reduces the capital cost of the fusion power core, reduces, as a result, the sensitivity of COE to plasma performance, and may ease maintenance;

2. High LSA, meaning demonstrability of public safety based on low radioactive inventorles and passive mechanisms for preventing releases, which should reduce cosis for active safety systems and nuclear-grade components as well as factlitating siting and licensing;

3. Advanced energy-conversion systems, which should be able to reduce balance-of-plant costs and may increase capactty factors.

Each of these features has the potential to generate COE reductions in the range of 20 to $30 \%$. If two or more of them can be combined in one design, the resulting $C O E$ reduction will be larger.

Advanced-fuel reactors, which offer significant environmental and safety benefits, may be able to reach economically competitive levels of COE with the help of direct conversion, advanced magnets, and simplified, long-life blankets. All of these features are elther more feasible or more heipful in the case of advanced fuels than they are in the D-T case, thus partly offsetting the $D-T$ advantage in plasma reactivity.

While strong economies of scale are expected to be associated with the scaling characteristics of fusion plaswas, other aspects of the economics of scaling in fusion (and other) power plants remain inadequately understood. It is possible that important diseconomles of scale--assoclated in some instances with reduced avallability--will be encountered in important components (e.g.. blankets, magnets). The posstble trade-offs between scale economies and potential benefits of modularization and learning need more thorough exploration; experience being acquired with fission systems will be informative about fusio.i's prospects in this respect.

Anong the specific reference cases examined by ESECOM, some of the most potentially attractive are those in which technological uncertainties or lack of design detail loomed largest--notably the SIC-He, V-FLIBe, V-IWI, and D-He ${ }^{3}$ toksans. This observation underscores our recommendation for expanding 
the R\&D efforts directed at clarifying the feasibility of advanced design concepts.

ENVIRONMENT, SAFETY, AND ECONOMICS

We belfeve the categorization of different designs into four LSA--based on the extent to which assurance of public safety depends only on low inventories of radioactivity and passive mechanisms to prevent releases--is an informative way to characterize differences relevant to the interaction of safety and economics. Although reliance on active safety systems and/or the proper performance of containment bulldings can provide adequate safety in terms of actual values of risk, relying instead on low radioactive inventories and on passive safety features tends to produce a still safer system. In addition, the passive approach greatly eases the problem of demonstrating the adequacy of safety, not only in the technical and regulatory comminities but also to decision makers and the public. This advantage is lik o translate into cost. savings through reduced expenditures on active safety sysiems, reduced requiremente "nuclear-grade components, diminished siting and licensing problems, aila fewer delays in construction.

Increases neutron wall loading contributes to (but is not the cnly basis for) high-mass power density and associated economic benefits; very high neutron wall loading, however, can reduce the chance of attaining high LSA. There is thus a potential tension between pursuing high wall loading to get the economic benefits and operational advantages of compactness, and pursuing the economic, regulatory, and public acceptance benefits of high LSA. The magnitude of neutron wall loading at which this tension becomes an actual trade-off is strongly design dependent, and detalled safety analysis is needed to determine it. It may be possible to alleviate this tension to economic advantage by careful cholce of materials and other safety-related aspects of design.

With suitable cholce of structural materlals and blanket design, even a large Ithiu fire would not produce any prompt fatalities off-site. The potential destructiveness of l1thium fires in terms of plant investment and public acceptability nonetheless dictates the use of special design features against such fires in plants that use liquid lithium as the primary coolantbreeder. These features should include avolding the use of water cooling for 1 initers/divertors and other high-heat-flux in-vessel components, as well as 
other measures to prevent 1 ithium-water, lithium-alr, and 11 thium-concrete fires in the event of a 11 thium spill.

Use of structural materials with low short-term activation is important in achleving high LSA. Such materials reduce the potential for off-site doses in accidents in two ways: reduction of the total amount of radioactivity potentlally avaflable for release, and reduction oi the decay heat that can contribute to the mobilization of this material.

Active inventories of tritilum in reactor designs are sall enough that even complete release under adverse meteorological conditions would not produce any prompt fatalities off site. The blanket and coolant-breeder inventories of tritium in ESECON's reference designs are in the range of 100 to 500 grams; release of the larger amount as tritfated water would produce a maximum whole-body critical dose in the range of 4 to 40 rem at the plant boundary. The Inactive tritium supply stored at the plant, although larger, can be divided up and extremely well protected.

Releases of trition in nomal operation are 11 kely to dominate other sources of routine radiation exposure to members of the pubitic from fusion, but it is feasible to make these releases as low as regulations require. The economic costs of meeting tight standards on tritium releases will depend on reactor type and on the combinations of tritium-control technologies that are adopted. The design of tritium-control systems for different reactor configurations deserves continuing detalled investigation.

Carbon-14 constitutes another source of routine public radiation exposure of possible concern, and the sources and fate of this isotope in fusion reactors need closer investigation. Carbon-14 is formed by neutron activation of nitrogen, oxygen, and carbon 1sotopes in reactor materials. In some instances, the quantities produced and their potential moblifity may require special control technologies to avold the global population dose that accumulat:s over many thousands of years (at dose rates tiny compared to geographic variations in natural background) if this material is released.

Routine radiation exposures of plant workers will be a copmlicated function of in-plant tritiun distribution, air and coolant activation. configuration and activation of solid reactor components, and maintenance procedures. This 1ssue cannot be analyzed in sat1sfying detall at the current stage of knowledge about fusion-reactor design and operation. It is reasonable to suppose that designs and procedures w1ll be configured in such a way as to avold worker exposures in excess of the 500 to 1000 person-rem per 
plant-year characteristic of commercial fission-reactor practice, but the cost of meeting tlis guideline is uncertain. It is already clear, however, that the contact doses from even the lowest-activation structural materials will be too high to permit hands-on maintenance of any components inside the shield within months of reactor operation.

Choice of fusion-reactor structural materials to reduce or el iminate formation of the most troublesome long-lived activation products leads to large reductions in the key indices of radioactive-waste hazards, conpared to fission. In some of the reference designs examined by ESECON, all of the radioactive wastes would qualify for shallow burial under the logic of current regulations. We do not conclude here that shal low burial is necessarily the best management scheme for fusion-reactor wastes, having made no systematic study of waste-management options. We simply offer the finding that fusion wastes would qualify for shallow burlal in some cases--and would come close to qualifying in most of the others--as an illuminating indicator of the reduction made possible by fusion in the size of the waste-management problem.

An electricity-supply system based on magnetic fusion energy would be less likely than a fission-energy system to contribute to the acquisition of nuclear-weapons capabilities by subnational groups, and would also be easter to safeguard against clandestine use for fissile-material production by governments. Except for the special case of hybrid breeders, fusion reactors need not produce or contain any fissile material, and a fusion-based electricity-supply system would not cirrilate any. Because fusion reactors could be modified to produce fisstle material, they will need to be subjected to international safeguards. $0:$ the other hand, using fusion reactors for fissile-material production would require prolonged control over the reactor (unlikely for subnational groups) and would be easier to detect by international safeguards (hence less likely to be judged an attractive option by governments) than is diversion from fissile fuel cycles. In principle, tritium in D-T fusion reactors could be stolen by subnational groups or diverted to weapons prograns by governments, but the consequences of this vulnerability are less profound than those of fissile-materials vulnerability in fission energy systems: the sophistication in nuclear weapons design and construction needed to make use of tritfum is likely to remain beyond the reach of subnational groups, and for governmental nuclear-weapons programs tritium can be useful but it is not an essential ingredient in the sense that fissile materials are. 
Far more system-level design and analysis work than has been conducted so far is needed to perilt better definition of the econoulcs and safety characteristics of fusion. Emphases in these systems studies should include:

1. Improved characterization of accident pathways and radioactivity release mechanisus;

2. Developwent of reactor designs conbining high LSA, high mass power density, direct conversion, and design simplicity for rellability and ease of maintenance.

More detailed designs are needed to allow more sophisticated analyses of fusion safety, environmental characteristics, reliability, and economics; such analyses are nizeded, in turn, to permit more informed decisions on which fusion concepts siould receive priority for development. The possible systemlevel advantages of advanced fuels have not been suffictently evaluated and deserve further study. Fusion-hybrid studies should also continue, with particular emphasis on optimizing the choice of fuel cycle.

The ultinate viability and attractiveness of MFE depends so strongly on waterials issues that a strong, sustained materials-development and testing progran must be considered second only to confinement studies as a prerequisite for fusion's success. The materials program should be closely integrated with the systems studies called for above, as well as responding to the materials issues posed by current fusion devices. Because of the diversity of candidate materials and the international distribution of materiais-science capabilities, coordination of materials development in the U.S. with corresponding programs in Europe, Japan, and the Soviet Union would be highly beneficial to all parties.

A balanced Rad progran in both physics and technology is needed to realize the possibility of cost-competitive electricity. Our economic analysis indicates that a competitive tokamak reactor $(40-50 \mathrm{mlls} / \mathrm{kW}-\mathrm{hr}$ ) will require attainment of either (a) values of beta (10\%) and current-drive efficiency ganma (greater than or equal to about 1.4) near the upper range of theoretical extrapolation from experimental values, or (b) advanced magnets good enough to relax these stringent requirements, or (c) full safetyassurance cost credits, or (d) inexpensive direct conversion to reduce balance-of-plant cost. Because none of these economics-related development 
tasks will be easy or will guarantee success, a multiple-pronged R\&D approach is only prudent.

Additional RED effort should be focused on resolution of technology Issues that affect the feastbility of particular fusion concepts. Any assessment of the relative safety and economic merits of different fusion cases depends on the credibility of engineering assumptions that require experimental verification. Such concept-feasibility issues arise for all of the ESECOM cases including the point-of-departure tokamak. A partial 1ist of these issues includes: the extent of surface erosion of plasma-interactive components, limits of high surface-heat-flux removal in realistic component geometries, 11 mits of blanket internal heat transfer using 11quid-metal coolants in strong magnetic fields, tritium solubllities and penetrativities, feasibility of thorium-cycle fuel reprocessing for hybrid breeders, and operational and 11fetime-reliability characteristics of MHD direct-conversion systems.

Notwithstanding the difficulty of the physics and engineering challenges that must be addressed in the next generation of fusion factlities--such as the compact-Ignition TORUS and the engineering test reactor--it is important that these factlities also be used to develop and dewonstrate the kinds of safety features that will be needed for comercial reactors. Postponing major attention to safety issues until more physics and technology issues have been resolved would reduce the chance of fusion's achieving its safety potential and could increase the chance of accidents at the experimental facilities themselves. (Such accidents could damage fusion's prospects as well as the devices, even in the absence of significant off-site radiation doses.)

The diversity of MFE confinement and blanket concepts, together with the inevitability of new Ideas and new discovertes, call for a long-term Rai strategy afwed at developing successive, Improving generations of fusion reactors. Results of near-term systems and materials studies should be used to select blanket candidates for separate effects tests over the next 10 years and for integrated tests in an international Engineering Test Reactor in the period 2000 to 2010, leading to an acceptable first-generation fusion reactor (exemplified in our study by the point-of-departure tokamak) that could become operational in the period 2010 to 2015 . In parallel with these developments, more advanced confinement and blanket concepts should be pursued at a pace 
appropriate to their evolving promise, alming for fimproved second- and thirdgeneration reactors for the period 2020 and later.

\section{ACKNOWLEDGEMENTS}

The committee members wish to recognize the extraordinary work of Steve Fetter (at LLNL through much of the study, now at Harvard and MIT), Steve Piet (INEL), Carroll Maninger (LLNL), and John Massida (MIT) in computing the environnental and safety Indices central to our effort. Their work has substantially increased the scope and thoroughness of our study. other valuable technicâl assistance was provided by John Sheffield (ORNL). Administrative and secretarial support was provided by Don Hall, 0lga Jones, Judy Balley, Debble Holmes, Sara Sanders, and Donna Schreiber (LLNL) and by Claudia Vaughn, Kate Blake, and Bette Francis of the Energy and Resources Group at the University of California, Berkeley, Calif. Technical editing was ably performed by Elaine Price and Kevin Gleason and word processing by Martelle Mays (all at LLNL).

We are grateful, finally, to Ken Fowler, Associate Director for MFE at LLNL, and to Greg Haas and Gene Nardella in the OFE of the U.S. DOE, for their unfalling encouragenent and support. 


\section{REFERENCES}

1. J. P. Holdren, D. H. Berwald, R. J. Budnitz, J. G. Crocker, J. G. Delene, R. D. Endicott, M. S. Kazimi, R. A. Krakowski, B. G. Logan, and K. R. Schultz, Report of the Senior Committee on Environmental, Safety, and Economic Aspects of Magnetic Fusion Energy, Lawrence Livermore National Laboratory, Livermore, Calif., UCRL-53766 (to be published).

2. Committee on Nuclear and Alternative Energy Systens, Mational Academy of Sciences, Energy in Transition, 1985-2010 (W. H. Freeman, San Francisco, Calif., 1980).

3. J. P. Holdren, "Energy and the Human Predicament," K. R. Sinith, F. Fesharaki, and J.P. Holdren, Earth and the Human Future (Westriew Press, Boulder, Colo., 1986), Chap. 7.

4. World Resources Institute/International Inst 1tute for Environment and Development, World Resources 1986 (Basic Books, Hew York, N.Y., 1986).

5. Energy Systems Group, International Institute for Applied Systems Analysis, Energy in a Finfte World (Ballinger, Cambridge, Mass., 1981).

6. 3. Goldemberg, T. B. Johansson, A. K. N. Reddy, and R. H. Willilams, "An End-Use Oriented Energy Strategy," Annual Review of Energy 10613 (1985).

7. W. Haefele, J. P. Holdren, G. Kessler, and G. L. Kulcinski, Fusion and Fast Breeder Reactors, International Institute for Applled Systems Analysis, Laxenburg, Austria, RR-77-8 (July 1977).

8. K. R. Schultz, R. F. Bourque, E. T. Cheng, B. A. Engholm, M. J. Schaffer, and C. P. C. Wong, "The Fusion Applications Study--FAME," Fus. Technol. 10(3), 1279 (1986).

9. R. W. Moir and R. S. Frost, Eds., Study of a Magnetic Fusion Production Reactor, Lawrence Livermore National Laboratory, Livermore, Calif., UCRL94408 (1986). 
10. R. W. Conn, E. E. Bloom, J. W. Davis, R. E. Gold, R. Little, K. R. Schultz, D. L. Smith, and F. W. Wiffen, Report of the DoE Panel on Low Activation Materials for Fusion Applications, University of California, Los Angeles, Calif., UCLA-PPG-728 (1983).

11. Argonne National Laboratory, McDonnell Douglas Astronautics Co., General Atomic Co., and The Ralph M. Parsons Co., STARFIRE: A Comiercial Tokamak Fusion Power Study, Argonne National Laboratory, Argonne, [11., ANL/FPP80-1 (1980).

12. Lawrence Livermore National Laboratory, TRW Energy Deyelopnent Group, General Dynamics/Convair Division, EBASCo Services, Inc., Science Applications, Inc., University of Wisconsin-Madison, Grumman Aerospace Corp., and Energy Technology Engineering Center, Mirror Advanced Reactor Study, Lawrence Livermore National Laboratory, Livermore, Calif., UCRL53480 (1984).

13. D. L. Smith, C. C. Baker, D.-K. Sze, G. D. Morgan, M. A. Abdou, S. J. Piet, K. R. Schulcz, R. W. Moir, and J. D. Gordon, "Overview of the Blanket Comparison and Selection Study," Fus. Technol. 8(1), Part 1, 10 (1985).

14. J. Sheffield, R. A. Dory, S. M. Cohn, J. G. Delene, L. F. Parsly, D. E. T. F. Ashby, and W. T. Reiersen, "Cost Assessment of a Generic Magnetic Fusion Reactor," Fus. Technol. 9, 199 (1986).

15. Nuclear Energy Cost Data Base, Office of Nuclear Energy, U.S. Department of Energy, Washington, D.C., DOE/NE-0044/3 (1985).

16. S. J. Piet, Potential Consequences of Tokamak Fusion Reactor Accidents: The Materials Impact, Ph.D. thesis, Massachusetts Institute of Techno:egy, Cambridge, Mass. (1982).

17. S. A. Fetter, Radiological Hazards of Fusion Reactors: Models and Comparisons, Ph.D. thesis, University of California, Berkeley, Calif. (1985). 
18. J. B. Cannon, Ed., Background Information and Technical Basis for Assessment of Environmental Implications of Magnetic Fusion Energy, Office of Energy Research, U.S. Department of Energy, Washington, D.C., DOE/ER0170 (1983).

19. Fusion Safety Status Report. International Atomic Energy Agency, Vienna, Austria, IAEA-TECDOC-388 (1986).

20. D. F. Holland, B. J. Merril1, J. S. Herring, S. J. Piet, and G. R. Longhurst, Fuston Safety Program Annual Report, F1scal Year 1986, Idaho National Engineering Laboratory, Idaho Falls, Idaho, EGG-2508 (1987.

21. J. E. Massida, Thermal Design Considerations for Fusion Reactors Passive Safety, Ph.D. thesis, Massachusetts Institute of Technology, Cambridge, Mass. (1987).

22. B. Keisch, C. Auerbach, A. Fainberg, S. Fiarman, L. G. Fishbone, W. A. Higinbotham, J. R. Lemley, and J. O'Brien, Long-Term Proliferation and Safeguards Issues in Future Technologies, Brookhaven National Laboratory, Upton, Long Island, N.Y., BNL 52010 (1986).

23. M. A. B. Bodin, R. A. Krakowski, and S. Ortolant, "The Reversed-Field Pinch from Fxperiment to Reactor," Fus. Technol. 10(3), 307 (1986).

24. G. R. Hopkins, E. T. Cheng, R. L. Creedon, I. Maya, K. R. Schultz, P. Trester, and C. P. C. Wong, "Low Activation Fusion Design Studies," Nucl. Technol./Fus. 4(2), 1251 (1985).

25. R. W. Mo1r, J. D. Lee, F. J. Fulton, F. Huegel, W. S. Neef, Jr., A. E. Sherwood, D. H. Berwald, R. H. Whitely, C. P. C. Wong, J. H. Devan, W. R. Grimes, and S. K. Ghose, "Design of a Hellum-Cooled Molten-Salt Fusion Breeder," Fus. Technol. 8(1), Parts 2(A) and 2(B), 465 (1985).

26. TPA Steering Committee, Technical Planning Activity: Final Report, Argonne National Laboratory, Argonne, I11., ANL/FPP-87-1 (1987). 
27. Environmental Impact and Economic Prospects of Nuclear Fusion, Comission of the European Communities, Brussels, Belgium, EURFU BRU/XII-828/86 (1986).

28. Kenzo Yamamato, Chairman, Investigation of Feasibility of Nuclear Fusion, Report by the Japanese Atomic Energy Society to the Atomic Energy Commission of Japan, Tokyo, Japan (1986). (In Japanese.)

29. F. Troyon, R. Gruber, H. Saurenmann, S. Semenzato, and S. Succ1, "MHD Limits to Plasma Confinement," Plasma Physics and Controlled Fusion 26, 209 (1984).

30. University of California, Los Angeles, GA Technologies, Inc., Los Alamos National Laboratory, and Rennselaer Polytechnic Institute, The Titan Reversed-Field Pinch Fusion Reactor Study: Scoping Phase Report, University of California, Los Angeles, Callf., UCLA-PPG-1100 (1987). (See also Iitan Final Report, to be published.)

31. D.-K. Sze, "IPFR, Integrated Pool Fusion Reactor Concept," Fus. Technol. $10(3), 875$ (1986).

32. R. B. Campbel1, B. G. Logan, and M. A. Hoffman, "In-Situ MHD Conversion for Fusion," Fus. Technol. 10(3), 881 (1986).

33. L. J. Wittenberg, J. F. Santarius, and G. L. Kulcinski, "Lunar Source of $\mathrm{He}^{3}$ for Commercial Fusion Power," Fus. Technol. 10(2), 167 (1986).

34. D. H. Berwald, R. H. Whitely, J. K. Garner, R. J. Gromada, T. J. McCarville, R. W. Moir, J. D. Lee, B. R. Bandini, F. J. Fulton, C. P. C. Wong, I. Maya, C. G. Hoot, K. R. Schultz, L. G. Miller, J. M. Beeston, B. L. Harris, R. A. Westman, N. M. Ghoniem, G. Orient, W. G. Wolfer, J. H. DeVan, and P. Torterelli, "Updated Reference Design of a Liquid-Metal Cooled Tandem Mirror Fusion Breeder," Fus. Technol. (to be published).

35. Phase VII Update Keport for the Energy Economic Data Base Program, U. S. Department of Energy, Washington, D.C., DOE/NE-0051/2 (1984). 
36. United Engineers and Constructors, Technical Reference Book for the Energy Economic Data Base Program, U.S. Department of Energy, Washington, D.C., DOE/NE-0059/1 (1985).

37. F. E. Tippets, L. N. Salerno, and C.R. Snyder, "Progress Report on PRISM: A Passively Safe, Economic, and Testable Advanced Power Reactor," presented at the American Power Conference, Chicago, Ill., April 27 - 29, 1987.

38. W. Breher, A. Neyland, and A. Shenoy, "Modular High-Temperature Gas-Cooled Reactor (MHTGR) Status," presented at the Intersociety Energy Conversion Engineering Conference, Philadelphia, Pa., August $10-14,1987$.

39. E. F. Plechaty and J. R. Kimlinger, TARTNP: A Coupled Neutron-Photon Monte Carlo Transport Code, Lawrence Livermore National Laibratory, Livermore, Calff., UCRL-50400, vol. 14 (1976).

40. J. A. Blink, R. E. Dye, and J. R. Kimlinger, ORLIB: A Computer Code that Produces One-Energy-Group, Time- and Spatially-Averaged Neutron Cross Sections, Lawrence Livermore National Laboratory, Livermore, Calif., UCRL53262 (1981).

41. J. A. Blink, FORIG: A Computer Code for Calculating Radionuclide Generation and Depletion in Fusion and Fission Reactors, Lawrence Livermore National Laboratory, Livernore, Calif., UCRL-53633 (1985).

42. A. G. Croff, ORIGEN2: Isotope Generation and Depletion Code--Matrix Exponential Method, Oak Ridge National Laboratory, Oak Ridge, Tenn., ORNL/TM-7175 (1980).

43. Reactor Safety Study, U.S. Nuclear Regulatory Commission, Washington, D.C., WASH-1400 (1975).

44. A. Bayer and J. Ehrhardt, Unfallfolgenrechnungen und RIs/koabchatzungen in Rahmen der "Risikoorientierten Analyse zum SNR 300," Kernforschungszentrum Karlsruhe, FRG, KfK-3423 (1983). 
45. A. Bayer and J. Ehrhardt, "Risk-Oriented Analysis of the German Prototype Fast Breeder Reactor SNR-300: Off-Site Accident Consequence Model and Results of the Study, "Nucl. Technol. 65, 232 (1984).

46. I. Maya, C. G. Hoot, C. P. C. Wong, K. R. Schultz, J. K. Garner, S. J. Bradbury, W. G. Steele, and D. H. Berwald, Special Topics Report for the Reference Tandem Mirror Fusion Breeder: Reactor Safety Assessment, Lawrence Livermore National Laboratory, Livermore, Calif., UCID-20166, vol. 2 (1984).

47. Reassessment of the Technical Basis for Estimating Source Terms, U.S. Nuclear Regulatory Commission, Washington, D.C., NUREG-0956 (1985).

48. Industry Degraded Core Rulemaking Program (IDCOR), Reassessment of Emergency Planning Requirements with Present Source Terms, IDCOR, Technical Report 85.4(5.3) (1986).

49. International Nuclear Safety Advisory Group, Summary Report on the PostAccident Review Meeting on Chernobyl Accident. International Atomic Energy Agency, Vienna, Austria (1986).

50. Supplement to Final Environmental Statement Related to Construction and Operation of the Clinch River Breeder Reactor Plant, U.S. Nuclear Regulatory Commission, Washington, D.C., NUREG-0139, Supplement 1, vol. 2 (1976).

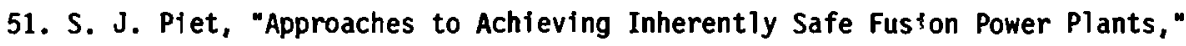
Fus. Technol. 10(1), 7 (1986).

52. Committee to Review the Literature of Nuclear Risks, National Academy of Sciences, Risks Associated with Nuclear Power: A Critical Review of the Literature, Washington, D.C. (1979). See also Ref. 2.

53. "Report to the American Physical Society by the Study Group on Nuclear Fuel Cycles and Waste Management," Rev. Mod. Phys. 50, No. 1, Part II (1978). 
54. W. E. Bickford, Iransport and Deposition of Activation Products in a Helfum-Cooled Fusion Power Plant, Pactfic Northwest Laboratory, Richland, Wash., PNL-3487 (1980).

55. A. C. Kle1n and W. F. Yogelsang, "Radiation Hazards Due to Activated Corrosion and Neutron Sputtering Products in Fusion Reactor Coolants and Tritium Breeder Fluids," Nucl. Eng. Des. 2(4), 355 (1985).

56. D. R. Diercks and D. L. Smith, "Corrosion Behavior of Vanadium-Based Alloys in Pressurized Water at $288^{\circ} \mathrm{C}$, " J. Hucl. Mater, $141-143,617$ (1986).

57. A. C. Klein and D.-K. Sze, "Activation Product Transport in a FlibeVanadium-HT-9 System," MINIMARS Conceptual Design Study: Report I. App. E, Lawrence Livermore National Laboratory, Livermore, Calif. UCID20559, vol. 2 (1985).

58. Final Environmental Impact Statement on 10 CFR Part 61 , Licensing Requirements for Land Disposal of Radioactive Waste, U.S. Nuclear Regulatory Commission, Washington, D.C., NUREG-0945 (1982).

59. Committee on Fusion Hybrid Reactors, Outlook for the Fuston Hybrid and Iritium-Breeding Fusion Reactors (National Academy Press, Washington, D.C., 1987).

60. J. P. Holdren, "Fusion Power and Nuclear Weapons: A Significant Link?" Bul1. At. Sc1. 34(3), 4 (1978).

61. M. W11lrich and T. B. Taylor, Nuclear Theft: Risks and Safeguards (Ballinger, Cambridge, Mass., 1974).

62. A. B. Lovins, "Thorium Cycles and Proliferation," Bull. At. Sc1. 35(2), 16 (1979). 
63. Nuclear Proliferation and Civilian Nuclear Power, Report of the Nonproliferation Alternative Systems Assessment Program, vol . 2, U.S. Department of Energy, Washington, D.C., DOE/NE-0001/2 (1980).

64. J. P. Holdren, "Fuston-Fission Hybrids: Environmental Aspects and Their Role in Hybrid Rationale," J.Fus. Energy 1, 197 (1981).

65. T. B. Cochran, W. M. Arkin, and M. M. Hoenig. Nuclear Weapons Databook, Vol. I: U.S. Nuclear Forces and Capabilities (Ballinger, Cambridge, Mass., 1984).

66. T. B. Cochran, W. M. Arkin, R. S. Norris, and M. M. Hoenig, Nuclear Weapons Databook. Vol. II: U.S. Nuclear Warhead Production (Ballinger, Cambridge, Mass., 1987).

67. J. P. Holdren, "Nuclear Power and Nuclear Weapons: The Connection is Dangerous," Bul1. At. Sc1.., January, $40-45$ (1983).

68. L. D. Hamilton, "Health Effects of Electricity Generation," Proc. 1st Intern. Conf. on Health Effects of Energy Production, Chalk River Laboratories, Atomic Energy of Canada Ltd., Chalk River, Ontario, Canada, AECL-6958 (1979).

69. J. P. Holdren, K. B. Anderson, P. M. Deibler, P. H. Glelck, I. M. Mintzer, and G. P. Morris, "Health and Safety Impacts of Renewable, Geothermal, and Fusion Energy," Health Risks of Energy Technologies, C. C. Travis and E. L. Etnier, Eds. (Westview Press, Boulder, Colo., 1983).

70. M. S. Kazimi, "Risk Considerations for Fusion Energy," Nucl. Technol./ Fusion 4, 527 (1983).

71. L. J. Perkins, Lawrence Livermore National Laboratory, Livermore, Calif., private communication (August 1985). 
72. I. Maya, K. R. Schultz, and Project Staff, Inertial Confinement Fusion Reactor Chamber and Power Conversion System Study, GA Technologies, San Diego, Calif., GA-A17842 (1985).

73. D. R. Cohn, J. Schwartz, L. Bromberg, and J. E. C. Williams, Tokamak Reactor Concepts Using High Temperature High Field Superconductors, Plasma Fusion Center, Massachusetts Institute of Technology, Cambridge, Mass., PFC/RR-87-5 (1987).

74. P. Finn, J. Brooks, D. Ehst, Y. Gohar, R. Mattas, and C. Baker, An Evaluation of Polarized Fuels in a Commercial Deuterium/Tritium Reactor, Argonne National Laboratory, Argonne, I11., ANL/FPP-85-1 (1985).

75. R. A. Krakowsk1, R. L. Miller, and R. L. Hagenson, "The Need and Prospects for Improved Fusion Reactors," J. Fusion Energy 5(3), 213 (1986). 